\title{
Templated synthesis of nickel nanoparticles: Toward heterostructured nanocomposites for efficient hydrogen storage
}

\author{
by \\ Nicholas Cole Nelson \\ A thesis submitted to the graduate faculty \\ in partial fulfillment of the requirements for the degree of \\ MASTER OF SCIENCE \\ Major: Chemistry \\ Program of Study Committee: \\ Javier Vela, Major Professor \\ Gordon Miller \\ Klaus Schmidt-Rohr
}

Iowa State University

Ames, Iowa

2013 


\section{TABLE OF CONTENTS}

\section{Page}

ACKNOWLEDGEMENTS _..............

ABSTRACT

CHAPTER 1. INTRODUCTION _...

Motivation: The Hydrogen Economy _...

Hydrogen Storage Methods .

Overview

Liquefaction and Compression

Physisorption

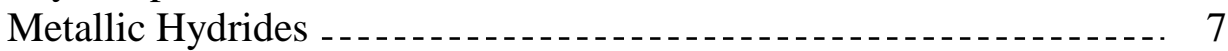

Bimetallic Nanocomposites for Efficient Hydrogen Storage _............ 9

Hydrogen Spillover

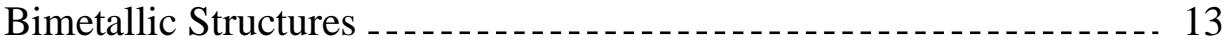

Benefits of Nanoarchitectures . .

Goals and Approach

CHAPTER 2. HARD TEMPLATE APPROACH FOR THE SYNTHESIS OF

METALNANORODS _... 20

Introduction _.

Results and Discussion

Synthesis of $\mathrm{NiC} \mathrm{SiO}_{2} \ldots \ldots$

Heterogeneous Nucleation and Seeded Growth of $\mathrm{Ni} \subset \mathrm{SiO}_{2}$......... 47

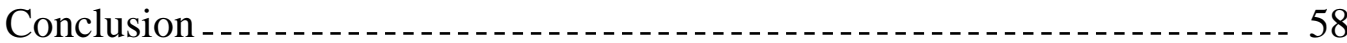

Experimental

REFERENCES 


\section{ACKNOWLEDGEMENTS}

I would like to thank my advisor, Dr. Javier Vela, for providing me with the opportunity to pursue my interests within his group. His guidance, encouragement, and patience were key factors that allowed me to learn how to efficiently conduct scientific studies and equipped me with the knowledge needed for a successful career. I would also like to thank my committee members, Dr. Gordon Miller and Dr. Klaus Schmidt-Rohr, for their time, commitment, and dedication toward mentoring me and many other students throughout the years.

I would like to thank April Brown for her continued love, support, and understanding throughout the many demanding and difficult times. I would also like to thank Derek Quam for his generosity and willingness to invest his time to help me grow spiritually. Also, thanks to my friends, colleagues, and lab mates for their companionship and insights.

Finally, I would like to thank my parents for their unwavering love, kindness, and support throughout the years that allowed me to get to this point.

Some of the data present in this document was obtained by instrumentation at the Ames Laboratory. The document number assigned to this thesis is IS-T 3094. 


\section{ABSTRACT}

The world is currently facing an energy and environmental crisis for which new technologies are needed. Development of cost-competitive materials for catalysis and hydrogen storage on-board motor vehicles is crucial to lead subsequent generations into a more sustainable and energy independent future. This thesis presents work toward the scalable synthesis of bimetallic heterostructures that can enable hydrogen to compete with carbonaceous fuels by meeting the necessary gravimetric and volumetric energy densities and by enhancing hydrogen sorption/desorption kinetics near ambient temperatures and pressures. Utilizing the well-known phenomenon of hydrogen spillover, these bimetallic heterostructures could work by lowering the activation energy for hydrogenation and dehydrogenation of metals. Herein, we report a novel method for the scalable synthesis of silica templated zero-valent nickel particles $\left(\mathrm{Ni} \subset \mathrm{SiO}_{2}\right)$ that hold promise for the synthesis of nickel nanorods for use in bimetallic heterostructures for hydrogen storage. Our synthesis proceeds by chemical reduction of a nickel-hydrazine complex with sodium borohydride followed by calcination under hydrogen gas to yield silica encapsulated nickel particles. Transmission electron microscopy and powder X-ray diffraction were used to characterize the general morphology of the resultant nanocapsules as well as the crystalline phases of the incorporated $\mathrm{Ni}^{0}$ nanocrystals. The structures display strong magnetic behavior at room temperature and preliminary data suggests nickel particle size can be controlled by varying the amount of nickel precursor used in the synthesis. Calcination under different environments and TEM analysis 
provides evidence for an atomic migration mechanism of particle formation.

$\mathrm{NiC} \mathrm{SiO}_{2}$ nanocapsules were used as seeds to induce heterogeneous nucleation and subsequent growth within the nanocapsule via electroless nickel plating. Nickel nanoparticle growth occurs under high temperature alkaline conditions, however silica nanocapsule integrity is not maintained due to the incompatibility of silica with the growth conditions. Silica nanocapsule integrity is maintained under low temperature neutral conditions, but nickel particle growth is not observed. Through FTIR and UV/Vis analysis, we show the degree of crosslinking and condensation increases in calcined silica compared to as-synthesized silica. We propose the increased density of the silica nanocapsule hinders mass transfer of the bulky nickel precursor complex from solution and onto the surface of the "catalytic" zero-valent nickel seed within the nanocapsule cavity. Decreasing the density of the silica nanocapsule can be achieved through cocondensation of tetraethylorthosilicate with an alkyl functionalized silane followed by calcination to remove the organic component or by chemical etching in alkaline solution, but will not be addressed in this thesis. 


\section{CHAPTER 1. INTRODUCTION}

\section{Motivation: The Hydrogen Economy}

Air quality has become a hot topic in the last few decades because of its effect on public health, ecosystem stability, and global climate change. One of the major contributors to air quality, or lack thereof, is motor vehicle emissions. It is estimated that $14 \%$ of worldwide greenhouse gas emissions and $19 \%$ of $\mathrm{CO}_{2}$ emissions can be attributed to motor vehicles and the percentage is expected to increase with the quick economic growth of developing countries. ${ }^{1}$ Hydrogen $\left(\mathrm{H}_{2}\right)$ has been proposed as an alternative fuel, especially for use in the transportation sector, because its combustion produces water and the most energy released by any fuel on a mass basis (Scheme 1$).^{2}$

\section{Scheme 1.}

$$
\begin{array}{r}
\mathrm{H}_{2}+1 / 2 \mathrm{O}_{2} \longrightarrow \mathrm{H}_{2} \mathrm{O}+\text { heat, } \Delta \mathrm{H}=-285.8 \mathrm{~kJ} \mathrm{~mol}^{-1} \text { at } 25^{\circ} \mathrm{C} \\
\Delta \mathrm{G}=-237.2 \mathrm{~kJ} \mathrm{~mol}^{-1} \text { at } 25^{\circ} \mathrm{C}
\end{array}
$$

There are numerous advantages to use hydrogen as a fuel for vehicles including, but not limited to: Hydrogen's combustion by-products are restricted to water vapor and minute quantities of nitrogen oxides when used in an internal combustion engine (ICE) and only water vapor when used in a fuel cell (FC); hydrogen can be obtained from a wide assortment of primary energy sources making it readily accessible in most parts of the world; and, hydrogen is the most abundant element in the universe. With all of these advantages in hand, hydrogen technology has surged to the forefront of energy research and development. 
Although hydrogen is a good alternative energy candidate, there are major technological hurdles that need to be overcome in order to realize its full potential. The overwhelming majority of hydrogen is chemically bound in the form of water and hydrocarbons, and therefore energy (and money) must be spent to isolate $\mathrm{H}_{2}$ from other sources. Cheap and efficient $\mathrm{H}_{2}$ production methods from renewable energy sources, either directly or indirectly, are needed to make $\mathrm{H}_{2}$ more competitive with carbonaceous fuels and eventually wean us from our dependence on them. Another problem becomes how to efficiently, effectively, and safely store hydrogen on-board a vehicle. In order to implement hydrogen as a transportation fuel, a suitable storage device must meet several requirements outlined by the United States (US) Department of Energy (DOE) (Table 1). ${ }^{3}$ High gravimetric energy density and high volumetric energy density are both required to provide long vehicle range comparable to gasoline and allow for adequate passenger room. A working system must also exhibit refueling times comparable to gasoline and function at or near ambient temperature and pressure to ensure passenger safety as well as maintain energy efficiency. In addition, whatever material the storage device is made from, it must not be prone to poisoning by oxygen. The development of low cost hydrogen production methods and storage materials with high gravimetric and volumetric energy density, quick fill times, and ambient operating conditions is thus critical to realizing zero-emission vehicles.

There are several candidates for materials or methods possessing attributes that meet the DOE hydrogen storage goals. Of these, solid-state devices (e.g. metallic hydrides) are seemingly the best candidates due to their outstanding high volumetric energy densities, adequate gravimetric energy densities, indefinite storage capability, and 
safety. Unfortunately, metallic hydrides lie in a thermodynamic well (i.e., they are very stable) and oftentimes the dehydrogenation temperature and pressure conditions used are undesirable for on-board storage. It has been demonstrated that certain transition metal dopants can vastly improve the sorption and desorption kinetics of metal hydride containing compounds. ${ }^{4,5,6,7,8}$ Fabrication of other novel solid-state materials and devices with good sorption-desorption kinetics remains an outstanding goal and challenge.

Table 1. DOE Targets for On-board Hydrogen Storage Systems for Light-Duty Vehicles

\begin{tabular}{lc}
\hline \multicolumn{1}{c}{ Storage Parameter } & Ultimate Goal \\
\hline System gravimetric capacity & $0.075 \mathrm{~kg} \mathrm{H}_{2} \mathrm{~kg}^{-1}$ system \\
& $2.5 \mathrm{kWh} \mathrm{kg}^{-1}$ \\
System volumetric capacity & $0.070 \mathrm{~kg} \mathrm{H}_{2} \mathrm{~L}^{-1}$ system \\
& $2.3 \mathrm{kWh} \mathrm{L}^{-1}$ \\
System fill time$(5 \mathrm{~kg})$ & $2.5 \mathrm{~min}$ \\
Durability/operability & \\
- Operating temperature & $-40 / 60^{\circ} \mathrm{C}$ \\
- Min/max delivery & $-40 / 85^{\circ} \mathrm{C}$ \\
- temperature & $1500 \mathrm{cycles}$ \\
- Operational cycle life & Min delivery pressure from \\
& storage system \\
Max delivery pressure from & $3 \mathrm{FC} / 35 \mathrm{ICE}$ bar (abs) \\
$\quad$ storage system & $12 \mathrm{FC} / 100 \mathrm{ICE}$ bar (abs) \\
\hline
\end{tabular}

The world is currently facing an energy and environmental crisis for which new technologies are needed. Long-term development and sustainability will become much easier if we are able to find alternative energy sources and utilize them efficiently. Advancing the field of hydrogen storage with new materials could allow for more 
sustainable energy and environmental practices, achieve energy independence, and assure economic prosperity for future generations.

\section{Hydrogen Storage Methods}

\section{Overview}

An immediate reason for the nonexistence of a hydrogen fuel network is the lack of an efficient and effective on-board-vehicle hydrogen storage system. At ambient temperature and pressure, $1 \mathrm{~kg}$ of hydrogen gas (about a gasoline gallon equivalent) occupies a volume of over 3,000 $\mathrm{gal}^{9}$. Clearly, the low density of hydrogen gas restricts its practical and widespread use as a transportation fuel today and innovative storage technologies are needed to allow for efficient and operative storage. Hydrogen can be stored as a gas, a cryogenic liquid, physisorbed on large specific surface area structures, and bound to other elements (e.g. metallic hydrides).

\section{Liquefaction and Compression}

Liquefied hydrogen offers the advantage of possessing a relatively high density at ambient pressure $\left(71.0 \mathrm{~kg} / \mathrm{m}^{3}\right)$, but liquefaction is an energy intensive process. The simplified phase diagram in Figure 1 shows the boiling point of liquid hydrogen is $20.4 \mathrm{~K}$ at 1 bar and the critical point is $33.2 \mathrm{~K} .{ }^{10}$ Liquefaction of hydrogen gas from room temperature costs about $15 \mathrm{~kW}-\mathrm{h}_{\mathrm{e}} / \mathrm{kg}$, which is about $30 \%$ of the lower heating value (LHV) for hydrogen combustion. ${ }^{2}$ In addition, the tanks must be well insulated adding to the overall system weight. ${ }^{2}$ Furthermore, liquid hydrogen cannot be contained in a closed system due to boil off. At room temperature over $75 \%$ of hydrogen exists as ortho- 
hydrogen that becomes unstable when cooled to liquid temperatures. ${ }^{11}$ Ortho-hydrogen undergoes a transition to para-hydrogen with the release of heat which is greater than the latent heat of vaporization for hydrogen and thereby contributes to vaporization of liquid hydrogen.

Compression is a convenient and familiar way to store hydrogen, but the cost is far too high to become practical. High pressure tanks built of carbon fiber can withstand pressures up to 700 atmosphere (11 wt. \%) and compression only costs $10 \%$ of the LHV for hydrogen combustion; however, the tank fabrication cost is $\$ 3000 / \mathrm{kg} \mathrm{H}_{2}{ }^{2}$ Unless there are significant advances in reducing the cost of liquefaction or the materials used to construct high pressure cylinders, there will need to be an alternative to these familiar methods of hydrogen storage for use in the transportation industry.

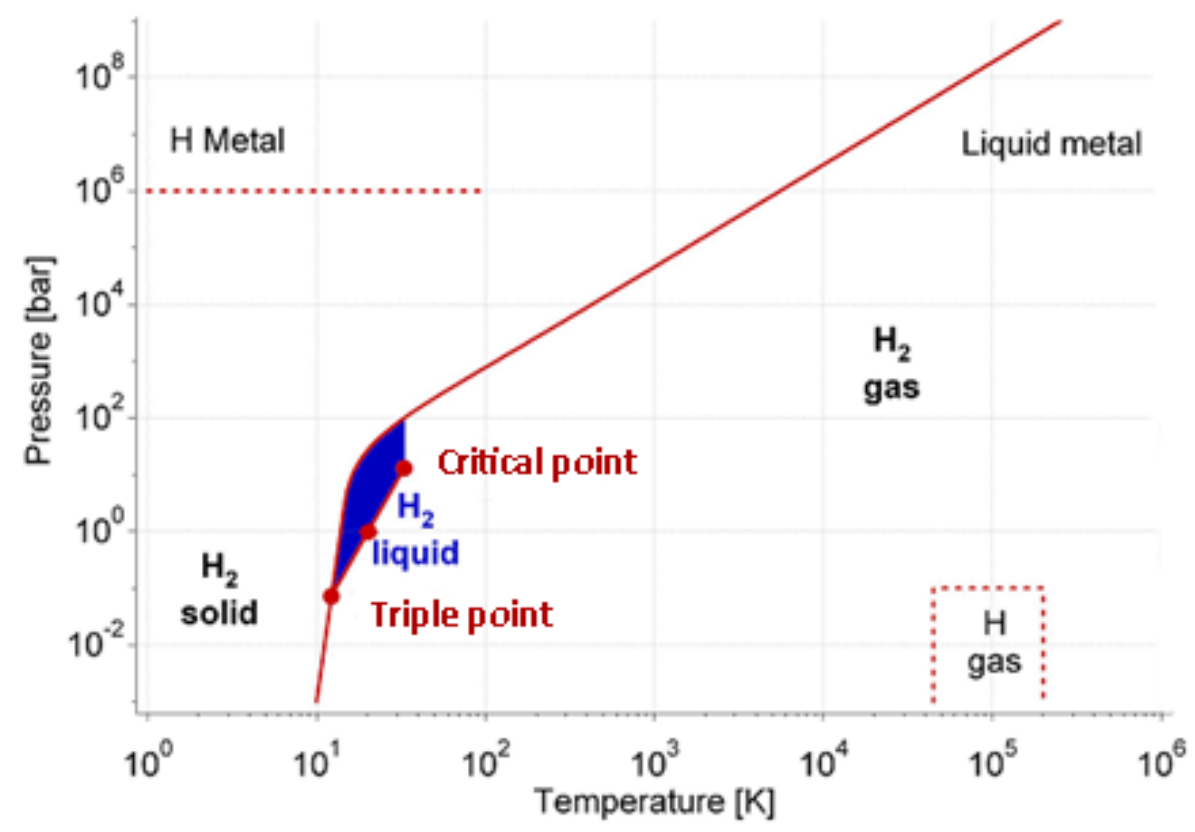

Figure 1 Hydrogen phase diagram. ${ }^{10}$ 


\section{Physisorption}

Physical adsorption is the process by which gas molecules bind with an adsorbent via van der Waals (vdW) forces. This process is reversible due to the weak interaction between the absorbed species and the adsorbent (i.e. there are no chemical bonds being formed). Adsorption of supercritical gases on solid surfaces takes place through monolayer adsorption according to Brunauer-Emmett-Teller (BET) theory. ${ }^{12}$ The first layer of gas molecules absorbed on the surface has a unique absorption energy characteristic of a gas-solid interaction. Subsequent layers have an absorption energy that differs from the first layer due to adsorbate-adsorbate interactions. As the number of layers increases the absorption energy approaches the latent heat of condensation for the

gas. ${ }^{13}$ However, supercritical gases like hydrogen cannot undergo condensation processes above their critical temperature. ${ }^{14}$

Hydrogen storage materials that work through physisorption alleviate thermal management problems associated with other storage methods because hydrogen is so weakly bound, resulting in reaction enthalpies for the hydrogenated and dehydrogenated forms to be small. However, the temperature must be reduced near liquid nitrogen temperature in order to achieve sufficient hydrogen absorption. Above these temperatures there is not enough hydrogen-adsorbate interaction to obtain any useful level of adsorption. The binding energy needed for physisorption of hydrogen at room temperature is $0.15-0.30 \mathrm{eV}$ and typical $\mathrm{vdW}$ binding energies for hydrogen at room temperature are usually a few times smaller than the lower limit. ${ }^{9}$ Engineering of materials that satisfy the binding energy requirements at room temperature remains a significant challenge. In addition, the specific surface area of the material must become 
very large $\left(>2600 \mathrm{~m}^{2} / \mathrm{g}\right)$ and the walls between any nanometer-sized pores must approach atomic thickness in order to increase gravimetric energy density. ${ }^{15}$ Current research in this area is focused on metal-organic frameworks (MOFs) which to date have exhibited surface areas of $7000 \mathrm{~m}^{2} / \mathrm{g} .{ }^{16}$ However, MOFs are still unable to achieve the necessary binding energies and therefore must still be cooled to liquid nitrogen temperatures.

\section{Metallic Hydrides}

There are two types of metallic hydrides proposed for hydrogen storage materials: Metal hydrides and complex hydrides. The main difference is the type of bonding that occurs. Most metal hydrides are crystalline and exhibit ionic bonding between cationic metal and anionic interstitial hydrogen (e.g. $\mathrm{LiH}, \mathrm{MgH}_{2}, \mathrm{AlH}_{3}$,). Complex hydrides typically consist of more than one metal or are a combination of a metal and a metalloid. They are characterized by ionic bonding between a metal cation and a molecular anion containing the hydride. The bonding in the anionic component is preferentially covalent (e.g. $\mathrm{NaAlH}_{4}, \mathrm{LiBH}_{4}, \mathrm{Mg}_{2} \mathrm{FeH}_{6}$ ). The advantages of metallic hydrides include their excellent volumetric energy densities and relative safety compared to liquefaction and compression. In addition, some complex hydrides can reversibly absorb hydrogen at or near ambient pressure and temperature, but in all cases the complex contains a transition metal which has devastating effects on gravimetric energy density. For example, $\mathrm{LaNi}_{5} \mathrm{H}_{6}$ has a volumetric energy density of $115 \mathrm{~kg} / \mathrm{L}$ and can reversibly store hydrogen at ambient pressure and temperature. ${ }^{9}$ Unfortunately, the gravimetric energy density is only $1.4 \%$. Therefore, special attention is has been paid to hydrides of light metals (e.g. $\mathrm{B}, \mathrm{Na}, \mathrm{Mg}$, $\mathrm{Al})$. 
Light metallic hydrides were long thought to be relatively inert toward hydrogen loss near ambient temperature and pressure. Pioneering work by Bogdanovic et al. showed that doping sodium alanates with titanium resulted in faster sorption-desorption kinetics at a given temperature and pressure (Figure 2). ${ }^{4,17}$ However, the gravimetric energy density of this system was not high enough to reach the goals initially set by the DOE for use in transportation.
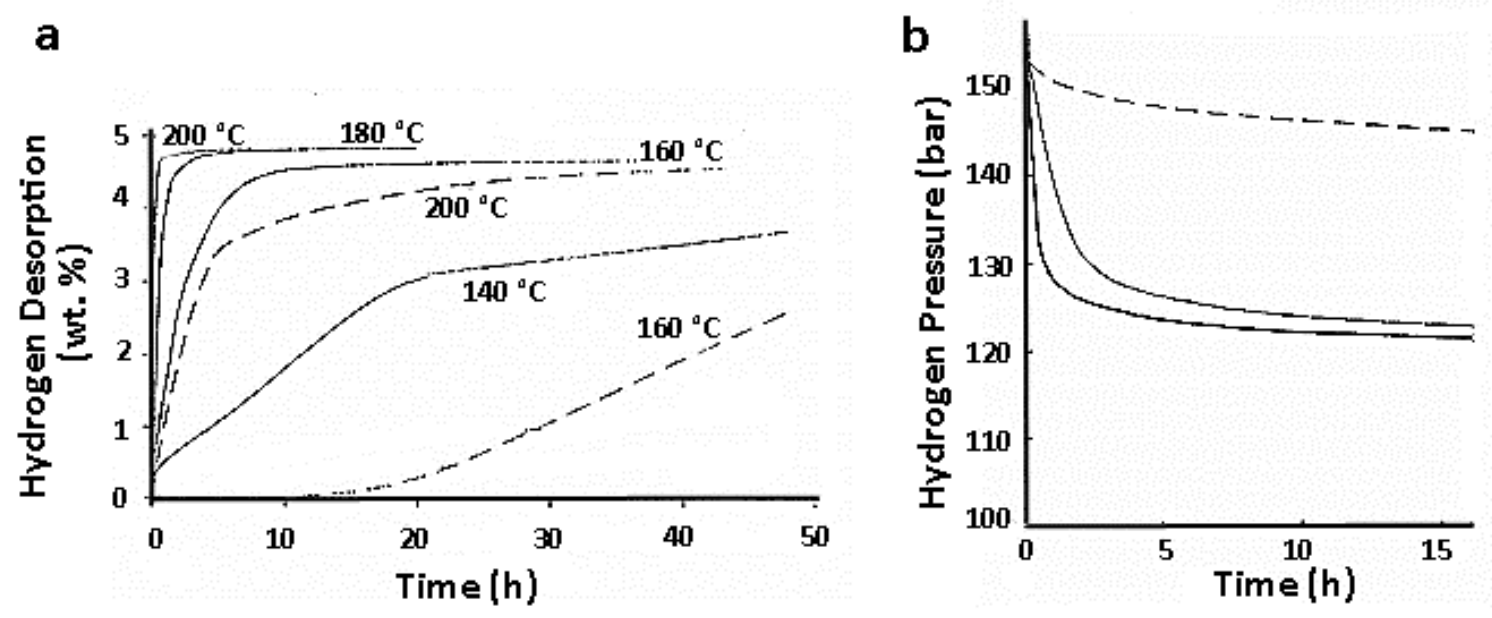

Figure 2. (a) Hydrogen desorption versus time at different temperatures for Ti doped $\mathrm{NaAlH}_{4}(-)$ and undoped $\mathrm{NaAlH}_{4}(------)$; (b) Hydrogen adsorption $\left(170^{\circ} \mathrm{C} / 152 \mathrm{bar}\right)$ as a function of time for Ti doped $\mathrm{NaAlH}_{4}(-)$ and undoped $\mathrm{NaAlH}_{4}(------){ }^{4}$

One main focus of hydrogen storage technology is to develop metallic hydrides meeting gravimetric energy density constraints that also show good kinetics for reversible hydrogen sorption-desorption at or near ambient pressure and temperature. Figure 3 lists the most promising metallic hydrides for use as hydrogen storage materials, as well as how these compare to some of the other storage methods available. ${ }^{9}$ Clearly there are several metallic and complex hydrides that meet the gravimetric and volumetric energy 
constraints, but to date none have met the necessary kinetic and thermodynamic constraints. Doping light metallic hydrides with dehydrogenation/hydrogenation metal catalysts is one of the most practical ways to meet the kinetic, thermodynamic, gravimetric, and volumetric energy requirements for hydrogen storage materials.

\section{Bimetallic Nanocomposites for Efficient Hydrogen Storage}

\section{Hydrogen Spillover}

An phenomenon of interest for hydrogen storage known as spillover was first

reported by several groups independently in the 1960 s. ${ }^{18,19,20,21,22,23}$ Sinfelt and Lucchesi ${ }^{24}$ found the rate of hydrogenation of ethylene was greatly enhanced when a $\mathrm{Pt} / \mathrm{SiO}_{2}$ catalyst was mixed with $\mathrm{Al}_{2} \mathrm{O}_{3}$ compared to the catalyst mixed with $\mathrm{SiO}_{2}$. The synergistic effect between $\mathrm{Pt} / \mathrm{SiO}_{2}$ and $\mathrm{Al}_{2} \mathrm{O}_{3}$ could not be explained by the additive catalytic effects of all three species. Since both $\mathrm{SiO}_{2}$ and $\mathrm{Al}_{2} \mathrm{O}_{3}$ are inert toward hydrogenation of ethylene, but only $\mathrm{Al}_{2} \mathrm{O}_{3}$ chemisorbs ethylene under the conditions used, the authors concluded that the enhanced rate of ethane formation must be due to the dissociation of hydrogen on $\mathrm{Pt}$ and subsequent migration to the $\mathrm{Al}_{2} \mathrm{O}_{3}$ substrate and reduction of chemisorbed ethylene.

Subsequent studies led to the following definition: "Spillover involves the transport of an active species which is adsorbed or formed on a first phase onto another phase that does not adsorb or form the species under the same conditions." 25 


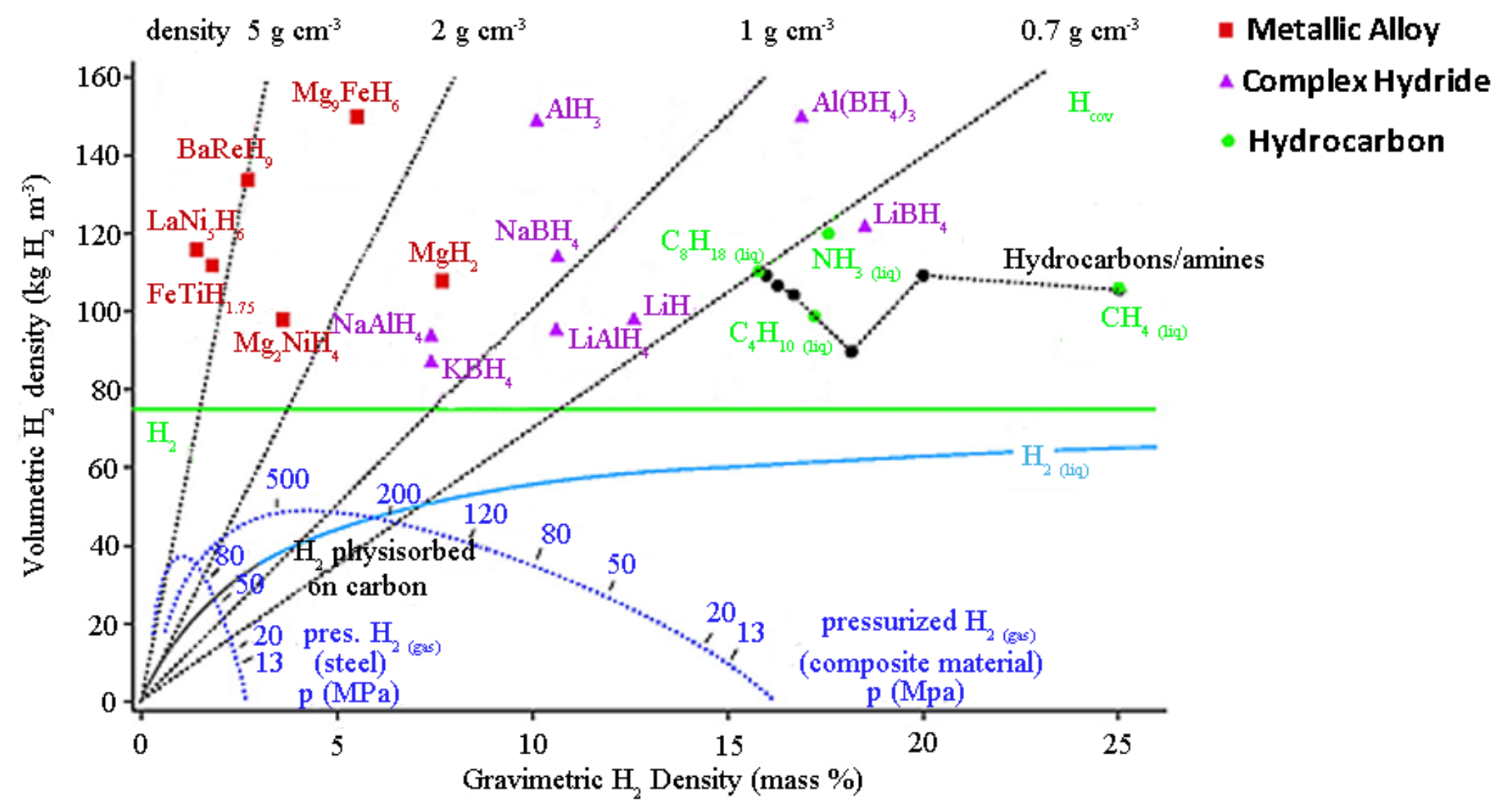

Figure 3. Volumetric and gravimetric hydrogen density of hydrogen storage materials. ${ }^{9}$ 
Hydrogen spillover can occur between a metal and a metal oxide ${ }^{18}$ or between two metals ${ }^{26}$ and is believed to occur through three principal steps (Scheme 2): (1) Dissociative chemisorption of hydrogen gas on a metal surface, (2) migration of hydrogen atoms to the metal-substrate interface, (3) and diffusion of hydrogen atoms across the metal-substrate interface. ${ }^{27}$ Often times, the rate-limiting step and key species in hydrogen spillover are surface diffusion of hydrogen atoms across the metal-substrate interface, or more generally the activator-acceptor interface (Figure 4$).^{22,28}$ The mobility of hydrogen atoms on the acceptor surface gives rise to catalytic behavior and also "cleans" the surface of the metal catalyst, allowing another hydrogen molecule to undergo dissociative chemisorption. The process of spillover is reversible, whereby the hydrogen atoms diffuse from the substrate to the metal and then undergo recombination and desorption.

\section{Scheme 2.}

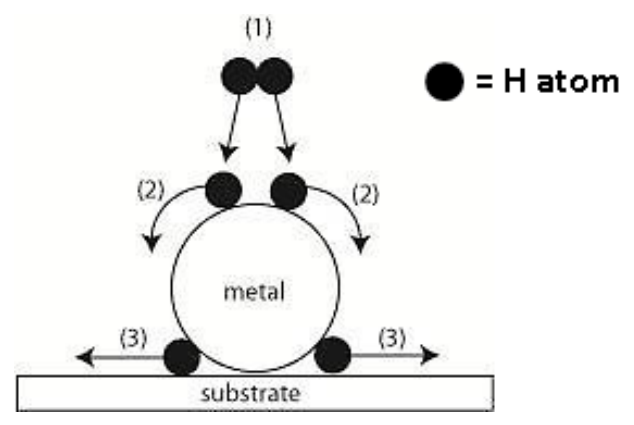

When the hydrogen concentration in certain metals exceeds the saturation concentration a hydride phase is formed. Studies have shown hydride nuclei normally "precipitate" near the metal surface, and the rate of near-surface hydride nuclei formation depend on the rate of hydrogen dissociation at the gas-metal interface. ${ }^{29}$ When the growing hydride nuclei overlap to form continuous hydride layers, the kinetics no longer 
depend upon the nucleation parameters, but switch to a so-called 'shrinking core' function. ${ }^{29}$ The main intrinsic kinetic parameter becomes the diffusion of hydrogen atom to the metal-metal hydride interface. Certain metals (e.g. Group 10) are able to dissociate hydrogen faster than other metals and this property can be exploited to possibly increase the hydrogenation rate of other metals via hydrogen spillover. For example, doping $\mathrm{Mg}^{\mathrm{O}}$ with $\mathrm{Ni}^{0}$ could increase the rate of $\mathrm{MgH}_{2}$ formation because $\mathrm{Ni}^{0}$ can catalyze the dissociation of hydrogen to form the initial near-surface hydride nuclei. The hydrogen atoms could then diffuse to the metal-metal hydride interface through hydrogen spillover. Minimizing the distance between the nickel active sites could be used to decrease the time necessary for the hydrogen atoms to reach the metal-metal hydride interface, thus facilitating and speeding the kinetics of hydrogenation. Dehydrogenation kinetics (the reverse process) could also benefit from a similar series of steps. Hydrogen spillover is therefore a key mechanism for building materials that exhibit reversible, fast hydrogenation/dehydrogenation kinetics.

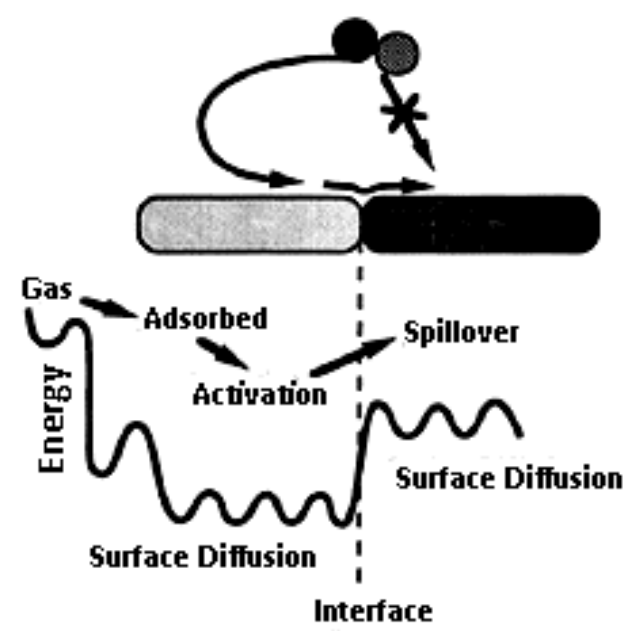

Figure 4. Qualitative energy diagram for hydrogen spillover process. ${ }^{18}$ 


\section{Bimetallic Structures}

Utilizing hydrogen spillover to enhance sorption-desorption kinetics of hydride forming metals is a plausible approach to develop better hydrogen storage materials. Studies focused on doping light metals (Mg, Al) with transition metals ( $\mathrm{Ti}, \mathrm{V}, \mathrm{Ni}, \mathrm{Mn}$, Fe) showed a marked increase in sorption-desorption kinetics of molecular hydrogen and lower dehydriding temperatures. ${ }^{5,6,7,8}$ Tan et al. ${ }^{30,31,32}$ showed that doping magnesium with iron $(\mathrm{Mg}-\mathrm{Fe})$ in the form of thin films capped with palladium resulted in significantly enhanced hydrogen sorption-desorption kinetics and lower activation energy compared to the undoped $\mathrm{Mg}$ films capped with palladium. In this system, palladium serves two purposes: It acts as a protecting layer to prevent surface passivation of the $\mathrm{Mg} / \mathrm{MgH}_{2}$ film and as a catalyst for hydrogen dissociation and the resultant spillover. ${ }^{33}$ The embedded iron is thought to act as a secondary metal catalyst to facilitate the diffusion of hydrogen atoms through the $\mathrm{MgH}_{2}$ phase. Furthermore, time resolved infrared (IR) measurements on wedge-shaped $\mathrm{Mg}$-Fe thin films showed the rate of $\mathrm{MgH}_{2}$ formation increases with increasing temperature and decreasing film thickness. The rate limiting step for phase front migration is diffusion of hydrogen atoms through the $\mathrm{MgH}_{2}$ layer to the $\mathrm{Mg} / \mathrm{MgH}_{2}$ boundary. The increase in rate of formation of $\mathrm{MgH}_{2}$ as the film thickness decreases is due to a larger fraction of the atoms occupying surface sites, which minimizes the extent to which hydrogen atoms must migrate through the hydride phase. Volumetric pressure-composition isotherms (PCI) on $600 \mathrm{~nm}$ thick $\mathrm{Mg}$-Fe thin films showed the enthalpy of adsorption-desorption $\left(66.9 \mathrm{~kJ} \mathrm{~mol}^{-1}\right)$ was less than bulk $\mathrm{Mg}(76$ $\mathrm{kJ} \mathrm{mol}^{-1}$ ) or thin films of undoped $\mathrm{Mg}\left(80 \mathrm{~kJ} \mathrm{~mol}^{-1}\right)$. In addition, the $\mathrm{Mg}$-Fe films exhibited good absorption-desorption hysteresis through two cycling experiments which 
is another necessary property of hydrogen storage materials. Bimetallic structures have thus shown enhanced kinetic hydrogenation rates and decreased thermodynamic hydrogenation barriers allowing hydrogenation to occur in less than one minute and $150^{\circ} \mathrm{C}$.

Another possible benefit of bimetallic structures is the development of a destabilized phase that could lower the heat of hydride formation. Dehydrogenation of metal hydrides is an energy intensive process and to decrease the enthalpy of formation the hydride complex needs to be activated or 'destabilized'. The metal catalyst responsible for hydrogen spillover could also form a new compound with the parent metal and hydrogen resulting in a destabilized product exhibiting decreased heats of formation for the metal and metal hydride. For example, a reduction of hydrogen desorption temperature was observed for nanocomposites of $85 \mathrm{wt}$ \% Mg-15 wt. \% $\mathrm{Mg}_{2} \mathrm{Ni}_{1-\mathrm{x}} \mathrm{Fe}_{\mathrm{x}}(\mathrm{x}=0,0.1$, and 0.3$) .{ }^{34}$ The enhanced desorption kinetics of the composite were attributed to a new hydride phase forming from the ternary intermetallic dopant.

Managing the heat evolved during the hydriding reaction is another crucial step toward meeting hydrogen storage goals. Bimetallic structures offer the advantage of good thermal conductivity which can help improve efficiency and sorption-desorption kinetics. The DOE has noted that the hydrogenation rate should be $1.98 \mathrm{kmol} \mathrm{H}_{2} \min ^{-1}$ (Table 1). For $\mathrm{Mg}$, with an enthalpy for $\mathrm{MgH}_{2}$ formation of $75 \mathrm{~kJ} \mathrm{~mol}^{-1} \mathrm{H}_{2}$, over $300 \mathrm{MJ}$ of heat is evolved assuming a fill time of 2.5 minutes. Supposing no heat removal, the temperature rise can be estimated from $\Delta T=Q /(n c)$, where $n$ is the number of moles, $c$ is the specific heat and $Q$ is the total heat supplied to the system. Metallic $\mathrm{Mg}$ has a specific heat of 24.9 $\mathrm{J} \mathrm{mol}^{-1} \mathrm{~K}^{-1}$ and thus gives temperatures on the order of $1000^{\circ} \mathrm{C} .{ }^{35,36}$ At these 
temperatures hydride formation will cease to occur and sintering will become a problem. However, metal hydrogenation/dehydrogenation catalyst dopants such as Fe or Ni have moderate thermal conductivities and the metal matrix could help dissipate the heat evolved during the hydriding reaction leading to more facile kinetics.

\section{Benefits of Nanoarchitectures}

Nanoscale materials are currently being researched as a replacement for bulk hydrogen storage materials due to their unique chemical, physical, thermodynamic, and kinetic properties. ${ }^{37}$ These materials help to address numerous problems associated with bulk metal hydrides: Inadequate storage capacity, sluggish sorption-desorption kinetics, and high dehydriding temperatures. Typically, metal hydride complexes are fairly stable and do not usually undergo dehydrogenation until temperatures above $200^{\circ} \mathrm{C}$. ${ }^{8}$ This is detrimental to the overall efficiency of the storage material. However, nanoparticle versions of these materials have considerably larger surface areas compared to the bulk and as such they have a higher surface energy. This helps to lower the heat of formation both for the metal and the metal hydride. When the surface energy of the hydride is greater than that of the metal, a portion of the heat of formation will be stored as excess surface energy permitting the heat released upon hydride formation to decrease and the heat needed for dehydrogenation to be diminished which improves efficiency compared to bulk materials. ${ }^{8}$ Furthermore, nanomaterials offer greater surface area and/or porosity compared to their bulk counterparts, which translates into more hydrogen adsorption sites (i.e. increased kinetics). Smaller particles also enhance sorption-desorption kinetics because the hydrogen atom has less material to diffuse through to fully accomplish the 
conversion to the metal hydride and likewise when going from the metal hydride to the metal. Together, these observations support the idea that bimetallic nanomaterials could revolutionize the field of reversible hydrogen storage and enable the use of hydrogen as a clean energy source.

\section{Goals and Approach}

As outlined above, development of materials that store hydrogen effectively and allow for fast, reversible hydrogen sorption-desorption under ambient conditions is needed in order to be able to use hydrogen as a way to reach a more sustainable and energy independent future. To achieve the necessary hydrogen storage goals set forth by the DOE, we propose a bimetallic heterostructured nanocomposite with interpenetrating transition metal veins (Figure 5). The interpenetrating veins will be made of known hydrogenation/dehydrogenation catalysts and serve as dissociation sites for molecular hydrogen. This could help reduce the kinetic barrier of hydride formation for the parent metal (e.g. Mg) (Figure 5) by catalyzing the formation of initial near-surface hydride nuclei through hydrogen spillover. The geometry of the interpenetrating network of veins could also help reduce the time that it takes for hydrogen atoms to diffuse to the metalmetal hydride interface by reducing the effective bulk of the parent metal. There are three main objectives that need to be realized for successful synthesis of the proposed novel bimetallic heterostructures: 
1. Research and development of a scalable, size-tunable synthesis of hydrogenation/dehydrogenation metal nanorod catalysts to facilitate quick conversion of metal to metal-hydride and vice versa.

2. Research and development of a method to successfully encapsulate metal nanocatalysts within particles or aggregates made of lighter hydride-forming metals ( $\mathrm{Li}, \mathrm{B}, \mathrm{Na}, \mathrm{Mg}, \mathrm{Al})$, or combinations thereof.

3. Investigation of hydrogenation/dehydrogenation catalytic and uptake experiments needed in order to optimize the numerous combinations and conditions that could be exploited.

Success of this research will be an enormous technological leap from the current status of on-board hydrogen storage materials, enabling the use of a clean and renewable fuel $\left(\mathrm{H}_{2}\right)$ for transportation purposes.
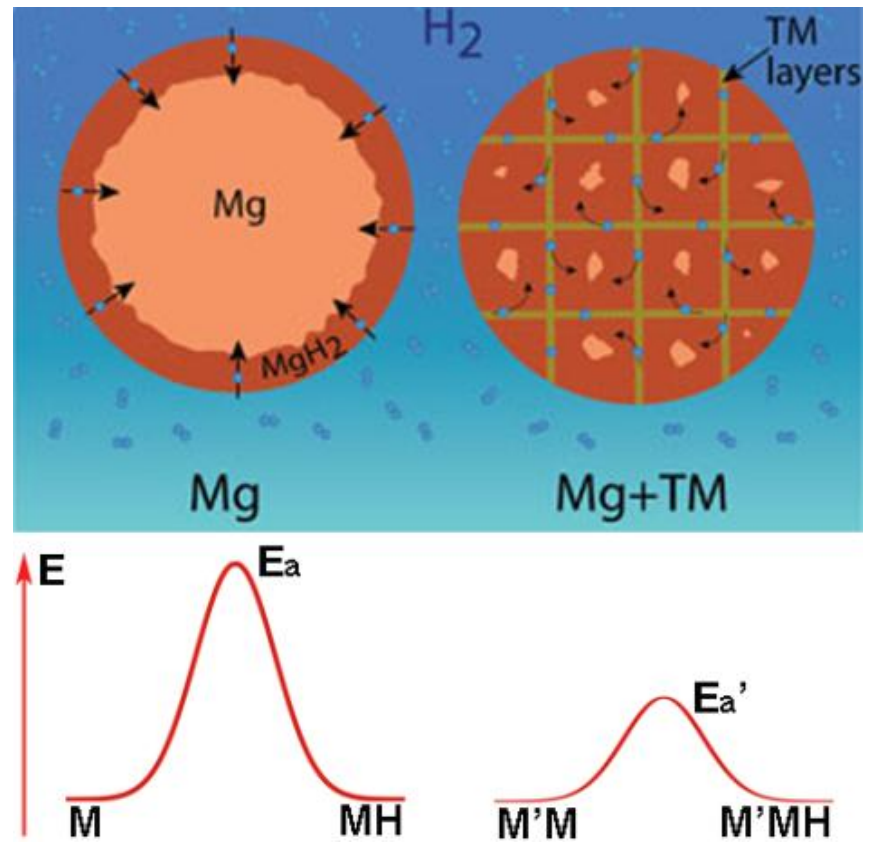

Figure 5. Schematic of bimetallic heterostructured nanocomposite for hydrogen storage. 
The first step in the synthesis of bimetallic heterostructured hydrogen storage materials is to investigate and develop a robust, scalable synthesis of size-controllable metal nanorods (Fe, Co, Ni, Rh, Pd, Pt, Ir, Ti, V). Ideally, this new method will produce the desired nanorods simply by varying the metal precursor and reductant used in their synthesis. A hard template approach is an ideal way to achieve the desired attributes of the aforementioned synthesis. The already known and available syntheses of size tunable templates allows for the possibility to fill such templates with any metal of interest, thus producing an inner cavity replica (duplicate) of the template in a single step. Silica is widely used as a hard template due to its hydrophilicity, thermal stability, chemical robustness, and ease of synthesis and processability. A silica shell structure also offers the advantage of processability in a wide range of solvents depending on the surface functionalities of the shell and can also protect against metal sintering or coalescence. Size-controlled, industrially scalable synthesis of silica nanocapsules has recently been demonstrated ${ }^{38}$ and is used as a hard template to confine the growth of zero-valent metals in the present work.

The synthesis of zero-valent metal nanorods is attempted through colloidal chemical methods. The silica nanocapsules are fabricated by condensation and hydrolysis of silica precursor onto a 1D nickel complex. Because nickel is already present inside the nanocapsule and is a fairly reactive metal, we employ chemical reduction of this same nickel complex. For other metals $(\mathrm{Fe}, \mathrm{Co}, \mathrm{Ti}, \mathrm{V}$, etc.) a seeded growth process could be employed, but is not explored here. A general approach for the seeded growth process requires functionalizing the inner surface of the silica nanocapsules with groups that have a strong affinity for the metal of interest (i.e. Fe, Co, Ti, and V). Treatment of internally 
functionalized silica nanocapsules with a solution of metal precursor could allow for retention of specific metal species inside the nanocapsule. Reduction of the thus retained metals would yield zero-valent metal clusters that can act as seeds for heterogeneous nucleation and subsequent growth. Retrieval of zero-valent nanorods can be achieved by chemical etching.

After optimizing the synthesis of the nanorods, the next step would be encapsulation of the nanorods in a light metal that has a high affinity for hydride formation. There is much precedent for metal-metal epitaxial growth in the literature, ${ }^{39,40}$ but to date this step in the process has not been explored. Once established, we could begin to experiment with different types of metals and loadings to find optimal conditions for hydrogen storage. This research could lead to the development of hydrogen storage materials that will at the minimum become a model system for future hydrogen storage solid-state materials. Ideally, these materials will result in unprecedented hydrogen sorption/desorption kinetics near ambient conditions while satisfying the gravimetric energy density needs to become a viable solution for obtaining energy independence and economic prosperity. 


\section{CHAPTER 2. HARD TEMPLATE APPROACH FOR THE SYNTHESIS OF METAL NANORODS}

\section{Introduction}

There are several literature examples citing the synthesis of one-dimensional (1D) nanomaterials. ${ }^{41}$ Six methods commonly employed include: (1) Intrinsic anisotropic crystallization of the material, (2) vapor-liquid-solid (VLS) processes from liquid droplet seeds, (3) using a 1D template to direct the formation of 1D structures, (4) using ligands to stabilize certain growing facets leading to anisotropic growth, (5) self-assembly of zero-dimensional nanostructures, and (6) size reduction of 1D microstructures. Templatedirected synthesis represents a simple, high-throughput, potentially cost-effective and straightforward approach to 1D nanostructure growth without complicated, ill-defined chemical methods and conditions that often accompany other methods. In this approach, the template serves as a rigid structure in which the desired material is generated within or around. The morphology of the new material generated is therefore complementary to the original template. The method is generic and template removal is often achieved through chemical etching (hard templating) or calcination (soft templating).

Templates commonly used include the step edges or V-grooves present on the surfaces of solid substrates, ${ }^{42,43}$ the channels and pores of mesoporous materials, ${ }^{44}$ solution-born micelles, ${ }^{45}$ biological macromolecules such as DNA strains, ${ }^{46,47}$ and preexisting nanostructures synthesized using one of the aforementioned methods. ${ }^{48}$ Templating against the features of a solid substrate is regularly exploited for the synthesis of nanowires when aspect ratio control is not important or critical. In solution-phase, 
certain surfactants are known to self-assemble into cylindrical or rod shaped micelles when their concentration exceeds a certain value and their anisotropic morphology can be used as a template. However, the preparation and removal of the micellar phase is frequently difficult and tedious. Biological templates offer a unique way to achieve 1D growth, and their use is conceptually similar to templating against pre-existing nanostructures described below. Templating against the channels of mesoporous materials usually results in polycrystalline materials. In addition, the method offers the major advantage of aspect ratio control, low size dispersion, and provides potential largescale production.

The most common mesoporous templates include track-etched polymer films, carbon nanotubes (CNTs), alumina films, and mesoporous silica. Track-etched polymer films require bombarding polymer films with heavy ions (from nuclear fission) to create damaged spots on the surface of the film and subsequent chemical etching to generate uniform, cylindrical pores piercing the membrane film. ${ }^{41}$ The films are easily removed through pyrolysis at elevated temperatures, but the resultant nanorods can be distorted or broken due to template removal before the complete densification of the rods. ${ }^{49} \mathrm{CNTs}$ have also been used as templates in the synthesis of $1 \mathrm{D}$ metals. ${ }^{50,51}$ However, wellcontrolled aspect ratios have not been achieved with this approach and template removal remains a challenge. Another commonly used template is anodized aluminum oxide (AAO). Anodization of aluminum in a strong acid electrolyte results in a self-organized process and formation of uniform pores. Pore dimensions are controlled by the anodization technique and the electro-chemical parameters employed. The diameters and lengths of the pores can be as small as $5 \mathrm{~nm}$ and $100 \mathrm{~nm}$, respectively; however, 
improvements must be made to increase the area of the ordered domains. Moreover, the fabrication time for long-range ordered domains must be decreased to increase costefficiency and become industrially scalable. ${ }^{52}$ One other commonly employed method for the synthesis of 1D materials consists of templating against the interior channels or pores of mesoporous silica nanoparticles (MSNs). Silica offers the advantage of high thermal stability, hydrophilicity, susceptibility to selective surface functionalization of inner and outer surfaces, wall structure porosity, facile synthesis, optical transparency (making it useful as a template in photochemical syntheses), and most importantly, scalability. By choosing the correct type of mesoporous silica material, the aspect ratio of 1D materials templated within their structure can be precisely controlled with reasonable monodispersity. Together, these attributes are ideal for synthesizing metal nanorods for bimetallic heterostructured hydrogen storage materials.

Templating against the channels in MSNs (e.g. MCM or SBA) to yield zerovalent metals ( $\mathrm{Fe}, \mathrm{Co}, \mathrm{Ni}, \mathrm{Cu}, \mathrm{Pd}, \mathrm{Pt}, \mathrm{Au}, \mathrm{Ag}$ ) has been demonstrated in the literature. $^{44,53,54,55,56}$ Typical procedures for the synthesis and harvesting of $1 \mathrm{D}$ metals involve three basic steps: Impregnation with a metal precursor, reduction of the metal precursor inside the channels, and subsequent etching of the template to yield nanostructures with high aspect ratio (1D) morphologies. For example, Chao et al., ${ }^{44}$ functionalized the surfaces of MCM-41 with organic ammonium chloride salts followed by the introduction of $\mathrm{MCl}_{\mathrm{m}}{ }^{\mathrm{n}-}$ salts, resulting in the exchange with chloride anions and subsequent adsorption of metal chlorides onto the pore surface. Reduction of the metal salts by calcination in an $\mathrm{H}_{2}$ atmosphere yielded metal nuclei inside mesoporous silica. Further growth of the primary metal nuclei resulted in metal nanowires of $\mathrm{Au}, \mathrm{Pt}$, and $\mathrm{Pd}$. 
In another approach, Cheon et al. ${ }^{57}$ utilized vapor infiltration to synthesize Pd nanowires. An organometallic precursor was sublimed into the empty pores of MSNs and then pyrolyzed under an $\mathrm{H}_{2}$ environment. In order to obtain unsupported Pd nanowires, the siliceous Pd composites were treated with an aqueous solution of hydrofluoric acid and XPS confirmed there were no palladium silicides present.

The methods used to synthesize metal nanorods in MSNs often result in a wide variation of nanorod lengths and incomplete pore filling. In one of the cases presented above (i.e. incipient wetness impregnation), capillary force drives the aqueous metal salt solution into the pores and complete pore filling during immersion is likely. However, the amount of solid occupying the pore space is limited by the solubility of the precursor in solution. Upon drying, the solubility limitations result in incomplete pore filling and lack of aspect ratio control in the final product (Figure 6) ${ }^{58}$ In addition, even if a method was developed to allow for complete pore filling, aspect ratios below 50 would be difficult to achieve based on typical MSN dimensions (pore length and diameter). Similarly, vapor infiltration methods rely on diffusion of the gaseous precursor into the channels of mesoporous silica. The process is slow and suffers from pore blockage, thus also resulting in incomplete pore filling and lack of aspect ratio control.

Silica nanocapsules are an emerging class of silica templates offering many advantages over MSNs. There has been significant progress in the fabrication of welldefined 1D silica nanocapsules over the past decade $;{ }^{59}$ unfortunately, most of the methods are limited by the difficulties associated with obtaining 1D templates of high quality and in large quantity. Very recently, Yin et al..$^{38}$ established a robust method for the synthesis of silica nanocapsules with precise aspect ratio control on the gram-scale by 
templating against 1D nanocrystals. Crystalline nanorods of a nickel-hydrazine complex were first formed in reverse microemulsion by ligand-mediated preferential growth of certain facets. Following silica coating, selective etching of the nickel-hydrazine complex gave rise to silica nanocapsules of high uniformity and yield. The inner length of the silica nanocapsules can be tuned by varying the nickel concentration, while their inner diameter can be tuned by choosing different surfactants. The persistent problem of aspect ratio control and magnitude associated with MSN templates is alleviated by the nanocapsules prepared by the aforementioned procedure.

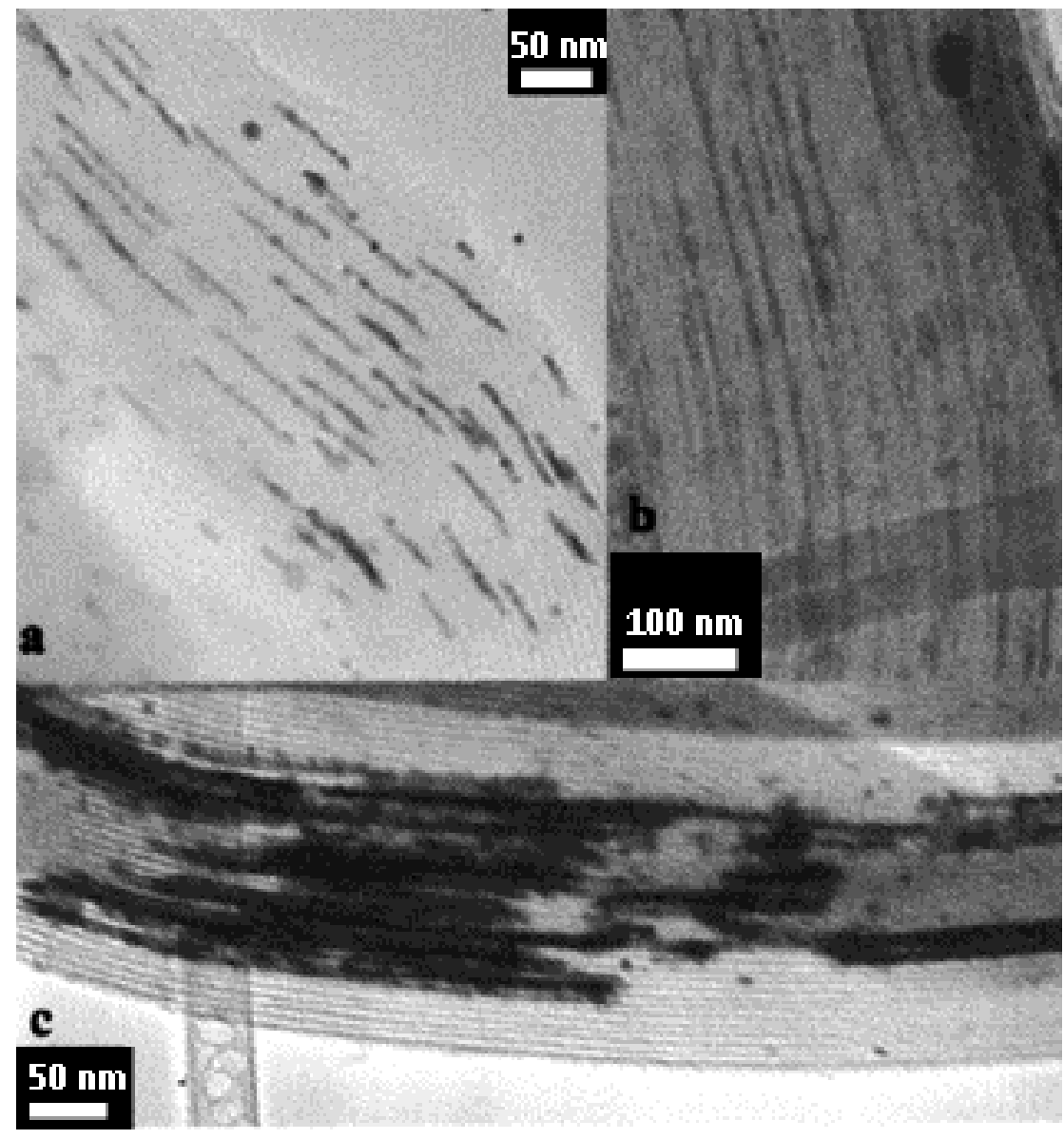

Figure 6. TEM micrographs of different metal nanowires grown within the framework of SBA-15: (a) Au/SBA-15; (b) Ag/SBA-15; (c) Pt/SBA-15. ${ }^{58}$ 
Template-directed synthesis of zero-valent metal nanorods offers increased advantages needed for the synthesis of bimetallic heterostructures compared to other commonly employed methods of nanorod synthesis. Utilizing discrete mesoporous silica templates results in superior aspect ratio control, increased monodispersity, and allows for scalability. Discrete mesoporous silica nanocapsules are therefore best suited for the synthesis of metal nanorods because of their many highly desirable properties relative to other templates and silica materials. The consistent and possibly scalable production of silica nanocapsules with high uniformity and size tunability makes them promising templates for the preparation of well-defined zero-valent metal nanorods.

\section{Results and Discussion}

\section{Synthesis of $\mathrm{NiCSiO}_{2}$}

By reduction of previously reported tris (hydrazine) nickel (II) chloride coated with silica $\left(\left[\mathrm{Ni}\left(\mathrm{N}_{2} \mathrm{H}_{4}\right)_{3}\right] \mathrm{Cl}_{2} \subset \mathrm{SiO}_{2}\right)$ by sodium borohydride $\left(\mathrm{NaBH}_{4}\right)$, followed by calcination under an $\mathrm{H}_{2}$ atmosphere, we synthesized zero-valent nickel nanoparticles templated by amorphous silica $\left(\mathrm{NiCSiO}_{2}\right)($ Figure $7 \mathrm{a}$ and $7 \mathrm{~b})$.Powder $\mathrm{X}$-ray diffraction (XRD), Fourier transform infrared spectroscopy (FTIR), high-resolution (HR) transmission electron microscopy (TEM), and energy-dispersive X-ray spectroscopy (EDX) showed that zero-valent nickel nanoparticles $\left(\mathrm{Ni}^{0}\right)$ are templated by amorphous silica. The structures display strong magnetic behavior at room temperature and preliminary data suggests $\mathrm{Ni}^{0}$ particle size can be tuned while maintaining nanocapsule dimensions. 

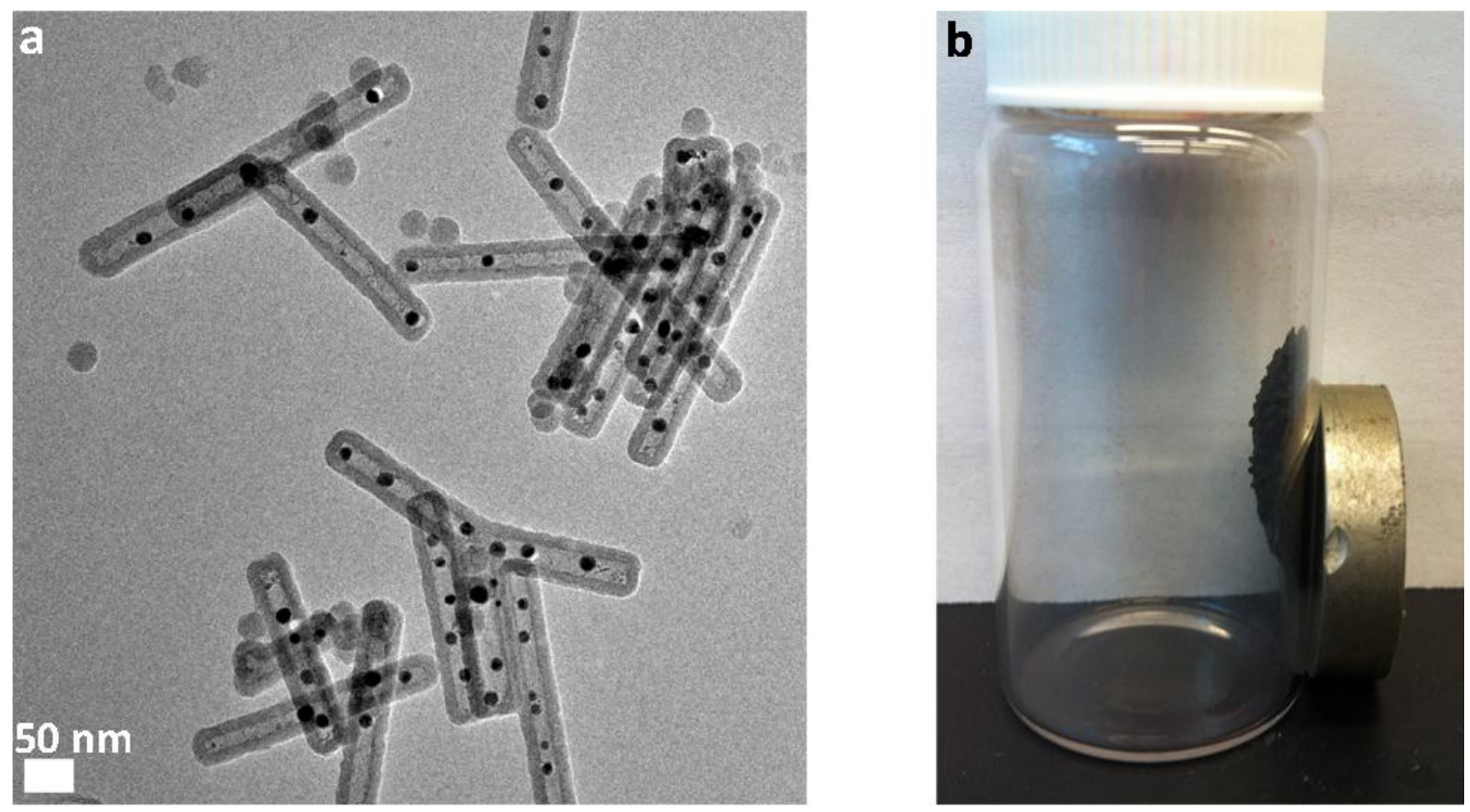

Figure 7. (a) TEM micrograph of $\mathrm{Ni}_{\mathrm{S}} \mathrm{SiO}_{2}$, and (b) Photograph showing its magnetic behavior.

Synthesis of the initial $\left[\mathrm{Ni}\left(\mathrm{N}_{2} \mathrm{H}_{4}\right)_{3}\right] \mathrm{Cl}_{2} \subset \mathrm{SiO}_{2}$ core-shell complex was carried out in a water-in-oil reverse microemulsion. ${ }^{38}$ Aqueous nickel (II) chloride hexahydrate $\left(\mathrm{NiCl}_{2} \bullet 6 \mathrm{H}_{2} \mathrm{O}\right)$ constituted the dispersed phase, cyclohexane the continuous phase, and polyoxyethylene (20) cetyl ether (Brij58) was used as the surfactant. After mixing, a homogenized solution was obtained and hydrazine hydrate $\left(\mathrm{N}_{2} \mathrm{H}_{4} \bullet \mathrm{H}_{2} \mathrm{O}\right)$ was added in excess. Hydrazine is thought to coordinate to nickel centers to form a one-dimensional tris(hydrazine) nickel (II) chloride $\left(\left[\mathrm{Ni}\left(\mathrm{N}_{2} \mathrm{H}_{4}\right)_{3}\right] \mathrm{Cl}_{2}\right)$ complex under these conditions. The 1D morphology was confirmed by scanning electron microscopy (SEM) (Figure 8a), and the complex was identified by its characteristic, previously reported XRD pattern (Figure 8b). Encapsulation by amorphous silica (Figure 8c) was obtained through in-situ introduction of tetraethylorthosilicate (TEOS) which easily undergoes hydrolysis and condensation catalyzed by diethylamine to yield amorphous silica. The diffraction pattern 
(Figure 8d) clearly shows crystalline $\left[\mathrm{Ni}\left(\mathrm{N}_{2} \mathrm{H}_{4}\right)_{3}\right] \mathrm{Cl}_{2}$ is present after silica coating in addition to amorphous material centered around $2 \Theta=24^{\circ}$.
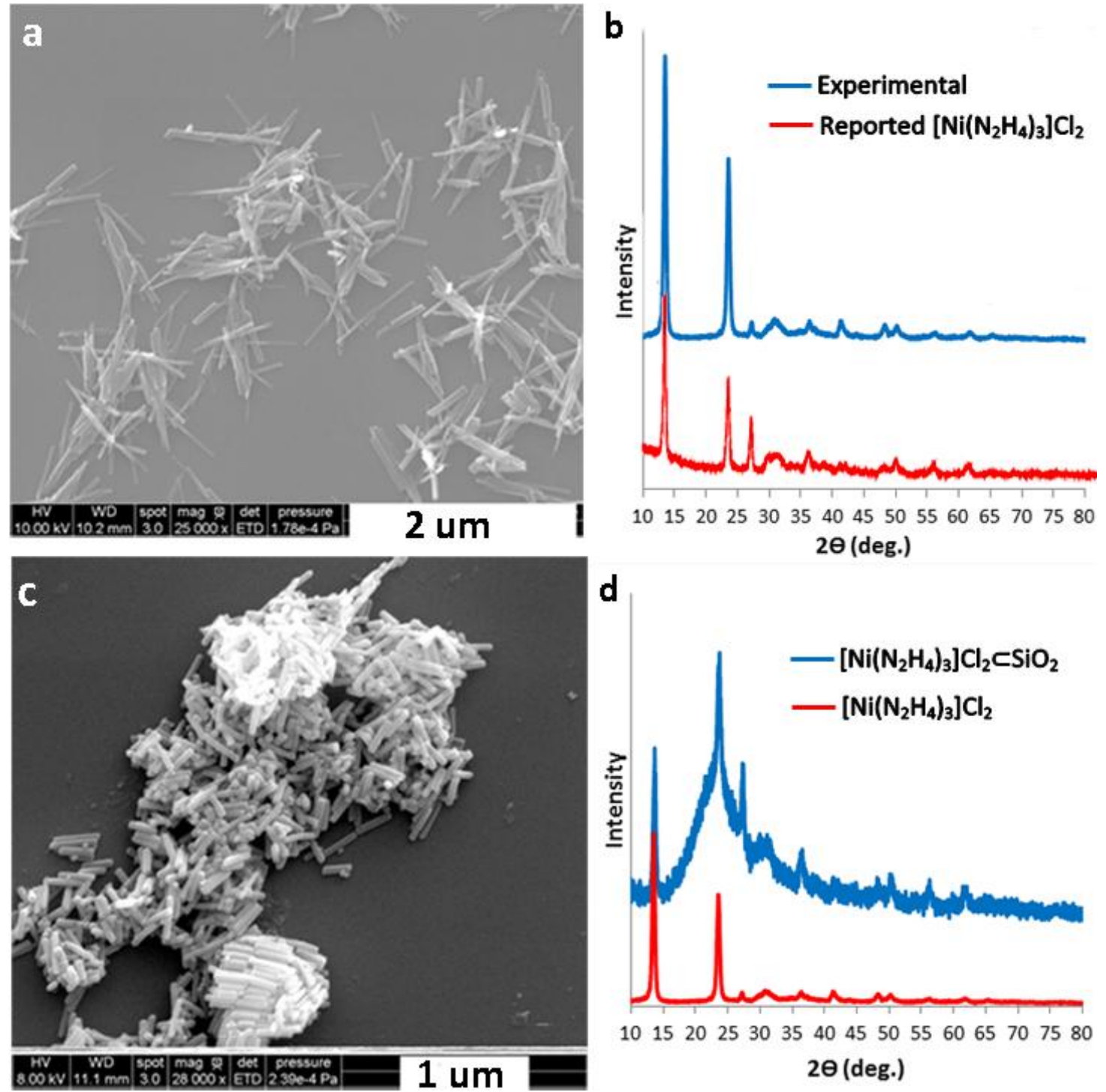

Figure 8. (a) SEM micrograph of $\left[\mathrm{Ni}\left(\mathrm{N}_{2} \mathrm{H}_{4}\right)_{3}\right] \mathrm{Cl}_{2}$ prepared by reverse microemulsion; (b) XRD pattern of experimental and $\left[\mathrm{Ni}\left(\mathrm{N}_{2} \mathrm{H}_{4}\right)_{3}\right] \mathrm{Cl}_{2}$ reference; ${ }^{60}$ (c) SEM micrograph of $\left[\mathrm{Ni}\left(\mathrm{N}_{2} \mathrm{H}_{4}\right)_{3}\right] \mathrm{Cl}_{2} \subset \mathrm{SiO}_{2}$; (d) XRD pattern of $\left[\mathrm{Ni}\left(\mathrm{N}_{2} \mathrm{H}_{4}\right)_{3}\right] \mathrm{Cl}_{2} \subset \mathrm{SiO}_{2}$ and $\left[\mathrm{Ni}\left(\mathrm{N}_{2} \mathrm{H}_{4}\right)_{3}\right] \mathrm{Cl}_{2}$.

FTIR can be used to detect the presence of $\mathrm{N}_{2} \mathrm{H}_{4}$ ligands and the $\mathrm{SiO}_{2}$ shell

(Figure 9). The N-H symmetric stretching vibrations at $3213 \mathrm{~cm}^{-1}$ and $3156 \mathrm{~cm}^{-1}$, and the 
$\mathrm{NH}_{2}$ bending and wagging between 1628-1192 $\mathrm{cm}^{-1}$ confirm the presence of hydrazine ligands in both $\left[\mathrm{Ni}\left(\mathrm{N}_{2} \mathrm{H}_{4}\right)_{3}\right] \mathrm{Cl}_{2}$ and $\left[\mathrm{Ni}\left(\mathrm{N}_{2} \mathrm{H}_{4}\right)_{3}\right] \mathrm{Cl}_{2} \subset \mathrm{SiO}_{2} .{ }^{61}$ The IR spectrum for $\left[\mathrm{Ni}\left(\mathrm{N}_{2} \mathrm{H}_{4}\right)_{3}\right] \mathrm{Cl}_{2} \subset \mathrm{SiO}_{2}$ shows a strong, broad peak at $1190 \mathrm{~cm}^{-1}$ and $1090 \mathrm{~cm}^{-1}$ attributed to the longitudinal-optical (LO) and transverse-optical (TO) mode of Si-O-Si asymmetric bond stretching vibration, respectively. ${ }^{62}$ The peaks present at $801 \mathrm{~cm}^{-1}$ and $461 \mathrm{~cm}^{-1}$ correspond to Si-O-Si symmetric stretching and bond bending vibrations, respectively. ${ }^{62}$ Furthermore, the N-N stretching frequency reveals the binding mode of the hydrazine ligands to the metal center. The N-N stretching frequency of $\mathrm{MCl}_{2}\left(\mathrm{~N}_{2} \mathrm{H}_{4}\right)_{2}(\mathrm{M}=\mathrm{Mn}, \mathrm{Fe}$, $\mathrm{Co}, \mathrm{Ni}, \mathrm{Cu}, \mathrm{Zn}$, and $\mathrm{Cd}$ ) was previously identified using isotopic labeling and found to lie in the range of $960-985 \mathrm{~cm}^{-1} \cdot{ }^{63}$ These compounds are isomorphous and characterized by a polymeric structure of bridging bidentate ligands $\left(-\mathrm{M}\left(\mathrm{N}_{2} \mathrm{H}_{4}\right)_{2} \mathrm{M}-\right)$; complexes containing unidentate ligands are expected to have decreased N-N stretching frequencies due to their less rigid environment. In 1968, Nicholls et al. ${ }^{64}$ synthesized and characterized various cobalt-hydrazine complexes, and by comparing the N-N stretching frequencies of unidentate hydrazine $\left[\mathrm{Co}\left(\mathrm{N}_{2} \mathrm{H}_{4}\right)_{6}\right] \mathrm{Cl}_{2}\left(v(\mathrm{~N}-\mathrm{N})=928 \mathrm{~cm}^{-1}\right)$ and bidentate hydrazine $\left[\mathrm{Co}\left(\mathrm{N}_{2} \mathrm{H}_{4}\right)_{2}\right] \mathrm{Cl}_{2}\left(v(\mathrm{~N}-\mathrm{N})=970 \mathrm{~cm}^{-1}\right)$, they confirmed that bidentate hydrazine ligands are blue-shifted relative to unidentate hydrazine ligands. The $\left[\mathrm{Ni}\left(\mathrm{N}_{2} \mathrm{H}_{4}\right)_{3}\right] \mathrm{Cl}_{2}$ spectrum clearly shows a peak at $972 \mathrm{~cm}^{-1}$ and can thus be attributed to N-N stretching of the hydrazine ligands, suggesting the complex contains bidentate hydrazine ligands. Furthermore, due to the thermal stability and insolubility of $\left[\mathrm{Ni}\left(\mathrm{N}_{2} \mathrm{H}_{4}\right)_{3}\right] \mathrm{Cl}_{2}$, the hydrazine ligands are believed to be bridging bidentate rather than chelating bidentate. A proposed coordination environment consistent with the above information is shown in as an inset of Figure 9. 


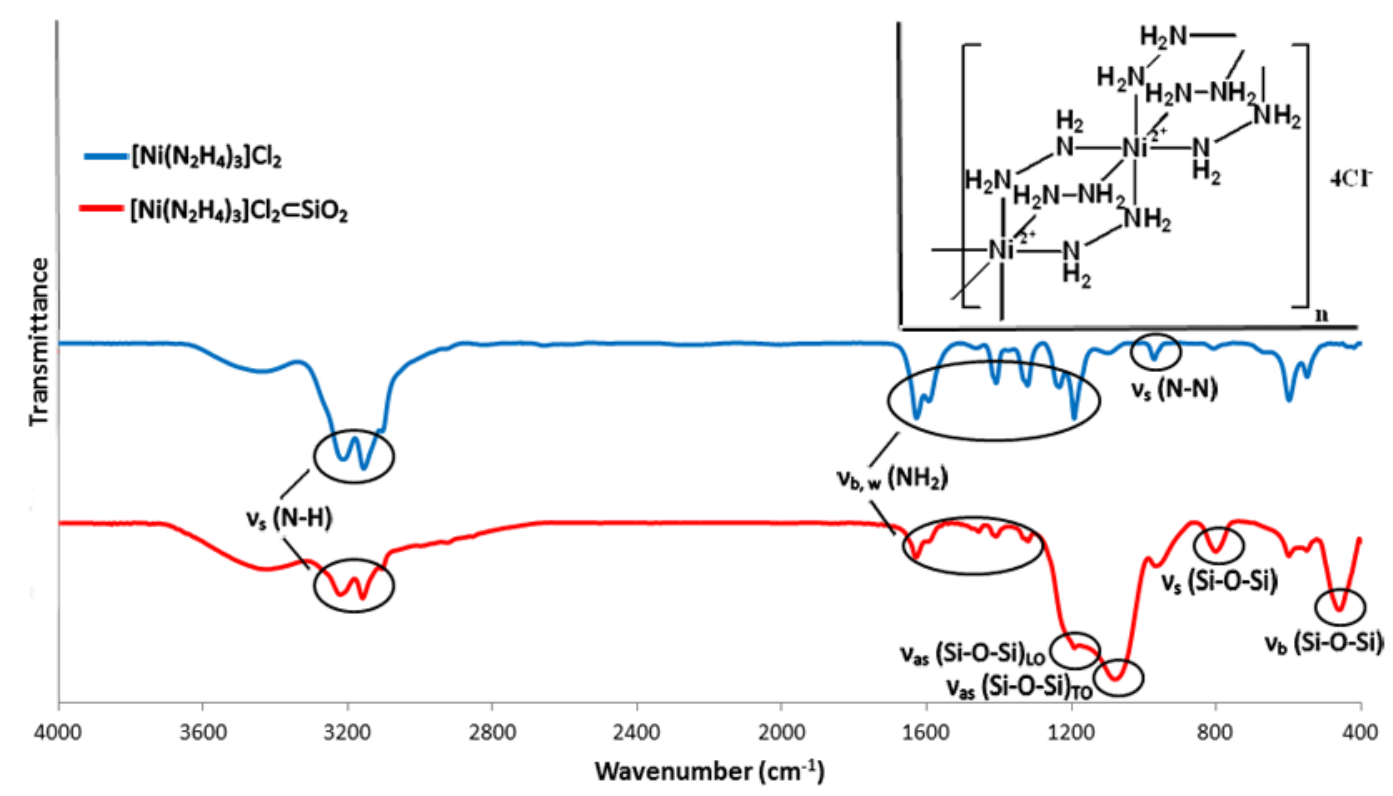

Figure 9. FTIR spectrum for $\left[\mathrm{Ni}\left(\mathrm{N}_{2} \mathrm{H}_{4}\right)_{3}\right] \mathrm{Cl}_{2}$ and $\left[\mathrm{Ni}\left(\mathrm{N}_{2} \mathrm{H}_{4}\right)_{3}\right] \mathrm{Cl}_{2} \subset \mathrm{SiO}_{2}$. Inset shows proposed $\mathrm{Ni}^{2+}$ coordination environment.

When $\left[\mathrm{Ni}\left(\mathrm{N}_{2} \mathrm{H}_{4}\right)_{3}\right] \mathrm{Cl}_{2} \subset \mathrm{SiO}_{2}$ is treated with hydrochloric acid $(\mathrm{HCl})$, the silica shell is retained while the tris(hydrazine) nickel (II) chloride core is selectivity etched away giving rise to amorphous silica $1 \mathrm{D}$ templates. ${ }^{38}$ The TEM micrograph (Figure 10a) confirms the templates have nanocapsule morphology. The thickness of the silica walls depends on the amount of TEOS used, in addition to the time used for hydrolysis and condensation reactions. Typical wall thicknesses are 15-20 $\mathrm{nm}$ under the conditions and times used. The FTIR spectrum (Figure 10b) confirms that hydrazine ligands are no longer present after acid etching evidenced by the lack of bands at $3213 \mathrm{~cm}^{-1}$ and 3156 $\mathrm{cm}^{-1}$. The post-etch spectrum shows peaks at $2849 \mathrm{~cm}^{-1}$ and $2919 \mathrm{~cm}^{-1}$ which are characteristic of $\mathrm{C}-\mathrm{H}$ stretching and can be attributed to incomplete removal of Brij 58 surfactant. The diffractogram (Figure 10c) shows that after treatment of $\left[\mathrm{Ni}\left(\mathrm{N}_{2} \mathrm{H}_{4}\right)_{3}\right] \mathrm{Cl}_{2} \subset \mathrm{SiO}_{2}$ with $\mathrm{HCl}$, crystalline material is no longer present. 

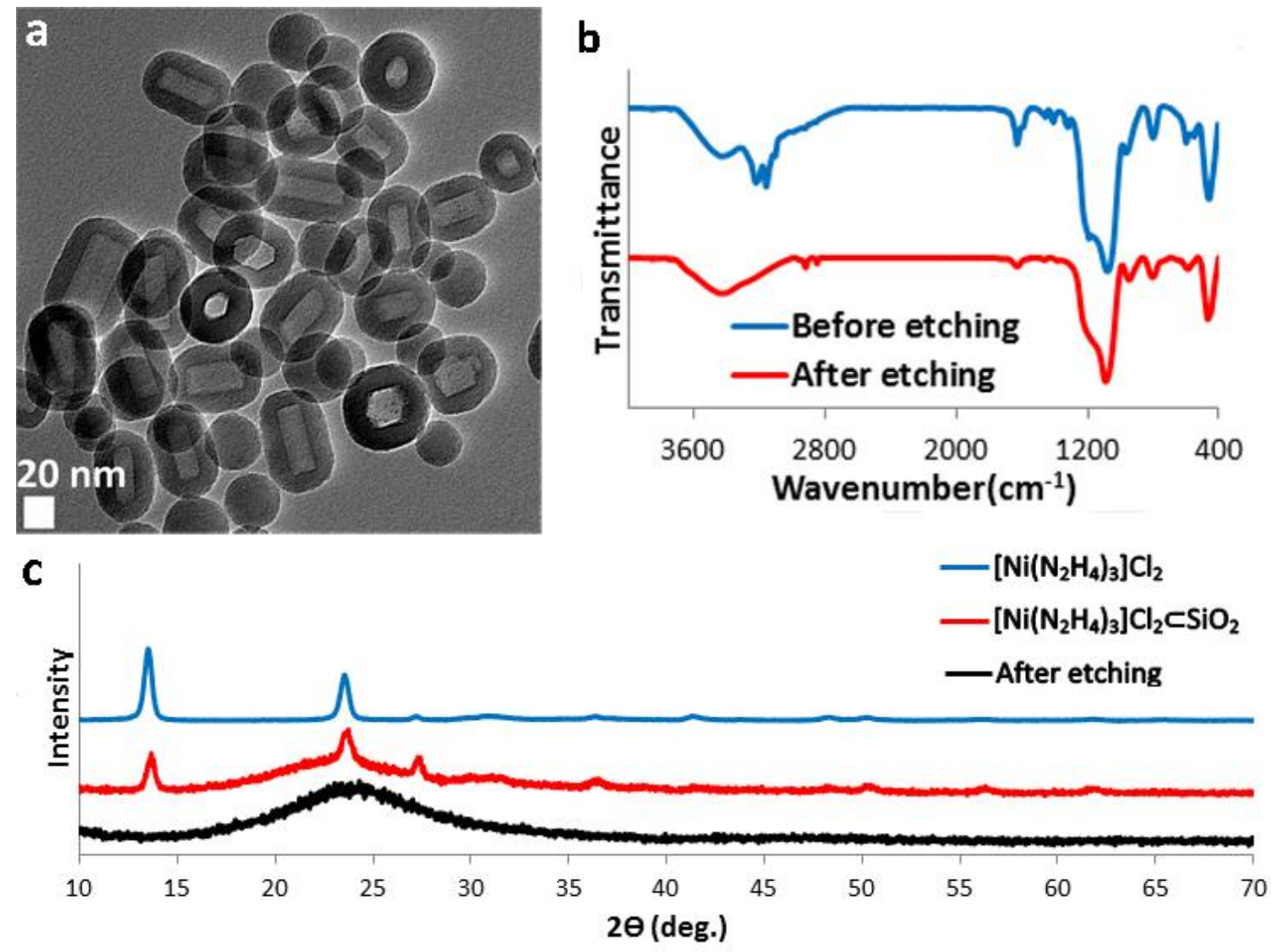

Figure 10. (a) TEM micrograph of silica nanocapsules; (b) FTIR spectrum before and after $\mathrm{HCl}$ etching $\left[\mathrm{Ni}\left(\mathrm{N}_{2} \mathrm{H}_{4}\right)_{3}\right] \mathrm{Cl}_{2} \subset \mathrm{SiO}_{2}$; (c) XRD data of $\left[\mathrm{Ni}\left(\mathrm{N}_{2} \mathrm{H}_{4}\right)_{3}\right] \mathrm{Cl}_{2}$, $\left[\mathrm{Ni}\left(\mathrm{N}_{2} \mathrm{H}_{4}\right)_{3}\right] \mathrm{Cl}_{2} \subset \mathrm{SiO}_{2}$, and after etching with $\mathrm{HCl}$ (i.e. silica nanocapsules).

Using different amounts of aqueous $\mathrm{NiCl}_{2} \cdot 6 \mathrm{H}_{2} \mathrm{O}$ while keeping the amount of Brij 58 and hydrazine constant allows the isolation of nanocapsules with different lengths (Figure 11a-d) ${ }^{38}$ The width of the nanocapsules in all experiments $(40-70 \mathrm{~nm})$ is constant and dependent on the length of the polar polyoxyethylene chain of the surfactant used in their synthesis. ${ }^{38}$ To demonstrate the degree of aspect ratio control that can be achieved by this method, we plotted the average nanocapsule length versus the amount of $\left[\mathrm{NiCl}_{2} \bullet 6 \mathrm{H}_{2} \mathrm{O}\right]$ used (Figure 11e). The SEM micrographs, histogram, and plot clearly show that nanocapsule aspect ratio can be precisely controlled and easily predicted. The 
deviation in nanocapsule lengths increases when $\left[\mathrm{NiCl}_{2} \bullet 6 \mathrm{H}_{2} \mathrm{O}\right]$ is greater than $1.1 \mathrm{mM}$ compared to when the ratio is less than $0.8 \mathrm{mM}$.
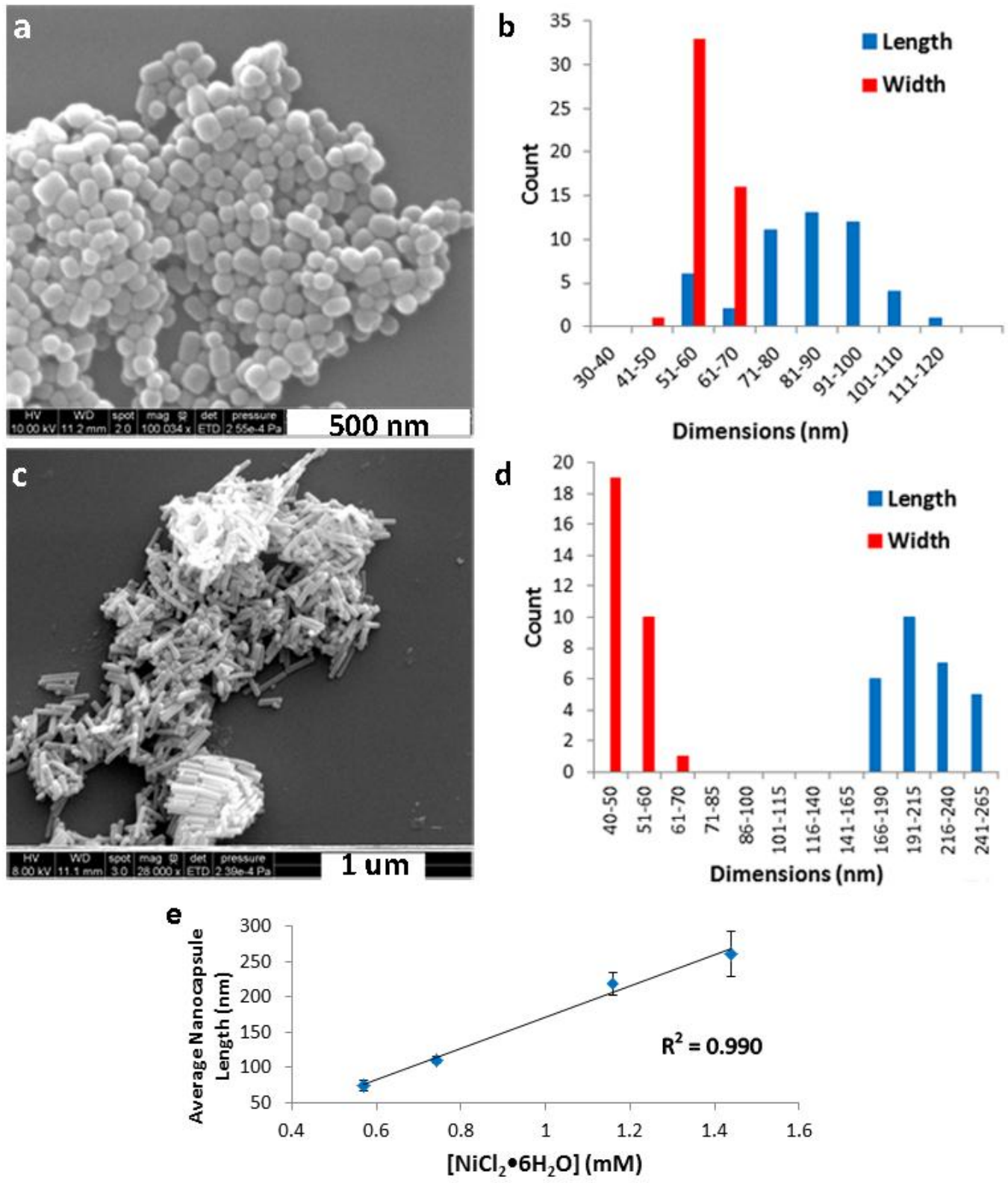

Figure 11. (a) and (c) SEM micrographs of silica nanocapsules prepared with different amounts of $\mathrm{NiCl}_{2}$; (b) and (d) Size histogram of silica nanocapsules corresponding to (a) and (c), respectively.(e) Plot of silica nanocapsule length versus $\left[\mathrm{NiCl}_{2} \bullet 6 \mathrm{H}_{2} \mathrm{O}\right]$. A linear regression line was used to fit the set of data points. The coefficient of determination is shown in the lower right of the plot area. The error bars represent one standard deviation from the mean. 
To synthesize zerovalent metal nanorods, we first explored the chemical conversion (reduction) of surfactant-stabilized tris(hydrazine) nickel (II) chloride to nickel metal. Nickel metal is fairly active and, if successful, could lead to indirect synthesis of other catalytic (dehydrogenation/ hydrogenation) metals (Pd, Pt, Rh, Ru, Ir) through galvanic exchange. The most notable colloidal synthesis of nickel nanorods has been demonstrated through thermal decomposition of nickelocene in the presence of hexadecylamine (HDA). ${ }^{65}$ Unfortunately, the cost of nickelocene precursor is too high for scalable synthesis, and therefore this method is not ideal for the synthesis of metal nanorods for use in bimetallic heterostructures. Other methods of synthesis include a polyol process, ${ }^{66}$ solvothermal decomposition of nickel acetate $\left(\mathrm{Ni}\left(\mathrm{CH}_{3} \mathrm{COO}\right)_{2},{ }^{67}\right.$ and reduction of $\mathrm{NiCl}_{2}$ by hydrazine in a reverse water/butanol/potassium oleate/kerosene microemulsion. ${ }^{68}$ However, these methods are fraught with wide polydispersities and lack of aspect ratio control or well-defined morphologies.

Hydrazine is a powerful reducing agent when present in alkaline environments (Scheme 3a) and is capable of reducing $\mathrm{Ni}^{2+}$ (Scheme 3b). ${ }^{60}$ Reduction of $\left[\mathrm{Ni}\left(\mathrm{N}_{2} \mathrm{H}_{4}\right)_{3}\right] \mathrm{Cl}_{2}$ complex by introduction of hydroxide $(-\mathrm{OH})$ ion has been reported for the synthesis of nickel powders. ${ }^{60}$ Given the $1 \mathrm{D}$ morphology of the $\left[\mathrm{Ni}\left(\mathrm{N}_{2} \mathrm{H}_{4}\right)_{3}\right] \mathrm{Cl}_{2}$ complex formed by reverse microemulsion, introduction of hydroxide ion could result in reduction while maintaining morphology. Literature XRD analysis suggests that reduction of $\left[\mathrm{Ni}\left(\mathrm{N}_{2} \mathrm{H}_{4}\right)_{3}\right] \mathrm{Cl}_{2}$ complex by addition of hydroxide ion proceeds through a nickel hydroxide $\left(\mathrm{Ni}(\mathrm{OH})_{2}\right)$ intermediate. ${ }^{60}$ Reduction of $\mathrm{Ni}(\mathrm{OH})_{2}$ is then accomplished through the combination of half-cell reactions shown in Scheme 3a and 3b. In-situ addition of sodium hydroxide $(\mathrm{NaOH})$ after reverse microemulsion formation of $\left[\mathrm{Ni}\left(\mathrm{N}_{2} \mathrm{H}_{4}\right)_{3}\right] \mathrm{Cl}_{2}$ 
complex resulted in face-centered cubic nickel (fcc-Ni ${ }^{0}$ ), as confirmed by its XRD pattern (Figure 12a). However, the TEM micrograph (Figure 12b) shows only a fraction of the product is present with the desired morphology, albeit this fractions ill-defined; most of the product was present as large spherical agglomerates. Clearly, introduction of $\mathrm{NaOH}$ did not preferentially maintain the $1 \mathrm{D}$ morphology upon conversion of $\left[\mathrm{Ni}\left(\mathrm{N}_{2} \mathrm{H}_{4}\right)_{3}\right] \mathrm{Cl}_{2}$ complex to $\mathrm{Ni}^{0}$, possibly due to the uncontrolled rate of $\mathrm{NaOH}$ addition or the inefficient ligand stabilization of the $\mathrm{Ni}(\mathrm{OH})_{2}$ intermediate and/or product that was shown to be present in this reaction. ${ }^{60}$ Better control over the rate of $\mathrm{NaOH}$ addition may be needed in order to obtain the desired $1 \mathrm{D} \mathrm{Ni}{ }^{0}$ morphology. Additional experiments may be necessary in order to determine what is (are) the best surfactant(s) required to effectively stabilize a preferential amount of the product exhibiting 1D morphology.
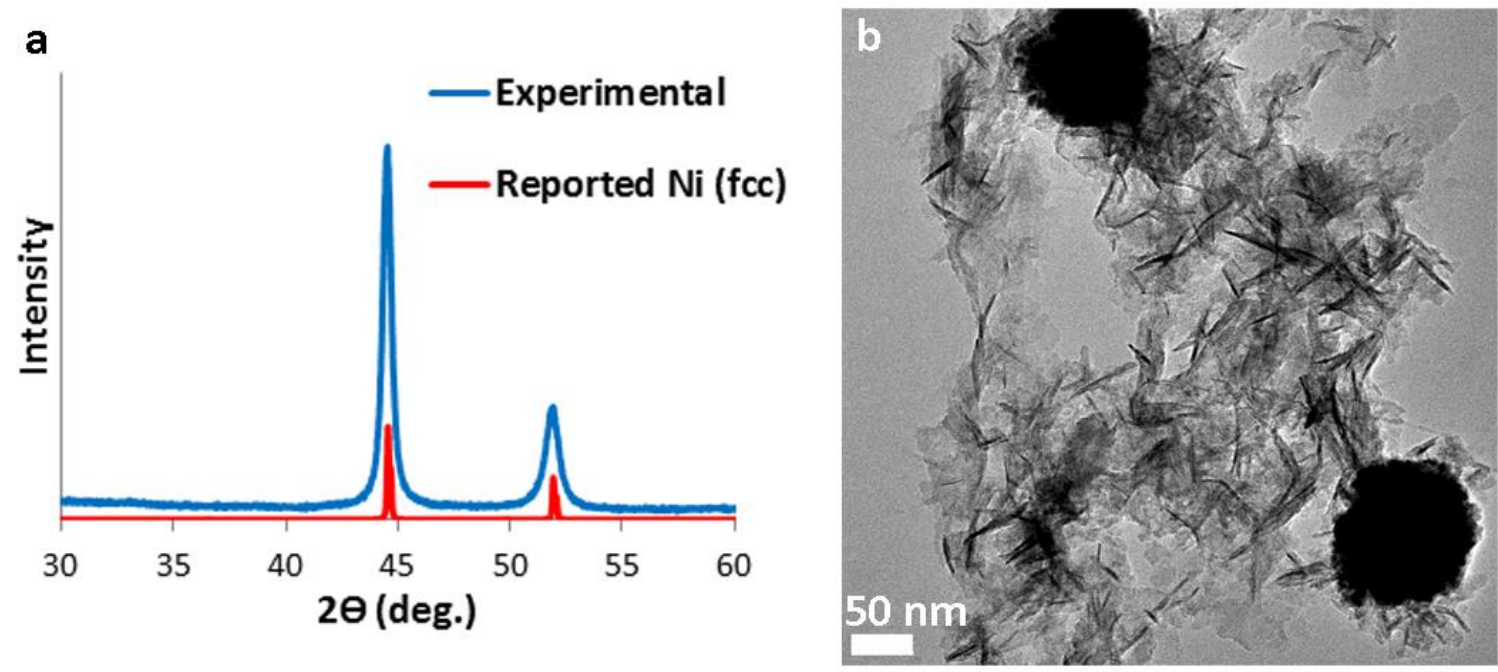

Figure 12. (a) XRD pattern and (b) representative TEM micrograph of the product obtained from in-situ addition of $\mathrm{NaOH}$ to $\left[\mathrm{Ni}\left(\mathrm{N}_{2} \mathrm{H}_{4}\right)_{3}\right] \mathrm{Cl}_{2}$ in reverse microemulsion. 


\section{Scheme 3.}

(a) $\mathrm{N}_{2} \mathrm{H}_{4}+4^{-} \mathrm{OH} \longrightarrow \mathrm{N}_{2}+4 \mathrm{H}_{2} \mathrm{O}+4 \mathrm{e}^{-} \quad \mathrm{E}^{\circ}=-1.16 \mathrm{~V}$

(b) $\mathrm{Ni}^{2+}+2 \mathrm{e}^{-} \longrightarrow \mathrm{Ni}^{0} \quad \mathrm{E}^{\circ}=-0.76 \mathrm{~V}$

The next approach we explored to obtain $1 \mathrm{D} \mathrm{Ni}^{0}$ materials was chemical reduction of $\left[\mathrm{Ni}\left(\mathrm{N}_{2} \mathrm{H}_{4}\right)_{3}\right] \mathrm{Cl}_{2} \subset \mathrm{SiO}_{2}$ with $\mathrm{NaBH}_{4}$. Briefly, $\left[\mathrm{Ni}\left(\mathrm{N}_{2} \mathrm{H}_{4}\right)_{3}\right] \mathrm{Cl}_{2} \subset \mathrm{SiO}_{2}$ was suspended in $\mathrm{H}_{2} \mathrm{O}$ and while stirring, an aqueous solution of $\mathrm{NaBH}_{4}$ was added dropwise. Upon addition of $\mathrm{NaBH}_{4}$, the suspension immediately underwent a color change from pink to black, with the evolution of copious amounts of gas. The FTIR spectrum (Figure 13a) of the product (amorphous materialс $\mathrm{SiO}_{2}$ ) confirms hydrazine ligands are no longer present, and the diffractogram (Figure 13b) shows no crystalline material. TEM (Figure 13c) shows varying degrees of contrast along the length of the nanocapsule cavity, suggesting there is material within the nanocapsule cavity, but the methods employed are unable to afford unambiguous characterization.

It is well established that reacting aqueous nickel salts with sodium borohydride produces nickel/nickel boride $\left(\mathrm{Ni}^{0} / \mathrm{Ni}_{\mathrm{x}} \mathrm{B}_{\mathrm{y}}\right)$ amorphous materials ${ }^{69,70,71}$ (Scheme $\left.4 \mathrm{a}-\mathrm{c}\right)$, but the mechanism by which $\mathrm{Ni}_{\mathrm{x}} \mathrm{B}_{\mathrm{y}}$ is formed remains unknown. ${ }^{72}$ The stoichiometry of the final compound (values of "x" and " $y$ ") obtained upon crystallization depend on the amount of boron in the amorphous material. Crystallization of $\mathrm{Ni}^{0} / \mathrm{Ni}_{\mathrm{x}} \mathrm{B}_{\mathrm{y}}$ is achieved through thermal treatment under inert atmosphere and post-heating $\left(500^{\circ} \mathrm{C}\right) \mathrm{XRD}$ analysis has shown fcc-Ni is the major product. ${ }^{73}$ Thus, thermal treatment of amorphous material $\subset \mathrm{SiO}_{2}$ from room temperature to $500^{\circ} \mathrm{C}$ under Argon (Ar) was utilized to form crystalline $\mathrm{Ni}^{0}$. However, the XRD pattern (Figure 14) shows rock-salt nickel oxide 
$(\mathrm{NiO})$ is the prevalent phase and an average crystallite size of $5.3 \mathrm{~nm}$ was found using the Scherrer equation. TEM analysis (Figure 18a and 18b) shows the average particle size $(4.9 \pm 2.0 \mathrm{~nm})$ is in good agreement with XRD data.
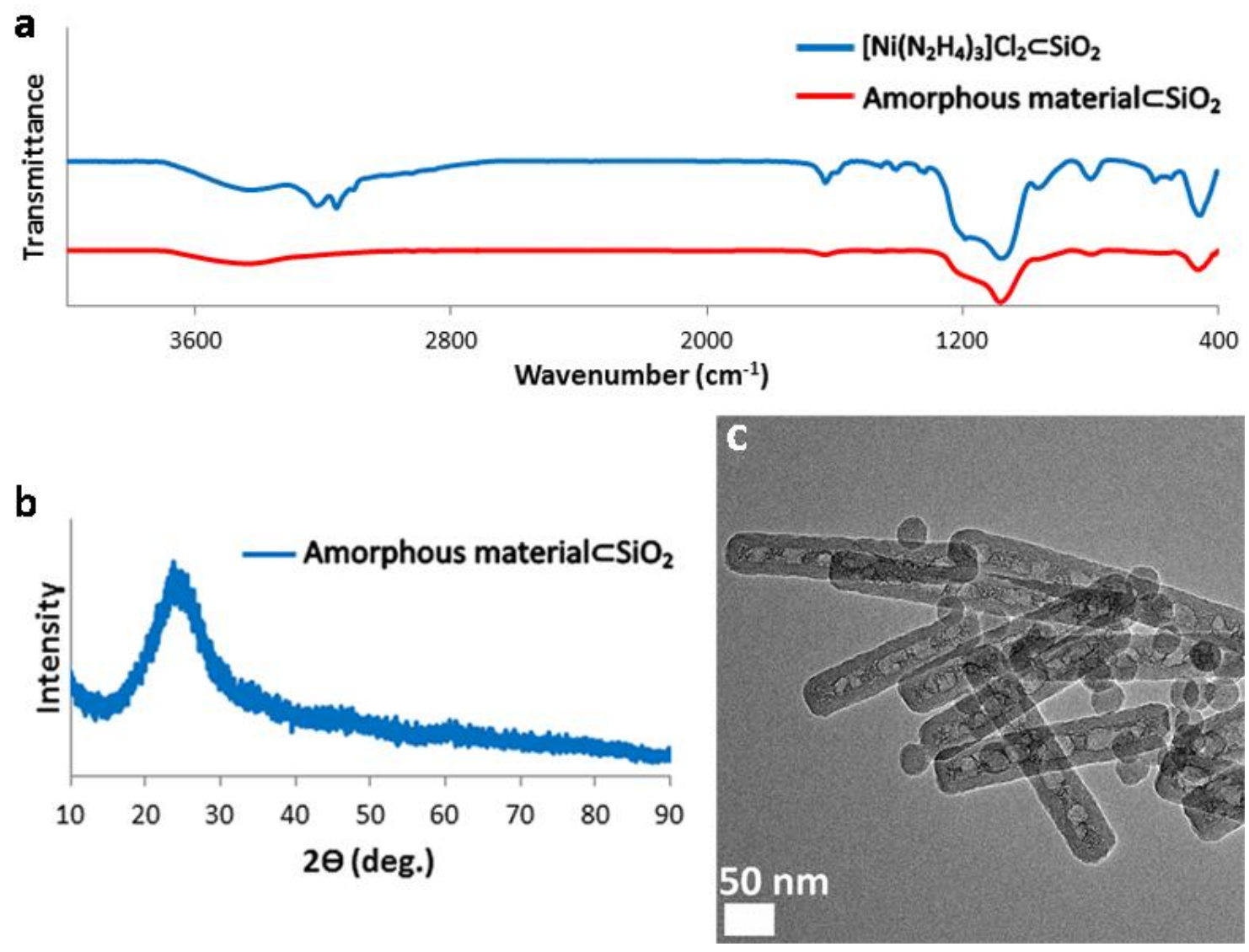

Figure 13. (a) XRD data, (b) FTIR spectrum, and (c) TEM micrograph of amorphous material $\subset \mathrm{SiO}_{2}$.

\section{Scheme 4.}

(a) $\mathrm{BH}_{4}{ }^{-}+4 \mathrm{H}_{2} \mathrm{O} \longrightarrow \mathrm{B}(\mathrm{OH})_{4}{ }^{-}+4 \mathrm{H}^{+}+2 \mathrm{H}_{2}+4 \mathrm{e}^{-}$

(b) $2 \mathrm{Ni}^{2+}+4 \mathrm{e}^{-} \longrightarrow 2 \mathrm{Ni}^{0}$

(c) $2 \mathrm{Ni}^{2+}+\mathrm{BH}_{4}^{-}+4 \mathrm{H}_{2} \mathrm{O} \longrightarrow 2 \mathrm{Ni}^{0}+\mathrm{B}(\mathrm{OH})_{4}^{-}+4 \mathrm{H}^{+}+2 \mathrm{H}_{2}$ 


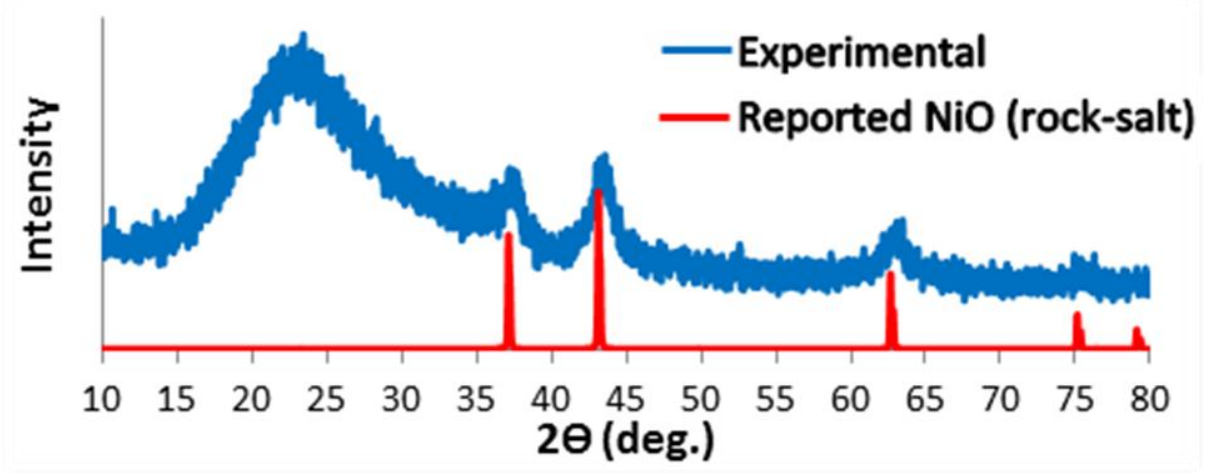

Figure 14. XRD pattern after thermal treatment of amorphous material $\subset \mathrm{SiO}_{2}$.

Silica is known to absorb water within the Si-O-Si matrix and silanol ( $\mathrm{Si}-\mathrm{OH})$ groups undergo dehydration to yield siloxanes at elevated temperatures which are possible sources of oxygen giving rise to $\mathrm{NiO} \subset \mathrm{SiO}_{2} \cdot{ }^{74}$ Silanol dehydration was confirmed by comparing the FTIR spectrum (Figure 15a) of as-synthesized and calcined silica ( $a s-\mathrm{SiO}_{2}$ and $c-\mathrm{SiO}_{2}$, respectively). The spectrum clearly shows the $\mathrm{Si}-\mathrm{OH}$ stretching frequency is present at $947 \mathrm{~cm}^{-1}$ in $a s-\mathrm{SiO}_{2}$, but upon calcination at $500^{\circ} \mathrm{C}$, the $\mathrm{Si}-\mathrm{OH}$ stretching frequency is no longer present in $c-\mathrm{SiO}_{2}$. To test this idea, the heating procedure was repeated without the silica shell. A $\left[\mathrm{Ni}\left(\mathrm{N}_{2} \mathrm{H}_{4}\right)_{3}\right] \mathrm{Cl}_{2}$ aqueous suspension was treated with aqueous $\mathrm{NaBH}_{4}$ and the resulting as-synthesized material was calcined under Ar flow at $500^{\circ} \mathrm{C}$ at a heating rate of $10^{\circ} \mathrm{C} \mathrm{min}^{-1}$. Indeed, calcination in this case resulted in nearly phase pure fcc-Ni as shown by the XRD pattern (Figure $15 b$ ). There is also peaks attributed to rock-salt $\mathrm{NiO}$ and could be due to the relatively high ramp rate used in the synthesis not allowing adequate time for the sample to dry before reaching oxidation temperatures. X'Pert HighScore Plus structural refinement shows the material consists of about $95 \% \mathrm{Ni}$ and $5 \% \mathrm{NiO}$. 

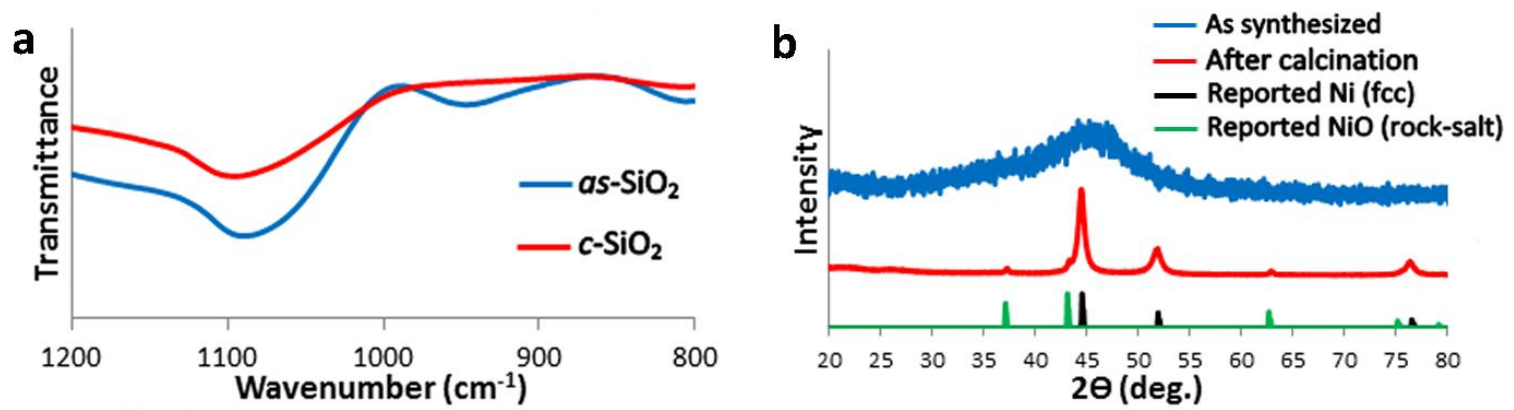

Figure 15. (a) FTIR spectrum of showing dehydration of Si-OH groups $\left(947 \mathrm{~cm}^{-1}\right)$ upon calcination; (b) XRD pattern showing amorphous material and its calcination products.

In order to circumvent nickel oxidation in the presence of silica during calcination, the reaction was run under a flow of $\mathrm{Ar} / \mathrm{H}_{2}$ while keeping all other conditions identical. In this case, the XRD pattern of the product (Figure 16a) shows fcc-Ni ${ }^{0}$ with an average crystallite size of $12 \mathrm{~nm}$ estimated using the Scherrer equation and is in good agreement with the average particle size $(13.7 \pm 3.5 \mathrm{~nm})$ obtained from TEM analysis (Figure 16c, 16d, 16e, and 16f). An EDX line scan was used to confirm the particles contained nickel. Weight percent nickel versus length along the rod (red line) is plotted (Figure 16b) for the micrograph shown to the right of the plot. Areas of high contrast correspond to high nickel X-ray intensities and areas of low contrast correspond to low nickel X-ray intensities providing strong evidence that nickel particles are contained within the silica nanocapsule. HR-TEM micrographs (Figure 16e) were taken and fast Fourier transform analysis resulted in observed $d$-spacings corresponding to (111) and (200) planes of fcc-Ni. Also observed where the (111) and (200) planes from rock-salt $\mathrm{NiO}$. It is common to have a thin oxide layer present on the surface of nickel. The thin oxide layer helps passivate and protect $\mathrm{Ni}$, making it relatively inert towards further oxidation at ambient temperature and pressure. The average number of particles per rod is 
$4 \pm 2$ (Figure $16 \mathrm{~g}$ ) and these are dispersed within the oxide support. Only about $1 \%$ of the capsules were found to be void of particles.
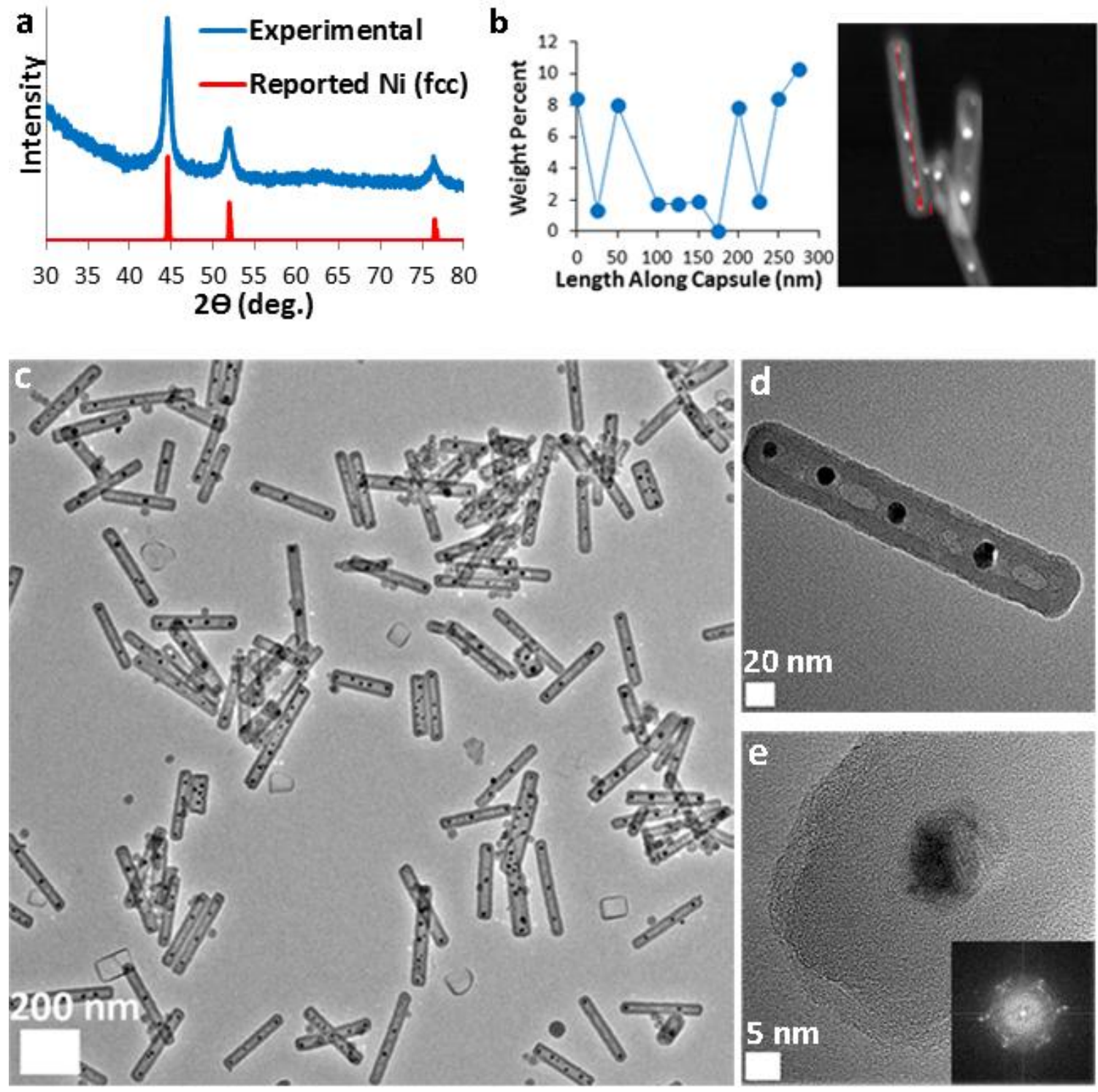

Figure 16. (a) XRD pattern of $\mathrm{Ni} \subset \mathrm{SiO}_{2}$; (b) Plot of weight percent nickel vs. length along rod from EDX data; (c) and (d) TEM micrograph of $\mathrm{Ni} \mathrm{SiO}_{2}$; (e) HRTEM micrograph and corresponding electron diffraction pattern for $\mathrm{Ni}_{\mathrm{SiO}}$. 

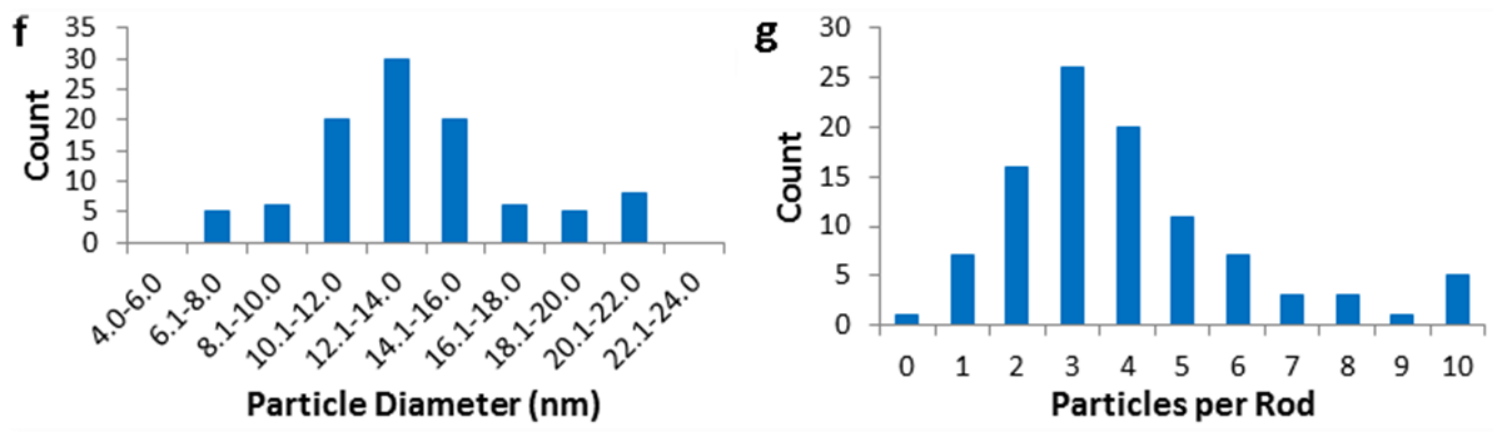

Figure 16 (continued). (f) Histogram showing particle size distribution; (g) Histogram showing number of particles per rod.

As previously mentioned, the reaction between $\left[\mathrm{Ni}\left(\mathrm{N}_{2} \mathrm{H}_{4}\right)_{3}\right] \mathrm{Cl}_{2}$ and $\mathrm{NaBH}_{4}$ is expected to produce amorphous nickel boride (Ni-B). To probe the possible presence of $\mathrm{Ni}-\mathrm{B}$, a sample obtained from treating $\left[\mathrm{Ni}\left(\mathrm{N}_{2} \mathrm{H}_{4}\right)_{3}\right] \mathrm{Cl}_{2}$ with $\mathrm{NaBH}_{4}$ was studied by hotstage (variable temperature) XRD (Figure 17). The obtained diffractograms clearly show the amorphous material undergoing structural changes to yield fcc-Ni. At $275^{\circ} \mathrm{C}$, the diffraction pattern shows the emergence of peaks not attributable to fcc-Ni. The peaks become even more pronounced at $300^{\circ} \mathrm{C}$ and eventually disappear at $350^{\circ} \mathrm{C}$. The additional peaks observed in the diffraction pattern obtained upon calcination at $300^{\circ} \mathrm{C}$ match relatively well and may be due to orthorhombic nickel boride $\left(\mathrm{Ni}_{3} \mathrm{~B}\right)$. General Structure Analysis System (GSAS) structural refinement shows the material consists of about $91 \% \mathrm{Ni}$ and $9 \% \mathrm{Ni}_{3} \mathrm{~B}$. The slight observed shift to lower two-theta angle relative to the standard pattern may be due to thermal expansion of the lattice at the temperature used to collect the XRD. The shift to lower two-theta values is also demonstrated by observing the $\mathrm{XRD}$ patterns at $350^{\circ} \mathrm{C}$ and $400^{\circ} \mathrm{C}$ compared to the fcc-Ni standard pattern and the XRD pattern of the calcined product at $35^{\circ} \mathrm{C}$. It is clear that any $\mathrm{Ni}_{3} \mathrm{~B}$ phase has completely decomposed at $400^{\circ} \mathrm{C}$, but the decomposition product is not known. Previous 
XPS analyses on amorphous Ni-B materials show the presence of oxidized and reduced boron species identified as boron trioxide $\left(\mathrm{B}_{2} \mathrm{O}_{3}\right)$ and $\mathrm{Ni}_{\mathrm{x}} \mathrm{B}_{\mathrm{y}}$, respectively. ${ }^{73,75,76}$ Upon heat treatment of Ni-B materials under inert atmosphere, XPS analysis showed the disappearance of reduced boron and the enhancement of oxidized boron. ${ }^{73}$ It is unlikely that the intermediate $\mathrm{Ni}_{3} \mathrm{~B}$ phase undergoes gaseous decomposition due to the high boiling points of the constituents, but transforms instead to an amorphous form of the most stable oxide of boron $\left(\mathrm{B}_{2} \mathrm{O}_{3}\right) . \mathrm{B}_{2} \mathrm{O}_{3}$ is extremely difficult to crystallize under ambient pressures and this could be the reason why this phase is not detected using XRD analysis. ${ }^{77}$. Further elemental analysis and XPS studies may be necessary to fully establish the fate of the $\mathrm{Ni}_{3} \mathrm{~B}$ phase.

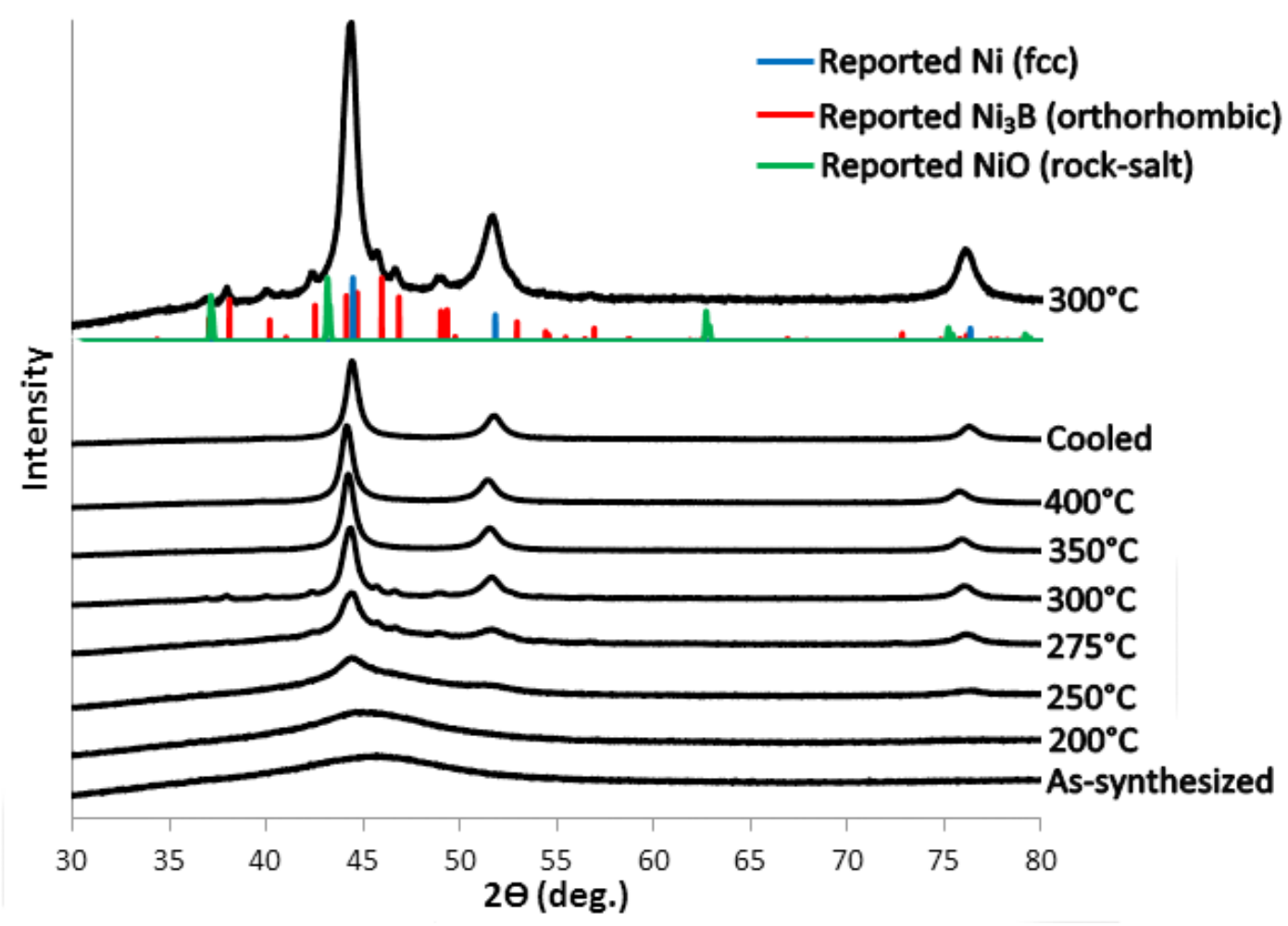

Figure 17. In-situ XRD data for product obtained from reaction of $\left[\mathrm{Ni}\left(\mathrm{N}_{2} \mathrm{H}_{4}\right)_{3}\right] \mathrm{Cl}$ with $\mathrm{NaBH}_{4}$ as a function of temperature. Heating rate $5^{\circ} \mathrm{C} \min ^{-1}$. 
It is interesting to note that the $\mathrm{Ni}^{0}$ particle sizes obtained by calcination under $\mathrm{Ar} / \mathrm{H}_{2}$ are significantly larger than the $\mathrm{NiO}$ particle sizes obtained by calcination under $\mathrm{Ar}$ (Figure 18a and 18b). This observation can be explained by particle-support interactions; nickel oxides interact more strongly with oxide supports than nickel metal, thus resulting in less particle mobility and sintering (i.e. smaller particles) for $\mathrm{NiOCSiO}_{2}{ }^{78} \mathrm{TEM}$ micrographs show NiO particles spread on the surface of silica more than $\mathrm{Ni}^{0}$ particles possibly due to the increased particle-support interaction and the spreading results in smaller, less uniform particle diameters for $\mathrm{NiO}$ compared to $\mathrm{Ni}^{0}$. In summary, conversion of the amorphous $\mathrm{Ni}-\mathrm{B}$ intermediate to $\mathrm{NiO}$ or $\mathrm{Ni}^{0}$ resulted in two different size particles, suggesting the observed $\mathrm{Ni}^{0}$ particles are formed by a sintering mechanism. This will be discussed further in the following paragraphs.
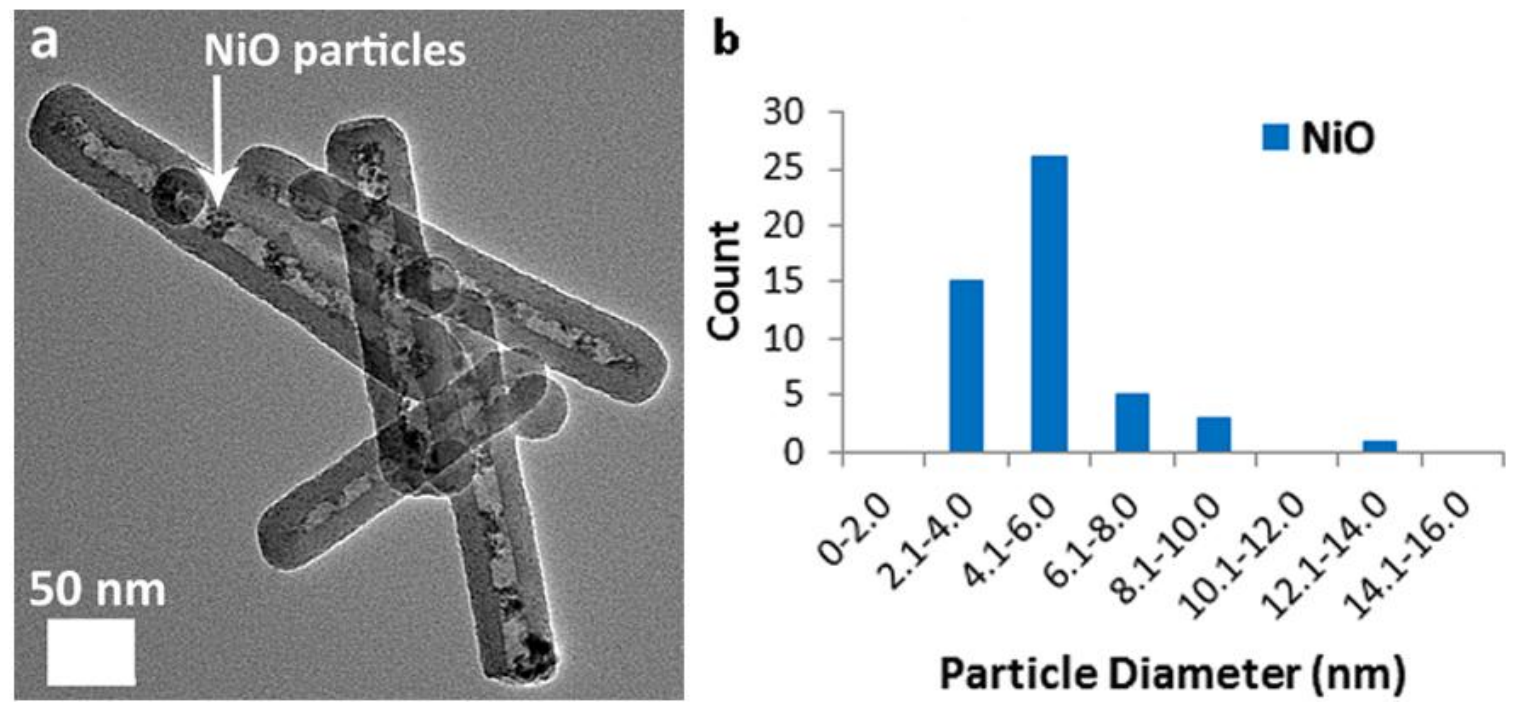

Figure 18 (a) TEM micrograph of $\mathrm{NiO} \subset \mathrm{SiO}_{2}$ obtained by calcination of $\mathrm{Ni}-\mathrm{B} \subset \mathrm{SiO}_{2}$ under Ar atmosphere; (b) Particle size distribution histogram of NiO. 
As observed by TEM, the $\left[\mathrm{Ni}\left(\mathrm{N}_{2} \mathrm{H}_{4}\right)_{3}\right] \mathrm{Cl}_{2} \subset \mathrm{SiO}_{2}$ materials possess relatively uniform contrast along the length of the nanocapsule interior, suggesting the nanocapsules are completely filled. This is consistent with the morphology of silica capsules after etching with $\mathrm{HCl}$ (Figure 10a). Upon treatment of $\left[\mathrm{Ni}\left(\mathrm{N}_{2} \mathrm{H}_{4}\right)_{3}\right] \mathrm{Cl}_{2} \subset \mathrm{SiO}_{2}$ with $\mathrm{NaBH}_{4}$, TEM (Figure 13c) exhibits a difference in contrast along the length of the nanocapsules, suggesting they are no longer completely and uniformly filled; however, no discernible particles were observed by TEM. After $\mathrm{NaBH}_{4}$ treatment, the product obtained has lost a significant amount of its original constituents (i.e. $\mathrm{N}_{2} \mathrm{H}_{4}$ ), as confirmed by FTIR analysis (Figure 13b). Thus, one should not expect complete filling of the nanocapsule interior. This could be the reason why rods are not formed during the subsequent calcination step and why there is clearly not enough $\mathrm{Ni}^{0}$ inside the nanocapsule cavity to fill the entire void space.

Calcination of amorphous $\mathrm{Ni}-\mathrm{B} \subset \mathrm{SiO}_{2}$ under $\mathrm{H}_{2}$ resulted in spherically-shaped, crystalline fcc- $\mathrm{Ni}^{0}$. Calcination of $\mathrm{Ni}-\mathrm{B} \subset \mathrm{SiO}_{2}$ under Ar gave rise to $\mathrm{NiO}$ particles (average diameter $=4.9 \mathrm{~nm}$ ) that exhibit smaller particle sizes and less shape uniformity compared to $\mathrm{Ni}^{0}$ particles (average diameter $=13.7 \mathrm{~nm}$ ). This suggests that during/after

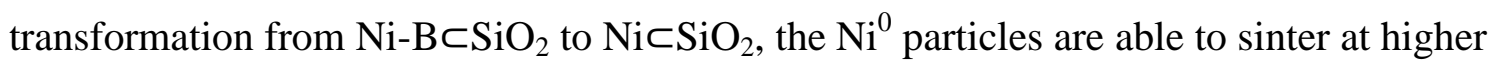
rates relative to $\mathrm{NiO}$ particles, leading to the observed spherical and more regular morphology. The two mechanisms that have been proposed to explain sintering of supported $\mathrm{Ni}^{0}$ are atomic migration (Ostwald ripening) and particle migration (coalescence). It has been shown that the mechanism of $\mathrm{Ni}^{0}$ sintering on silica depends on the atmosphere used during calcination. ${ }^{79,80}$ Under vacuum, $\mathrm{Ni}^{0}$ particle sintering has been shown to occur through both mechanisms. However, under $\mathrm{H}_{2}$ atmosphere, particle 
migration is suppressed and atomic migration becomes the predominant mechanism attributed to increased interaction between the $\mathrm{Ni}^{0}$ particle and the silica support, relative to vacuum. Upon closer examination of $\mathrm{Ni} \subset \mathrm{SiO}_{2} \mathrm{TEM}$ micrographs (Figure 19a), there is a bimodal distribution of particle sizes (Figure 19b) supporting an atomic migration sintering mechanism and consistent with the aforementioned literature results. However, other factors that contribute to particle mobility including support porosity and surface impurities cannot be overlooked in the formation of spherical nickel particles. ${ }^{78}$
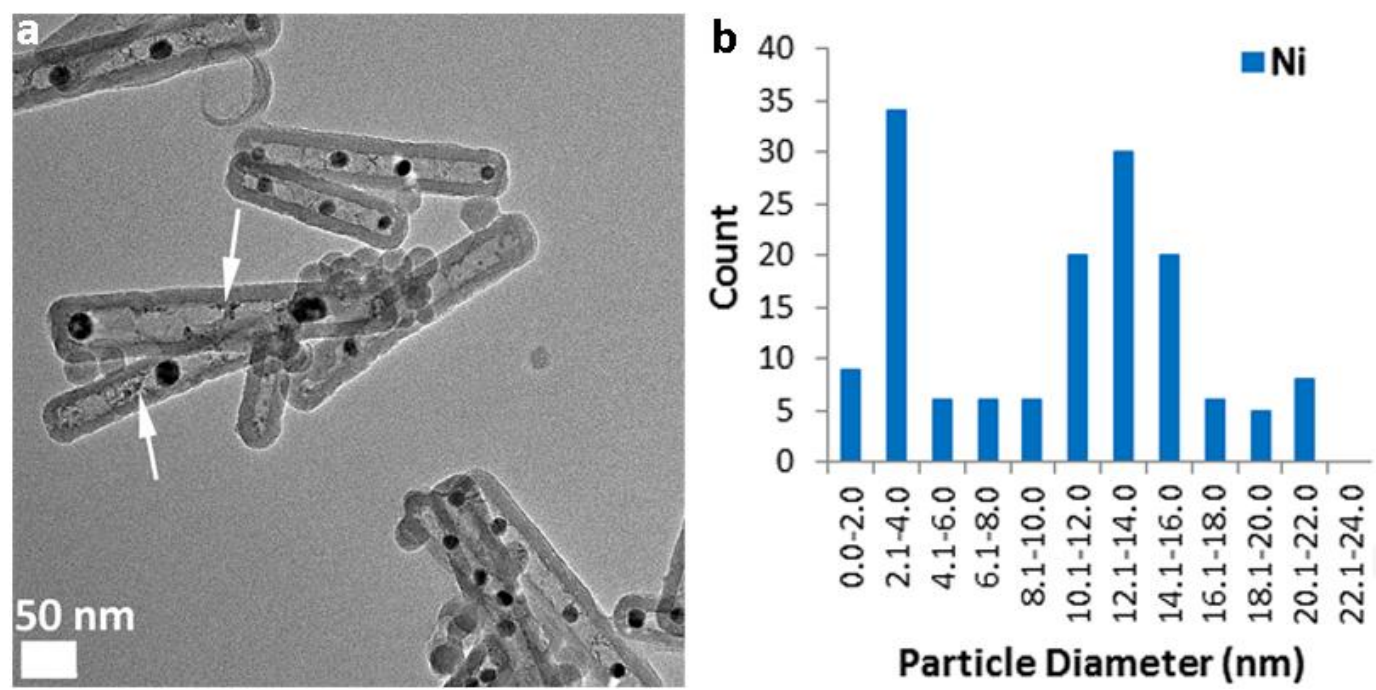

Figure 19. (a) TEM micrograph of $\mathrm{NiCSiO}$, showing different size particles obtained by calcination of Ni-BᄃSiO 2 under $\mathrm{H}_{2}$ atmosphere; (b) Particle size distribution histogram of $\mathrm{Ni}^{0}$ showing bimodal distribution.

Preliminary data suggests we are able to control $\mathrm{Ni}^{0}$ particle size while maintaining nanocapsule dimensions by varying the amount of aqueous $\mathrm{NiCl}_{2}$ used in the synthesis and keeping the surfactant to water ratio constant. The [Brij 58]: $\left[\mathrm{NiCl}_{2}\right]$ ratio was held constant at 5.0 and different amounts of aqueous $\mathrm{NiCl}_{2}$ were added into the 
system ( $9.27 \mathrm{mmol}$ of hydrazine hydrate was used in both experiments). Plotting particle diameter and number of particles per capsule versus concentration of $\mathrm{NiCl}_{2}$ (Figure 20c) and nanocapsule cavity dimensions versus concentration of $\mathrm{NiCl}_{2}$ (Figure 20d) clearly shows the effect of adding $\mathrm{NiCl}_{2}$ while keeping the same surfactant to water ratio. The plot in Figure 20c shows an increase in the amount of aqueous $\mathrm{NiCl}_{2}$ results in an increase of average particle size and a small, perhaps statistically insignificant decrease in the average number of particles per rod. The latter observation suggests that the increase in particle size cannot be solely attributed to differences in sintering rates. Figure $20 \mathrm{~d}$ shows that the cavity length did not change, which is not the case when the concentration of $\mathrm{NiCl}_{2}$ is increased without keeping the same [Brij 58]:[ $\left[\mathrm{NiCl}_{2}\right]$ ratio (Figure 11). In conventional $\mathrm{Ni} / \mathrm{SiO}_{2}$ catalysts, it was found that $\mathrm{Ni}^{2+}$ precursor loading is proportional to $\mathrm{Ni}^{0}$ particle size ${ }^{81}$ The observed increase in particle size for $\mathrm{Ni \subset} \mathrm{SiO}_{2}$ could be due to an increased amount of $\mathrm{Ni}^{2+}$ within the nanocapsule, resulting in slightly higher amounts of $\left[\mathrm{Ni}\left(\mathrm{N}_{2} \mathrm{H}_{4}\right)_{3}\right] \mathrm{Cl}_{2}$ within any given nanocapsule. Figure $20 \mathrm{~d}$ shows a statistically significant increase in cavity diameter when the concentration of $\mathrm{NiCl}_{2}$ is increased, suggesting there is an increased amount of $\left[\mathrm{Ni}\left(\mathrm{N}_{2} \mathrm{H}_{4}\right)_{3}\right] \mathrm{Cl}_{2}$ within the nanocapsule. If this is the case, the increased amount of $\mathrm{Ni}^{2+}$ upon reduction and calcination could result in the observed increase in particle size. More studies will be needed to confirm this hypothesis. Unfortunately, a similar paper was published in June $2012 .{ }^{82}$

The next approach used to synthesize $\mathrm{Ni}^{0}$ nanorods was thermal decomposition of $\left[\mathrm{Ni}\left(\mathrm{N}_{2} \mathrm{H}_{4}\right)_{3}\right] \mathrm{Cl}_{2} \subset \mathrm{SiO}_{2}$ to $\mathrm{Ni \subset SiO}$. $\left[\mathrm{Ni}_{(}\left(\mathrm{N}_{2} \mathrm{H}_{4}\right)_{3}\right] \mathrm{Cl}_{2} \subset \mathrm{SiO}_{2}$ powder was placed into a tube furnace and the temperature ramped up to $500^{\circ} \mathrm{C}$ at $10^{\circ} \mathrm{C} \mathrm{min}{ }^{-1}$ under $\mathrm{Ar}$ and $\mathrm{Ar} / \mathrm{H}_{2}$ atmospheres. TEM analysis of products obtained under Ar (Figure 21a) show 1D material 
in the interior of the nanocapsule. However, there is a significant amount of capsules (ca. $75 \%$ ) that show no contrast variation in their interior, leading us to think that a mobile species was present during the decomposition resulting in the diffusion of the material outside of the nanocapsule. The XRD pattern for the product obtained by decomposition of $\left[\mathrm{Ni}\left(\mathrm{N}_{2} \mathrm{H}_{4}\right)_{3}\right] \mathrm{Cl}_{2} \subset \mathrm{SiO}_{2}$ under $\mathrm{Ar}$ (Figure 21b) shows the presence of both $\mathrm{fcc}-\mathrm{Ni}^{0}$ as well as rock-salt $\mathrm{NiO}$, the latter attributed to absorbed water within the silica matrix and dehydration of $\mathrm{Si}-\mathrm{OH}$ groups. To circumvent $\mathrm{NiO} \subset \mathrm{SiO}_{2}$ as a product, decomposition was carried out under $\mathrm{Ar} / \mathrm{H}_{2}$ reducing environment. In this case, the XRD pattern (Figure 21d) shows the major product is fcc-Ni ${ }^{0}$, but the TEM micrograph (Figure 21c) shows a minimal amount of capsules (ca. 23\%) have material inside their cavity.
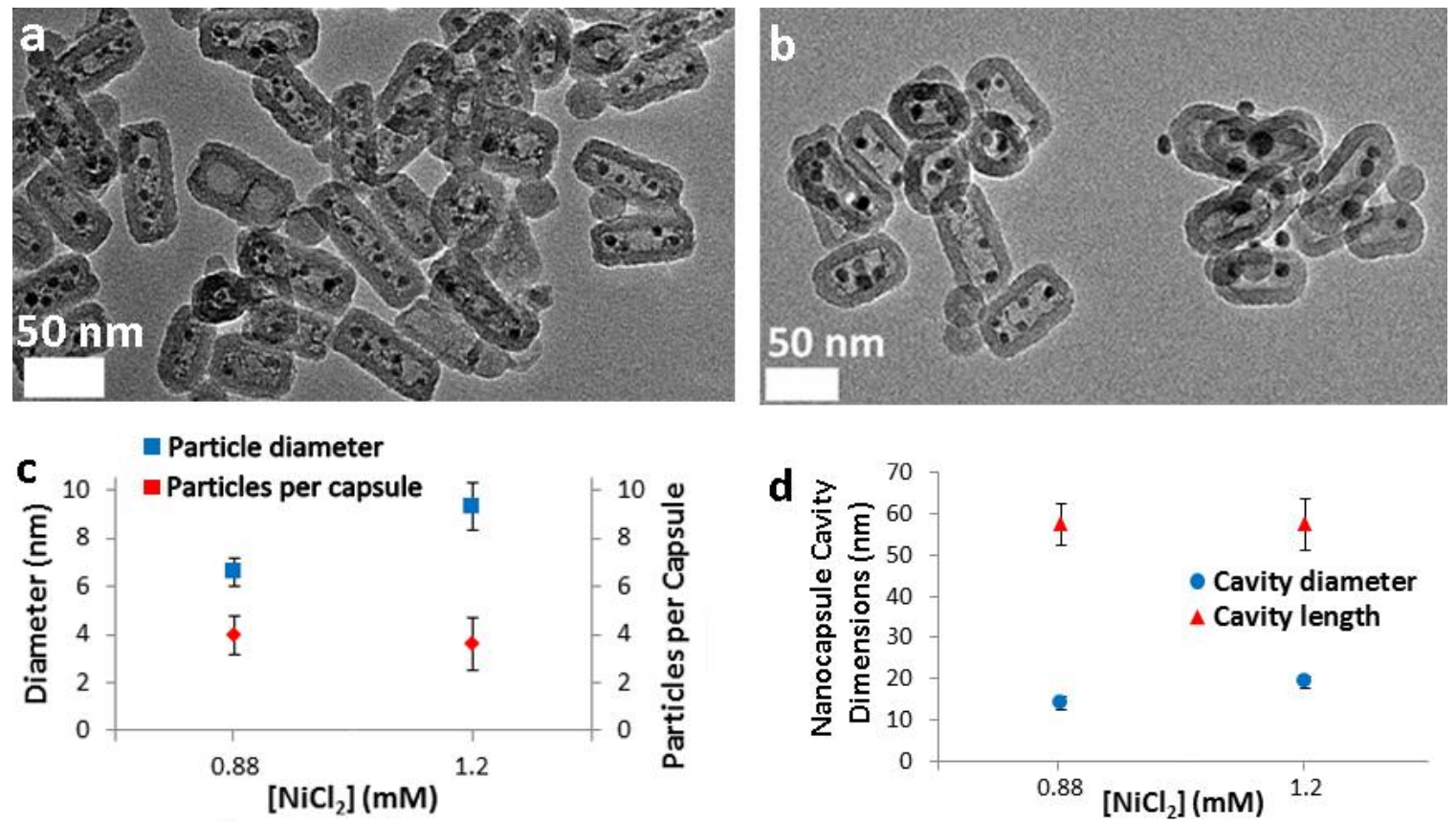

Figure 20. (a) TEM micrograph of $\mathrm{Ni} \subset \mathrm{SiO}_{2}$ using $0.88 \mathrm{mM} \mathrm{NiCl}_{2}$; (b) TEM micrograph of $\mathrm{Ni}_{-\mathrm{SiO}_{2}}$ using $1.2 \mathrm{mM} \mathrm{NiCl}_{2}$; (c) Plot of particles per capsule and diameter versus $\left[\mathrm{NiCl}_{2}\right]$; (d) Plot of average nanocapsule cavity dimensions versus $\left[\mathrm{NiCl}_{2}\right]$. Error bars represent standard deviation from the mean. 


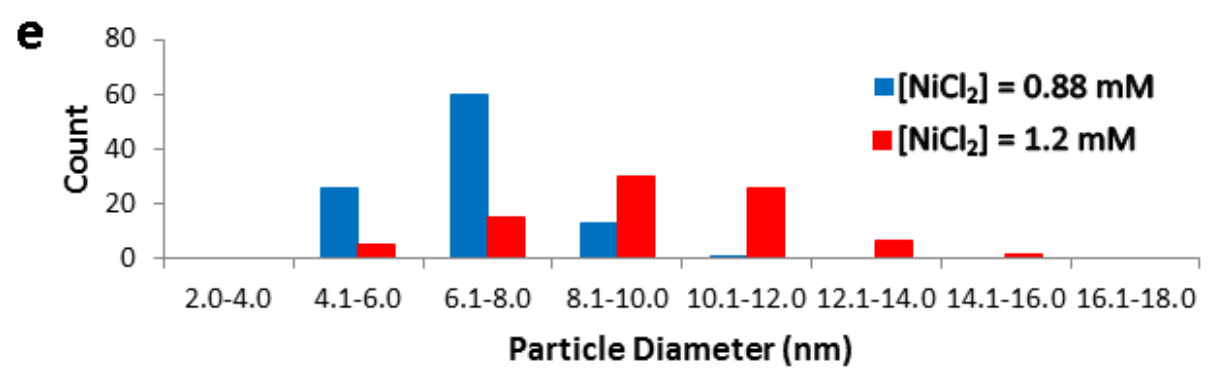

Figure 20 (continued). (e) Particle size distribution histogram corresponding to the TEM micrographs in (a) and (b).

Thermal treatment of metal-hydrazine complexes $\left[\mathrm{M}\left(\mathrm{N}_{2} \mathrm{H}_{4}\right)_{n}\right]^{2+}(\mathrm{M}=\mathrm{Mn}, \mathrm{Fe}, \mathrm{Co}$, $\mathrm{Ni}, \mathrm{Zn}$, and $\mathrm{Cd}, \mathrm{n}=2$ or 3 ) in air is known to result in the loss of hydrazine followed by metal oxide formation at higher temperatures. ${ }^{83}$ Hydrazine itself undergoes thermal decomposition to $\mathrm{N}_{2}$ and $\mathrm{NH}_{3}$ at $240^{\circ} \mathrm{C} .{ }^{84}$ Gaseous by-products from hydrazine decomposition during the thermal decomposition of $\left[\mathrm{Ni}\left(\mathrm{N}_{2} \mathrm{H}_{4}\right)_{3}\right] \mathrm{Cl}_{2} \subset \mathrm{SiO}_{2}$ under $\mathrm{Ar} / \mathrm{H}_{2}$ could explain why many capsules lack $\mathrm{Ni}$ metal. It has been shown that $\mathrm{NH}_{3}$ and $\mathrm{H}_{2}$ environments lead to substantially increased sintering rates (i.e. high particle mobility) during heat treatment of nickel particles on metal oxide surfaces compared to only $\mathrm{NH}_{3}$, $\mathrm{H}_{2}$, or $\mathrm{NH}_{3} / \mathrm{N}_{2}$ environments. ${ }^{85}$ The hydrazine decomposition product of ammonia coupled with the hydrogen reducing environment could possibly lead to formation of mobile species that give rise to the observed diffusion and agglomeration of nickel outside of the nanocapsule cavity shown in Figure 21c. A similar argument can be made for the decomposition experiment under $\mathrm{Ar}$, whereby the newly formed $\mathrm{Ni}^{0}$ particles could act as a catalyst for the decomposition of $\mathrm{NH}_{3}$ (from hydrazine ligand) to $\mathrm{N}_{2}$ and $\mathrm{H}_{2}$, thereby producing a $\mathrm{NH}_{3} / \mathrm{H}_{2}$ environment. 

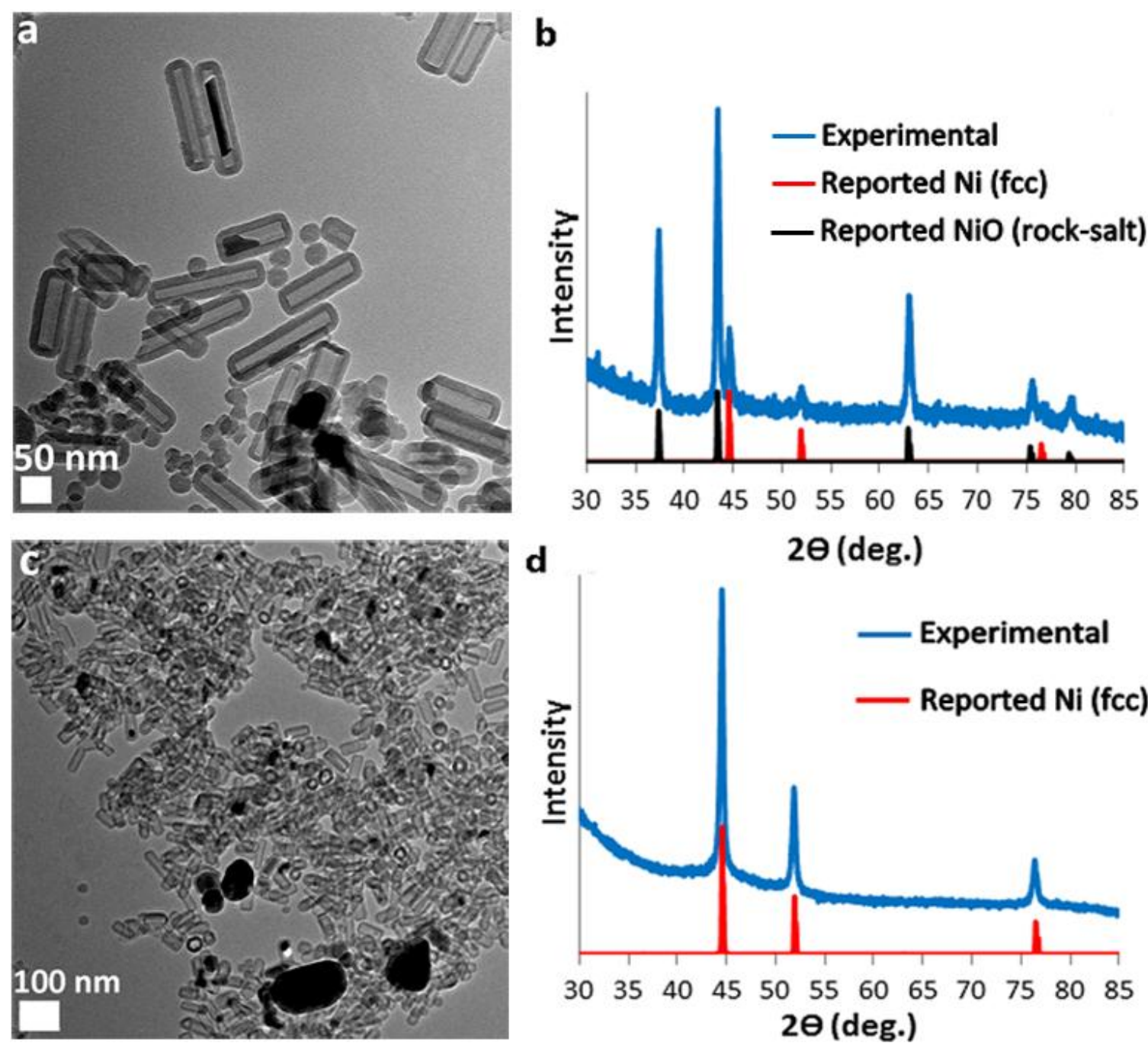

Figure 21. (a) TEM and (b) XRD pattern for thermal decomposition product of $\left[\mathrm{Ni}\left(\mathrm{N}_{2} \mathrm{H}_{4}\right)_{3}\right] \mathrm{Cl}_{2} \subset \mathrm{SiO}_{2}$ under Ar atmosphere; (c) TEM and (d) XRD pattern of thermal decomposition product of $\left[\mathrm{Ni}\left(\mathrm{N}_{2} \mathrm{H}_{4}\right)_{3}\right] \mathrm{Cl}_{2} \subset \mathrm{SiO}_{2}$ under $\mathrm{Ar} / \mathrm{H}_{2}$ atmosphere.

\section{Heterogeneous Nucleation and Seeded Growth of $\mathrm{Ni} \mathrm{SiO}_{2}$}

The next approach we explored to synthesize zero-valent nickel nanorods was to use $\mathrm{Ni \subset SiO}$ as seeds to induce heterogeneous nucleation and subsequent growth. An extensively studied, mature method that possesses the necessary attributes is termed electroless nickel plating. ${ }^{72}$ Electroless nickel plating is characterized by the selective 
reduction of nickel ions at the surface of a catalytically active substrate (e.g. Ni, Fe, Co, $\mathrm{Rh}, \mathrm{Pd}, \mathrm{Pt}$ ) that is submerged into an aqueous solution (bath) of nickel ions. Continued reduction and deposition on the substrate is accomplished through the catalytic activity of the deposit itself. This auto-catalytic process results in the deposition of nickel metal, nickel phosphide, or nickel boride depending on the reducing agent employed. The procedure is typically used in the coatings industry when wear resistance, hardness, and corrosion protection are required. Electroless nickel plating has also been used in the synthesis of nanoscale particle and rods for catalytic hydrogenations. ${ }^{70,86,87}$

There are four reducing agents commonly employed in electroless nickel plating baths: Sodium borohydride, sodium hypophosphite $\left(\mathrm{NaH}_{2} \mathrm{PO}_{2}\right)$, hydrazine, and borane dimethylamine $\left(\left(\mathrm{CH}_{3}\right)_{2} \mathrm{NH} \cdot \mathrm{BH}_{3}\right)(\mathrm{DMAB})$. All are structurally similar because they contain at least one reactive hydrogen. To suppress homogeneous nucleation (formation of new particles) in solution, organic acids or their salts are introduced to complex with and reduce the reactivity of nickel ions, rendering them kinetically inaccessible to the reducing agent in the solution. Extensive studies have determined optimum conditions (e.g. temperature, ligands, $\mathrm{pH}$, etc.) for plating with each of the reducing agents. ${ }^{72}$ Electroless nickel plating with $\mathrm{NaBH}_{4}$ requires elevated temperatures $\left(>70^{\circ} \mathrm{C}\right)$ and highly alkaline conditions ( $\mathrm{pH}=14)$, making it an unsuitable reducing agent for heterogeneous nucleation and growth of $\mathrm{Ni}_{\mathrm{SiO}}$.

Electroless nickel plating using $\mathrm{N}_{2} \mathrm{H}_{4}$ requires slightly alkaline conditions and undesirable temperatures (Table $2 \mathrm{a}$ ), but has the added advantage of resulting in the deposition of only $\mathrm{Ni}^{0}$ (Scheme 5). The commonly accepted net equation in Scheme 5 shows that $\mathrm{N}_{2}$ is the by-product of $\mathrm{N}_{2} \mathrm{H}_{4}$ decomposition, thereby resulting in a pure $\mathrm{Ni}^{0}$ 
deposit assuming the gases evolved are not trapped in interstices within the growing lattice. The reaction was carried out according to the conditions shown in Table $2 \mathrm{a}$ and the evolution of gases was visually observed throughout the duration of the reaction. The XRD pattern (Figure 23a) of the product obtained after plating shows the presence of fcc$\mathrm{Ni}$, although there is unaccounted amounts of amorphous material as evidenced by a hump around 62 two-theta degrees. The average crystallite size calculated from XRD using the Scherrer equation shows an increase from $9.1 \mathrm{~nm}$ to $10.9 \mathrm{~nm}$, suggesting growth occurred. TEM micrographs (Figure $23 \mathrm{~b}$ and 23c) show an average increase of silica encapsulated $\mathrm{Ni}^{0}$ particle size from $13.6 \pm 2.8 \mathrm{~nm}$ to $16.1 \pm 4.6 \mathrm{~nm}$ (Figure $23 \mathrm{~d}$ ).

\begin{tabular}{|c|c|c|c|}
\hline \multicolumn{2}{|c|}{$\begin{array}{l}\text { Table 2a. Nickel Bath Composition } \\
\qquad\left(\mathrm{N}_{2} \mathrm{H}_{4}\right)\end{array}$} & \multicolumn{2}{|c|}{$\begin{array}{c}\text { Table 2b. Nickel Bath Composition } \\
\text { (DMAB) }\end{array}$} \\
\hline $\mathrm{Ni} \subset \mathrm{SiO}_{2}$ & $1.40 \mathrm{mg} / \mathrm{mL}$ & $\mathrm{Ni} \subset \mathrm{SiO}_{2}$ & $1.65 \mathrm{mg} / \mathrm{mL}$ \\
\hline $\mathrm{Ni}\left(\mathrm{CH}_{3} \mathrm{COO}\right)_{2} \bullet 4 \mathrm{H}_{2} \mathrm{O}$ & $0.120 \mathrm{M}$ & $\mathrm{Ni}\left(\mathrm{CH}_{3} \mathrm{COO}\right)_{2} \cdot 4 \mathrm{H}_{2} \mathrm{O}$ & $0.030 \mathrm{M}$ \\
\hline $\mathrm{Na}_{2} \mathrm{C}_{4} \mathrm{H}_{4} \mathrm{O}_{6} \cdot 2 \mathrm{H}_{2} \mathrm{O}$ & $0.016 \mathrm{M}$ & $\mathrm{C}_{6} \mathrm{H}_{12} \mathrm{O}_{7}$ & $0.17 \mathrm{M}$ \\
\hline $\mathrm{C}_{6} \mathrm{H}_{12} \mathrm{O}_{7}$ & $0.15 \mathrm{M}$ & DMAB & $0.060 \mathrm{M}$ \\
\hline $\mathrm{N}_{2} \mathrm{H}_{4} \cdot \mathrm{H}_{2} \mathrm{O}$ & $0.40 \mathrm{M}$ & $\mathrm{pH}\left(\mathrm{NH}_{4} \mathrm{OH}\right)$ & 6.8 \\
\hline $\mathrm{pH}(\mathrm{NaOH})$ & 9.6 & Temperature & $20{ }^{\circ} \mathrm{C}$ \\
\hline Temperature & $75^{\circ} \mathrm{C}$ & Time & $2.0 \mathrm{~h}$ \\
\hline
\end{tabular}

\section{Scheme 5.}

$\left[\mathrm{NiL}_{\mathrm{m}}\right]^{-(\mathrm{n}-2)} \rightleftharpoons\left[\mathrm{Ni}^{2+}+\mathrm{mL}^{-\mathrm{n}}\right]+\mathrm{N}_{2} \mathrm{H}_{4}+\mathrm{H}_{2} \mathrm{O} \stackrel{\mathrm{Ni}^{0}}{\longrightarrow} \mathrm{Ni}^{0}+2 \mathrm{H}^{+}+\mathrm{mL}^{-\mathrm{n}}+\mathrm{N}_{2}+\mathrm{H}_{2}$ where $\mathrm{L}=\mathrm{CH}_{3} \mathrm{COO}^{-}, \mathrm{C}_{4} \mathrm{H}_{4} \mathrm{O}_{6}{ }^{2-}$, and/or $\mathrm{C}_{6} \mathrm{H}_{12} \mathrm{O}_{7} ; \mathrm{m}=0-6 \quad$ Although there is discernible growth present inside the capsules, (Figure 23d) there are also $\mathrm{Ni}^{0}$ particles that are not contained within the silica nanocapsules as shown in the upper left corner of Figure $23 \mathrm{~b}$ 
and scattered throughout Figure 23c. This could be the result of either or both homogeneous nucleation and the complete etching of silica capsules to yield free $\mathrm{Ni}^{0}$ particles. The TEM micrographs provide evidence for both pathways. The upper left corner of Figure $23 \mathrm{~b}$ shows anisotropic $\mathrm{Ni}^{0}$ particles suggesting that growth started in the interior of the nanocapsule, but after some time the nanocapsule was etched away by the high temperature alkaline environment. Furthermore, the background of the anisotropic particles shows a different contrast to that of the TEM grid, possibly attributed to the remnants of etched silica capsules. Further evidence of etching is shown by the thin silica nanocapsule present in the center of Figure 23c and the ruptured nanocapsule in the upper left hand corner. However, this does not account for the spherical free $\mathrm{Ni}^{0}$ particles observed in both micrographs. These particles could be the result of homogeneous nucleation events and/or the complete etching of a silica nanocapsule. Clearly, the temperature and $\mathrm{pH}$ conditions used in the synthesis are too harsh to maintain silica nanocapsule integrity and suppress homogeneous nucleation events from occurring making hydrazine an unsuitable reducing agent for the seeded growth of nickel nanorods.

The conditions previously cited for electroless nickel plating using DMAB as the reducing agent are inert towards silica nanocapsule degradation (Table 2b). Reduction of nickel salts with DMAB results in $\mathrm{Ni}^{0} / \mathrm{Ni}_{\mathrm{x}} \mathrm{B}_{\mathrm{y}}$ amorphous materials (Scheme 6), but the mechanism of $\mathrm{Ni}_{\mathrm{x}} \mathrm{B}_{\mathrm{y}}$ formation remains unknown. ${ }^{72}$ XRD (Figure 24) was used to probe the evolution of this material as a function of each reaction step. Electroless nickel plating using $\mathrm{DMAB}$ as the reducing agent in the presence of $\mathrm{Ni}_{\mathrm{SiO}}$ resulted in amorphous material (Figure 24). After calcination of amorphous material $\subset \mathrm{SiO}_{2}$ under $\mathrm{H}_{2}$, the XRD pattern shows fcc-Ni. Comparing the starting material to the final product, it 
is clear that the crystallite size has drastically increased as evidenced by the decrease in peak width from the starting material.
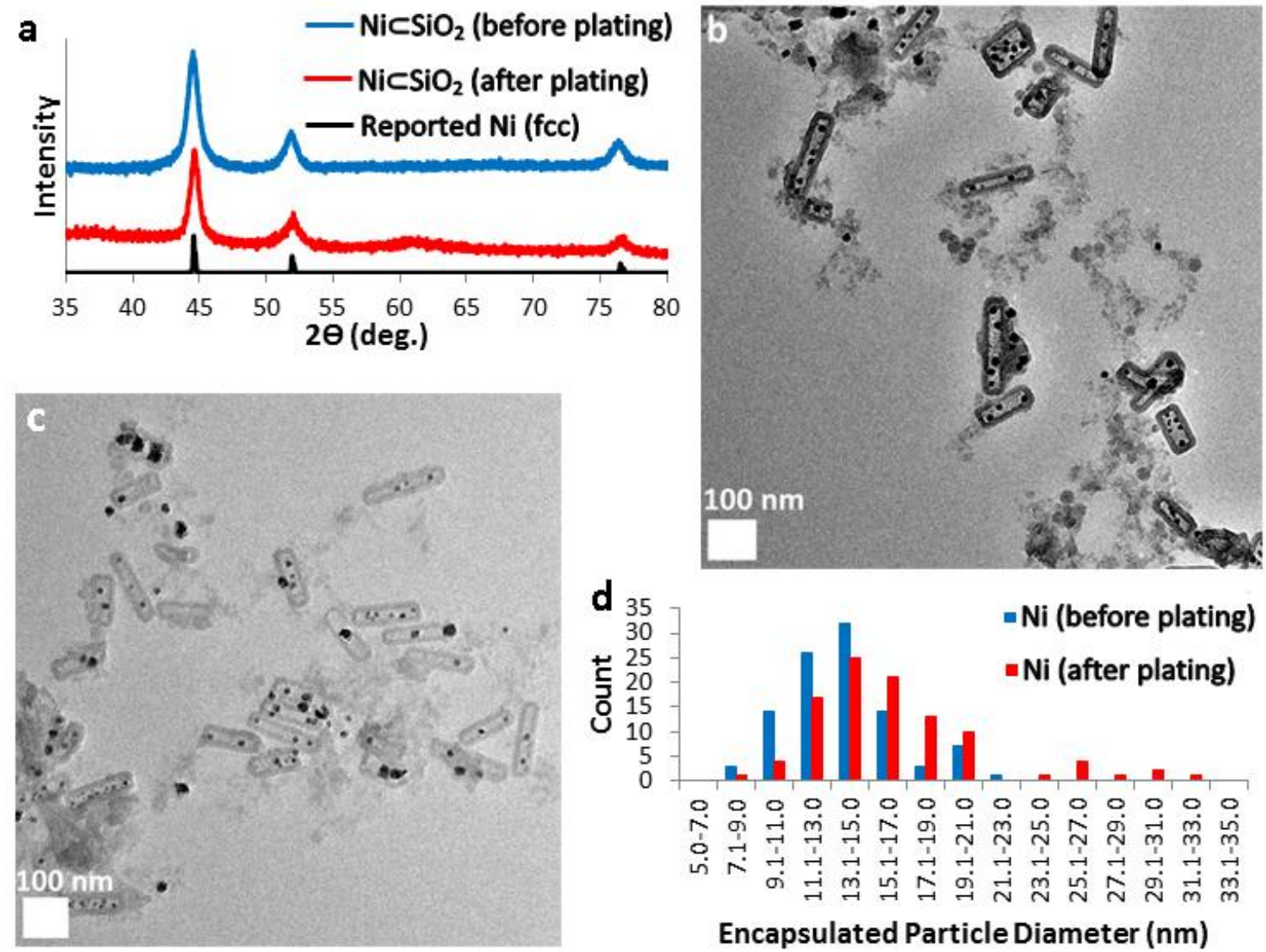

Figure 23. (a) XRD pattern of $\mathrm{Ni} \subset \mathrm{SiO}_{2}$ before and after plating; (b) and (c) TEM micrographs of $\mathrm{Ni} \subset \mathrm{SiO}_{2}$ after plating; (d) Particle size distribution histogram of encapsulated Ni particles.

Scheme 6.

$$
\begin{aligned}
& 3\left[\mathrm{NiL}_{\mathrm{m}}\right]^{-(\mathrm{n}-2)} \rightleftharpoons 3\left[\mathrm{Ni}^{2+}+\mathrm{mL}^{-\mathrm{n}}\right]+2\left(\mathrm{CH}_{3}\right)_{2} \mathrm{NHBH}_{3}+6 \mathrm{H}_{2} \mathrm{O} \stackrel{\mathrm{Ni}^{0}}{\longrightarrow} 3 \mathrm{Ni}^{0}+2\left(\mathrm{CH}_{3}\right)_{2} \mathrm{NH}_{2}^{+} \\
& +2 \mathrm{~B}(\mathrm{OH})_{3}+4 \mathrm{H}^{+}+3 \mathrm{~mL}^{-\mathrm{n}}+3 \mathrm{H}_{2}
\end{aligned}
$$

where $\mathrm{L}=\mathrm{CH}_{3} \mathrm{COO}^{-}, \mathrm{C}_{6} \mathrm{H}_{12} \mathrm{O}_{7} ; \mathrm{m}=0-6$ 


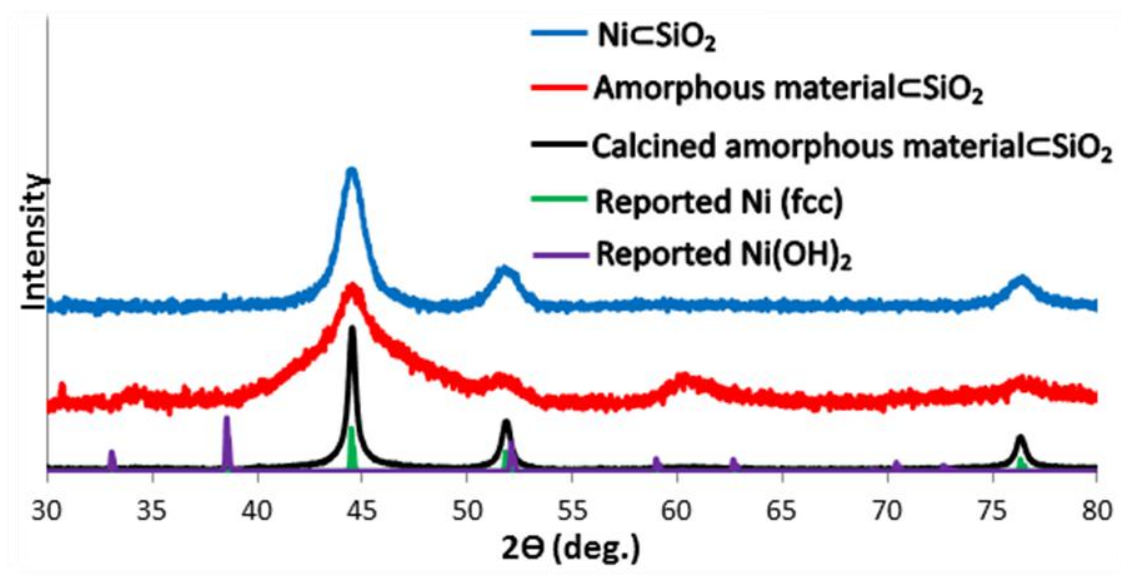

Figure 24. Evolution of XRD patterns during EN plating using DMAB as reducing agent.

The XRD pattern (Figure 24) shows crystal growth occurred during the reaction, but it does not confirm whether it was the result of heterogeneous or homogeneous nucleation. The $\mathrm{Ni}^{2+}$ concentration of the growth solution shown in Table $2 \mathrm{~b}$ (i.e. no $\mathrm{Nic} \mathrm{SiO}_{2}$ ) was monitored by UV/Vis spectroscopy (Figure 25a) to test for solution stability. The spectra show that the absorbance maximum at $390 \mathrm{~nm}$ does not decrease as a function of time for two hours suggesting that $\mathrm{Ni}^{2+}$ is not consumed. However, the absorbance maximum at $664 \mathrm{~nm}$ does show a slight decrease in absorbance (0.004) after two hours corresponding to decrease of $4.3 \mu \mathrm{mol}\left(2.8 \%\right.$ of the total $\mathrm{Ni}^{2+}$ concentration $)$ and may possibly be due to self-nucleation events. Another control experiment was run to determine whether the presence of silica nanocapsules (i.e. no encapsulated $\mathrm{Ni}^{0}$ ) could act as a substrate and allow for discernible homogeneous nucleation events by monitoring $\mathrm{Ni}^{2+}$ concentration. Silica nanocapsules obtained from etching $\left[\mathrm{Ni}\left(\mathrm{N}_{2} \mathrm{H}_{4}\right)_{3}\right] \mathrm{Cl}_{2} \subset \mathrm{SiO}_{2}$ with $\mathrm{HCl}$ (Figure 10a) were submerged into the growth solution shown in Table $2 \mathrm{~b}$ and the absorption spectra were recorded at different times (Figure 25b). The increase in 
absorption at $390 \mathrm{~nm}$ between the spectra can be attributed to incomplete removal of colloidal silica nanocapsules that scatter light and give an errant increase in absorption.

Due to silica colloids present in solution, not much can be concluded as to whether selfnucleation events were occurring or not. The aforementioned silica nanocapsules were subjected to thermal treatment under $\mathrm{H}_{2}$ to reduce any nickel species present on the surface of silica nanocapsules. The diffractogram (Figure 25c) shows there is no apparent difference between silica nanocapsules and the thermally treated silica nanocapsules. The three control experiments strongly suggest the growth solution is kinetically stable and without a catalyst heterogeneous or homogeneous nucleation events do not occur or occur to a degree which is scarcely detected by UV/Vis spectroscopy and XRD analysis.
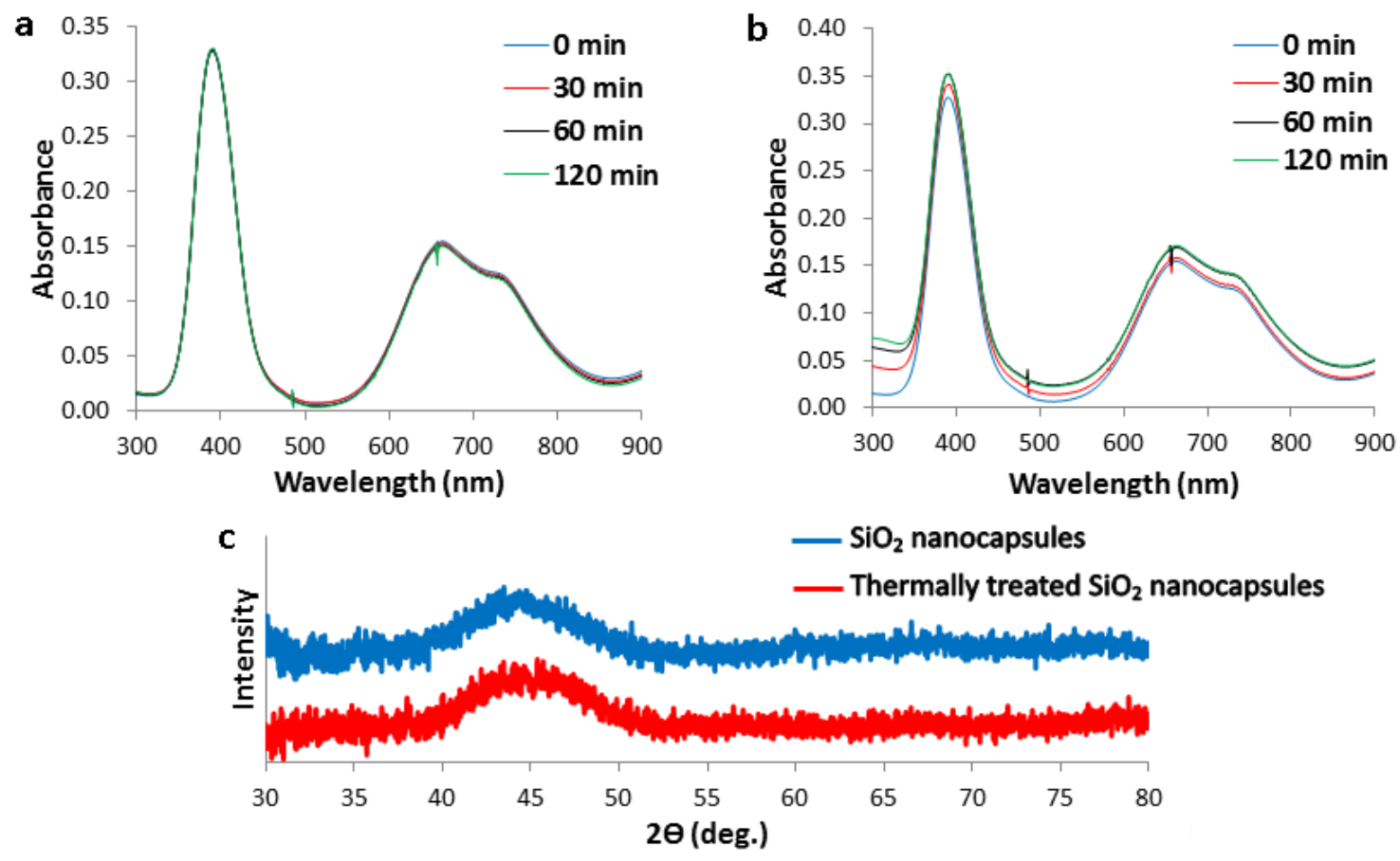

Figure 25. (a) UV/Vis spectra of growth solution shown in Table 2b; (b) UV/Vis spectra of growth solution shown in Table $2 b$ in the presence of silica nanocapsules (i.e. no $\mathrm{Ni}^{0}$ particles); (c) XRD data of silica nanocapsules (blue) and silica nanocapsules placed into growth solution, dried, and then thermally treated under $\mathrm{H}_{2}$ (red). 
Particle size distribution histograms (Figure 26d) were obtained from TEM micrographs (Figure 26b and 26c) of $\mathrm{Ni} \subset \mathrm{SiO}_{2}$ after electroless nickel plating using DMAB as the reducing agent and show no growth within the nanocapsule $(8.6 \pm 1.9 \mathrm{~nm}$ and $8.6 \pm 1.3 \mathrm{~nm}$ before and after, respectively). Agglomerated material was observed outside the nanocapsule (Figure 26c) suggesting homogeneous nucleation may have occurred. Another possible explanation for the observed agglomeration could be due to catalytic reduction of nickel ions on $\mathrm{Ni}^{0}$ particles that were not encapsulated by silica (Figure 26a). There is also a considerable amount of small $\mathrm{Ni}^{0}$ particles on the edge of a silica nanocapsule shown in Figure $26 \mathrm{~b}$ which could be the result of nucleation events occurring on the surface of silica capsules.

Treating $\mathrm{Ni \subset SiO} 2$ with a nickel growth solution containing DMAB resulted in formation of new material, but the material was not contained within the silica nanocapsule. However, when $\mathrm{Ni} \subset \mathrm{SiO}_{2}$ was treated with a nickel growth solution containing $\mathrm{N}_{2} \mathrm{H}_{4}$ as the reducing agent internal growth of $\mathrm{Ni}^{0}$ particles was observed. One important difference between the two experiments is the medium in which the reactions take place. Conditions used for electroless nickel plating using $\mathrm{N}_{2} \mathrm{H}_{4}$ etch silica, while the conditions used for electroless nickel plating using DMAB are inert towards silica. The TEM micrograph obtained from electroless nickel plating using $\mathrm{N}_{2} \mathrm{H}_{4}$ as a reducing agent (Figure 23c) shows a ruptured nanocapsule in the upper left corner. The ruptured nanocapsule likely resulted in an increase of mass transfer and led to a considerable amount of $\mathrm{Ni}^{0}$ filling the interior. A similar observation is made in the center of Figure $23 \mathrm{c}$. The silica nanocapsule is very thin and the particle contained within the nanocapsule is considerably larger than the particles contained in thicker silica capsules. These 
observations lead to the conclusion that there is a mass transfer hindrance of bulky nickel complexes into the nanocapsule interior during electroless nickel plating using DMAB, resulting in the absence of particle growth within the silica nanocapsule.
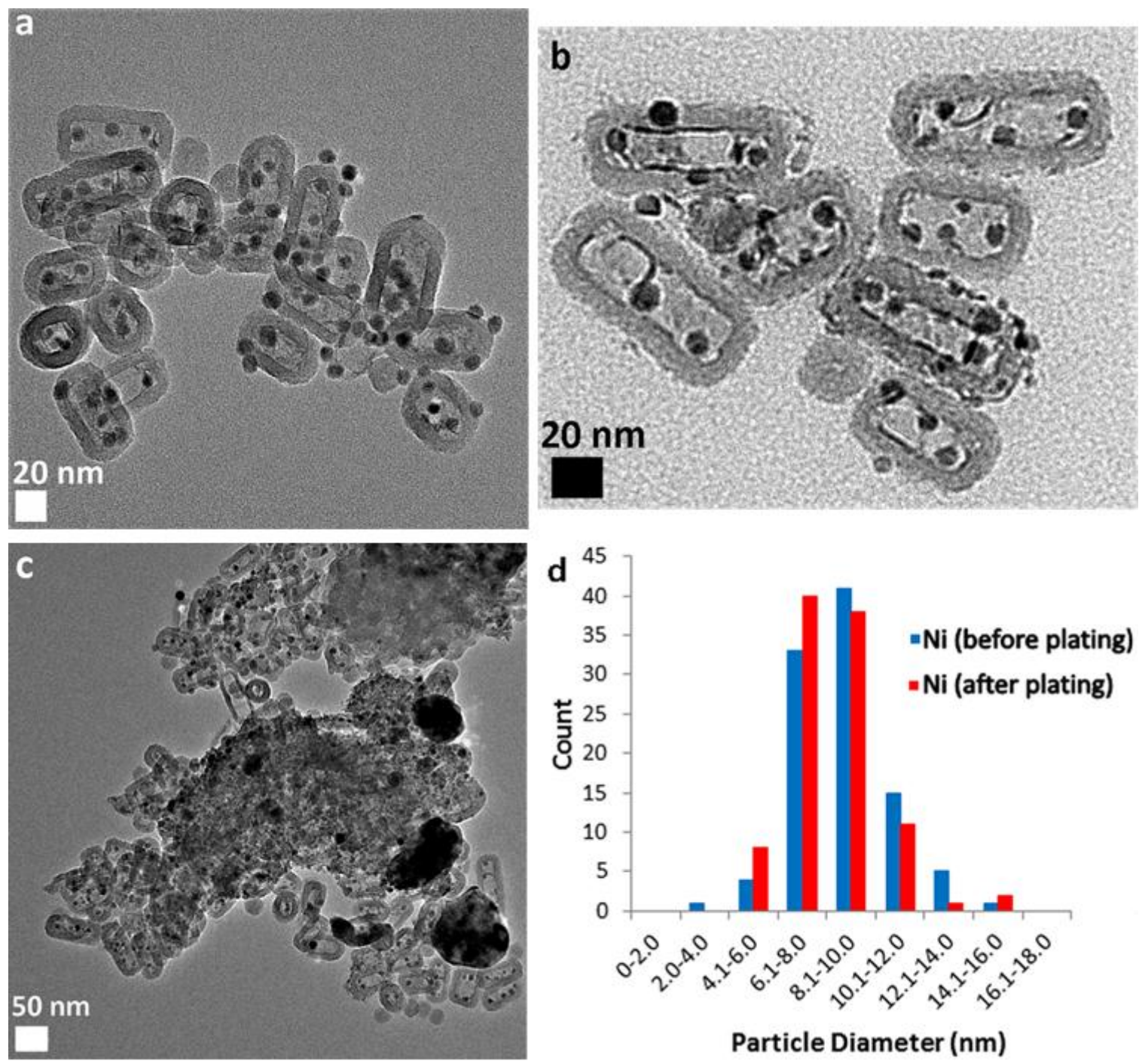

Figure 26. (a) TEM micrograph of $\mathrm{NiCSiO}$ before plating; (b) and (c) TEM micrograph of $\mathrm{Ni}_{\mathrm{SiO}}$ after plating; (d) Particle size distribution histogram for $\mathrm{Ni}_{2} \subset \mathrm{SiO}_{2}$ before and after plating using DMAB as reducing agent. 
Typically, colloidal silica particles are microporous if formed in alkaline solution and especially if formed at elevated temperature ${ }^{88}$, making it difficult to effectively diffuse molecules to internal metal nanoparticles for catalytic reactions. In addition, calcination of silica increases the condensation and crosslinking of the silica matrix, thereby increasing density and decreasing porosity. ${ }^{89,90}$ The latter is demonstrated by comparing the TO mode of Si-O-Si asymmetric bond stretching vibration of $a s-\mathrm{SiO}_{2}$ to $c$ $\mathrm{SiO}_{2}$ using FTIR spectroscopy (Figure 27a). The position of the Si-O-Si band is correlated with the density of silica; it blue-shifts as silica becomes more dense. ${ }^{91}$ There is clearly a shift of the Si-O-Si stretch to higher wavenumbers upon calcination, suggesting a more dense silica material.

UV/Vis transmission spectroscopy also provides evidence that calcination of silica nanocapsules results in increased density. As-synthesized and calcined silica nanocapsules were dispersed in ethanol to form $0.22 \mathrm{mg} \mathrm{mL}^{-1}$ dispersions and their visible light transmittance was monitored (Figure 27b). From the spectra you can clearly see that $c$-silica nanocapsules transmit less light than $a s$-silica nanocapsules. The difference in transmittance can be attributed to differences in density between the silica nanocapsules. As transmittance decreases, the intensity of scattered and/or absorbed light increases

$$
T=\frac{I}{I_{0}}, \text { where } I=I_{0}-I_{a b s}-I_{s c a}
$$

where $T$ is transmittance, $I$ is the intensity of radiation reaching the detector, $I_{0}$ is the intensity of incident radiation, $I_{a b s}$ is the intensity of light absorbed by the silica nanocapsules, and $I_{s c a}$ is the intensity of light scattered by the silica nanocapsules. ${ }^{92}$ Silica 
is optically transparent rendering the intensity of absorbed light negligible and thus the differences in transmitted light can be solely attributed to $I_{s c a}$. The light scattering intensity at perpendicular incidence to the diameter of a dielectric cylinder is proportional to the refractive index of the dispersion

$$
I_{s c a} \propto\left(m^{2}-1\right)^{2}
$$

where $m$ is the refractive index of the dispersion. ${ }^{92}$ The refractive index of colloidal solutions can be described by the refractive indices of the dispersed and continuous phases

$$
m=\phi_{d} n_{d}+\phi_{c} n_{c}
$$

where $\phi_{d}, n_{d}$ and $\phi_{c}, n_{c}$ are the volume fractions and refractive indices for the dispersed and continuous phases, respectively. ${ }^{93}$ Based on the equations, the transmittance of silica nanocapsule dispersions will decrease when the refractive index of the dispersed increases. Because the refractive index for silica increases as the density of silica increases,${ }^{90}$ the decrease in transmittance for $c-\mathrm{SiO}_{2}$ can be attributed to an increase in the silica nanocapsule density. However, there are also other factors that contribute to scattering that cannot be overlooked such as particle aggregation and dispersion homogeneity.

Furthermore, it has been shown that increased porosity from as-synthesized silica colloids is necessary to allow sufficient mass transfer into and out of silica shell materials for reactions to occur at the core. ${ }^{94,95,96}$ There are several methods in the literature to increase silica porosity $94^{, 97,98,99,100}$ that will be actively explored and possibly allow for increased mass transfer to the catalytic nickel center and permit seeded growth to occur preferentially within the silica nanocapsule. 

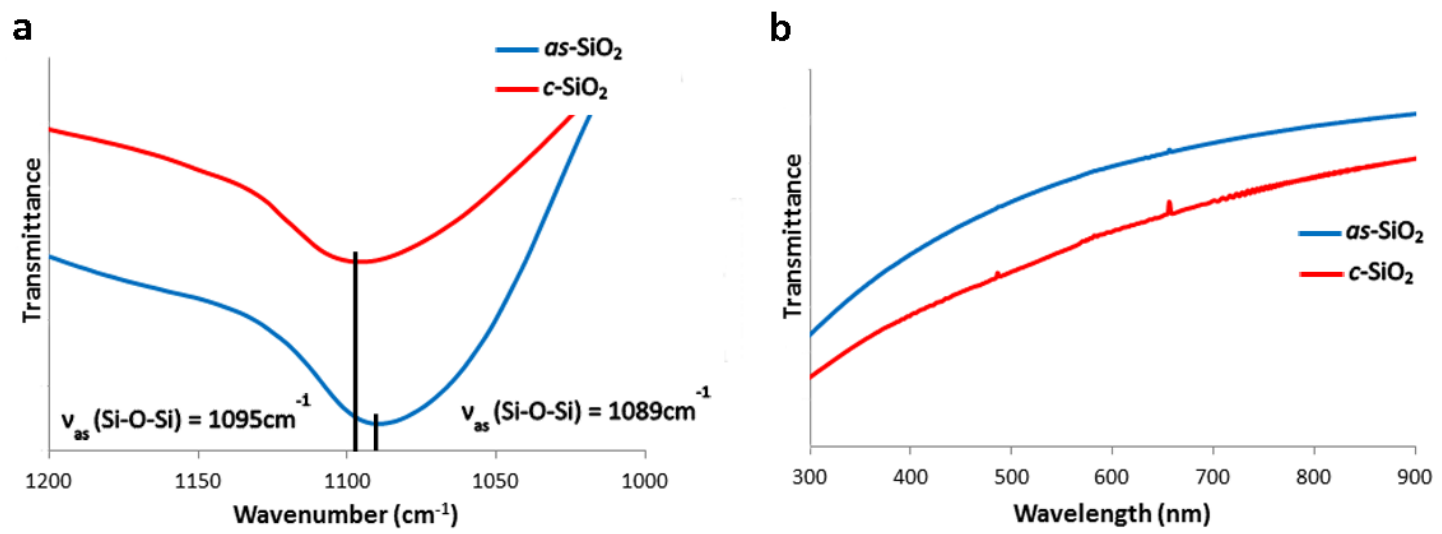

Figure 27. (a) FTIR spectrum of $a s-\mathrm{SiO}_{2}$ and $c-\mathrm{SiO}_{2}$; (b) UV/Vis transmittance spectrum of $a s-\mathrm{SiO}_{2}$ and $c-\mathrm{SiO}_{2}$.

\section{Conclusion}

In summary, a method for the reproducible and potentially scalable synthesis of silica templated $\mathrm{Ni}^{0}$ particles displaying strong magnetic behavior was developed. Unlike most reported methods for the synthesis of silica encapsulated metal particles, our approach encapsulates numerous particles in one shell. We have shown that $\mathrm{Ni}_{\mathrm{SiO}}$ can be synthesized by chemical reduction of $\left[\mathrm{Ni}\left(\mathrm{N}_{2} \mathrm{H}_{4}\right)_{3}\right] \mathrm{Cl}_{2} \subset \mathrm{SiO}_{2}$ using $\mathrm{NaBH}_{4}$ followed by calcination under $\mathrm{H}_{2}$. Preliminary data suggest that varying the amount of $\mathrm{NiCl}_{2}$ while keeping the same surfactant/water ratio allows size control of the $\mathrm{Ni}^{0}$ particles. Transformation of ill-defined $\mathrm{Ni}-\mathrm{B} \subset \mathrm{SiO}_{2}$ to well-defined crystalline fcc-Ni has been proposed to occur through atomic migration of newly formed $\mathrm{Ni}^{0}$ particles. Silica encapsulated $\mathrm{Ni}^{0}$ particles hold promise for the synthesis of nickel nanorods for use in bimetallic heterostructured hydrogen storage materials.

Attempts to synthesize $\mathrm{Ni}^{0}$ nanorods encapsulated by silica included thermal decomposition of $\left[\mathrm{Ni}\left(\mathrm{N}_{2} \mathrm{H}_{4}\right)_{3}\right] \mathrm{Cl}_{2} \subset \mathrm{SiO}_{2}$ and seeded growth of $\mathrm{Ni} \subset \mathrm{SiO}_{2}$. Thermal 
decomposition resulted in formation of a mobile species and significant amounts of nanocapsules were found void of $\mathrm{Ni}^{0}$ particles. Seeded growth was carried out via electroless nickel plating using $\mathrm{N}_{2} \mathrm{H}_{4}$ and DMAB as reducing agents. Discernible growth was observed inside the nanocapsule using $\mathrm{N}_{2} \mathrm{H}_{4}$, but the silica shell was etched during growth due to the high temperature and alkaline conditions employed. Experiments conducted under low temperature and $\mathrm{pH}$ neutral conditions using DMAB resulted in no internal growth of encapsulated $\mathrm{Ni}^{0}$ particles. We believe the main cause for this is minimal shell porosity of calcined silica which hinders sufficient mass transfer of bulky nickel complexes. Future work will focus on carrying out the growth reaction using DMAB with $\mathrm{Ni \subset SiO}$ 2 particles that have increased shell porosity. If successful, the metal nanorods will be used as building blocks for bimetallic heterostructured hydrogen storage materials.

\section{Experimental}

\section{Materials}

Polyoxyethylene (20) cetyl ether, tetraethyl orthosilicate ( $\geq 99.0 \%)$, borane dimethylamine complex (97\%), and gluconic acid (50 wt. \% in $\mathrm{H}_{2} \mathrm{O}$ ) were purchased from Sigma-Aldrich. Hydrazine monohydrate (100\%, hydrazine 64\%) and sodium borohydride ( $\geq 98 \%$ ) were purchased from Acros. Cyclohexane (99.9\%), diethylamine (reagent), sodium hydroxide (99.4\%), and ammonium hydroxide (28.54\%) were purchased from Fisher. Nickel (II) chloride hexahydrate $(\geq 99.9 \% \mathrm{Ni})$ was purchased from Strem. Hydrogen gas (99.995\%) and argon gas (99.996\%) were purchased from 
Linweld. Nickel (II) acetate tetrahydrate (reagent) was purchased from J.T. Baker.

Sodium tartrate dihydrate $(97 \%)$ was purchased from Mallinckrodt.

\section{Calcination Experiments}

Calcination experiments were conducted in a three-zone Lindberg/Blue M Tube Furnace (Thermo Scientific) equipped with a 3" diameter quartz tube. Specifications: 240 $\mathrm{V}, 3.8 \mathrm{~kW}, 50 / 60 \mathrm{~Hz}, 16 \mathrm{~A}$. A heating rate of $10^{\circ} \mathrm{C} \mathrm{min}^{-1}$ was used in all experiments.

\section{Synthesis of $\left[\mathrm{Ni}\left(\mathrm{N}_{2} \mathrm{H}_{4}\right)_{3}\right] \mathrm{Cl}_{2} \subset \mathrm{SiO}_{2}$}

In a typical synthesis, Brij $58(8.5 \mathrm{~g}, 7.6 \mathrm{mmol})$ was weighed into a $100 \mathrm{~mL}$ threeneck round-bottom flask. The flask was equipped with a Teflon stir bar and stainless steel thermocouple. The contents were sealed using a septa and a glass adapter and brought onto a Schlenk line. The flask was purged with argon and then cyclohexane $(15 \mathrm{~mL})$ was added. The contents dissolved upon heating to $50^{\circ} \mathrm{C}$ in an oil bath and this temperature was maintained throughout the experiment. Under stirring, $\mathrm{NiCl}_{2} \bullet 6 \mathrm{H}_{2} \mathrm{O}$ aqueous solution (1.5 mL, $1.2 \mathrm{mmol})$ was added to the colorless transparent solution and stirred until a green, transparent homogeneous reverse microemulsion was obtained. Then, $\mathrm{N}_{2} \mathrm{H}_{4} \bullet \mathrm{H}_{2} \mathrm{O}$ $\left(0.45 \mathrm{~mL}, 9.3 \mathrm{mmol} \mathrm{N}_{2} \mathrm{H}_{4} \bullet \mathrm{H}_{2} \mathrm{O}\right)$ was added dropwise, causing a gradual color change to pink. After stirring for $3 \mathrm{~h}$, diethylamine $(1.1 \mathrm{~mL})$ was added, followed by TEOS (3.44 $\mathrm{mL}, 15.4 \mathrm{mmol}$ ) addition. This was allowed to stir for $2 \mathrm{~h}$. The product was isolated by centrifugation (5000 rpm for $5 \mathrm{~min}$ ) and washed several times with isopropanol. The product was dried in air at $60^{\circ} \mathrm{C}$ overnight. Yield: $1.2 \mathrm{~g}$. 


\section{Synthesis of $\mathrm{Ni}-\mathrm{B} \subset \mathrm{SiO}_{2}$}

$$
\left[\mathrm{Ni}\left(\mathrm{N}_{2} \mathrm{H}_{4}\right)_{3}\right] \mathrm{Cl}_{2} \subset \mathrm{SiO}_{2}\left(1.2 \mathrm{~g}, \approx 1.2 \mathrm{mmol} \mathrm{Ni}^{2+}\right) \text { was placed into a } 125 \mathrm{~mL}
$$

Erlenmeyer flask equipped with a Teflon stir bar. To this, $\mathrm{H}_{2} \mathrm{O}(30 \mathrm{~mL})$ was added and the suspension sonicated for $15 \mathrm{~min}$. The flask was placed onto a stir plate at room temperature and under stirring, freshly prepared $\mathrm{NaBH}_{4}$ aqueous solution $(5 \mathrm{~mL}, 2.4$

mmol) was added dropwise, but fast, causing evolution of gases and a color change to black. The suspension was allowed to stir for 30 min before being collected by centrifugation and washed with water and ethanol. The product was dried under vacuum at for $6 \mathrm{~h}$.

\section{Calcination of $\mathrm{Ni}-\mathrm{B} \subset \mathrm{SiO}_{2}$ Under $\mathrm{Ar} / \mathrm{H}_{2}$}

$\mathrm{Ni}-\mathrm{B} \subset \mathrm{SiO}_{2}(0.6 \mathrm{~g})$ was placed into a ceramic combustion boat. The boat was placed into the center of a tube furnace equipped with 3 " diameter quartz tube. The quartz tube was fitted with an inlet adapter used to funnel $\mathrm{H}_{2} / \mathrm{Ar}$ into the system and the outlet adapter was equipped with an oil bubbler. A gas mixer equipped with Dwyer flow controls was used to purge the tube with a mixture of $\operatorname{Ar}\left(50 \mathrm{~mL} \mathrm{~min}^{-1}\right)$ and $\mathrm{H}_{2}(10 \mathrm{~mL}$

$\min ^{-1}$ ) gases for $30 \mathrm{~min}$ and the flow rates were maintained throughout the duration of the experiment. The temperature was then ramped from room temperature to $500^{\circ} \mathrm{C}$ at $10^{\circ} \mathrm{C}$ $\min ^{-1}$ and was sustained at this temperature for $2 \mathrm{~h}$ before convection cooling to room temperature. The diffraction pattern showed face-centered cubic nickel crystal structure.

\section{Electroless Nickel Plating Using $\mathrm{N}_{2} \mathrm{H}_{4} \cdot \mathrm{H}_{2} \mathrm{O}$}

In a $50 \mathrm{~mL}$ Erlenmeyer flask, $\mathrm{Ni}\left(\mathrm{CH}_{3} \mathrm{COO}\right)_{2} \bullet 4 \mathrm{H}_{2} \mathrm{O}(0.5843 \mathrm{~g}, 3.000 \mathrm{mmol})$ was dissolved in $\mathrm{H}_{2} \mathrm{O}(25 \mathrm{~mL})$. Then in order, $\mathrm{Na}_{2} \mathrm{C}_{4} \mathrm{H}_{4} \mathrm{O}_{6} \cdot 2 \mathrm{H}_{2} \mathrm{O}(0.0924 \mathrm{~g}, 0.402 \mathrm{mmol})$, 
$\mathrm{C}_{6} \mathrm{H}_{12} \mathrm{O}_{7}\left(1.4760\right.$ g solution, $\left.3.7622 \mathrm{mmol} \mathrm{C}_{6} \mathrm{H}_{12} \mathrm{O}_{7}\right)$, and $\mathrm{N}_{2} \mathrm{H}_{4} \bullet \mathrm{H}_{2} \mathrm{O}(0.49 \mathrm{~mL}, 10$. mmol) were added to the flask. The $\mathrm{pH}$ was adjusted to 9.6 with $\mathrm{NaOH}$ using a Fisher Scientific Accumet $\mathrm{AB}$ 15/ 15+ bench-top $\mathrm{pH}$ meter. The contents were transferred to an Erlenmeyer flask containing $\mathrm{Ni} \subset \mathrm{SiO}_{2}(0.0351 \mathrm{~g})$. The suspension was heated in air to $75^{\circ} \mathrm{C}(\approx 20 \mathrm{~min})$ on a Fisher Scientific Isotemp Basic Hotplate monitored with a mercury thermometer. The reaction was allowed to proceed for $30 \mathrm{~min}$ at $75^{\circ} \mathrm{C}$ and the evolution of gas was observed throughout the duration of the experiment. The product was collected by centrifugation, washed several times with $\mathrm{H}_{2} \mathrm{O}$, and then dried in air at $60^{\circ} \mathrm{C}$.

\section{Electroless Nickel Plating Using DMAB}

In a $50 \mathrm{~mL}$ Erlenmeyer flask, $\mathrm{Ni}\left(\mathrm{CH}_{3} \mathrm{COO}\right)_{2} \bullet 4 \mathrm{H}_{2} \mathrm{O}(0.1500 \mathrm{~g}, 0.6027 \mathrm{mmol})$ was

dissolved in $\mathrm{H}_{2} \mathrm{O}(20 \mathrm{~mL})$. Then in order, $\mathrm{C}_{6} \mathrm{H}_{12} \mathrm{O}_{7}(1.3215 \mathrm{~g}$ solution, $3.3684 \mathrm{mmol}$ $\left.\mathrm{C}_{6} \mathrm{H}_{12} \mathrm{O}_{7}\right)$ and DMAB $(0.0708 \mathrm{~g}, 1.20 \mathrm{mmol})$ were added to the flask. The $\mathrm{pH}$ was adjusted to 6.8 with $\mathrm{NH}_{4} \mathrm{OH}$. The contents were transferred to an Erlenmeyer flask containing $\mathrm{Ni}_{\mathrm{SiO}}(0.0330 \mathrm{~g})$. The suspension was heated to $45^{\circ} \mathrm{C}(\approx 10 \mathrm{~min})$. The reaction was allowed to proceed for $2.5 \mathrm{~h}$ at $45^{\circ} \mathrm{C}$ and the evolution of gas was observed throughout the duration of the experiment. The product was collected by centrifugation, washed several times with $\mathrm{H}_{2} \mathrm{O}$, and then dried in air at $60^{\circ} \mathrm{C}$.

\section{Structural Characterization}

$X$-ray Diffraction

Powder XRD data were measured using $\mathrm{Co} K \alpha_{1}, \mathrm{~K} \alpha_{2}$ split radiation ( $45 \mathrm{kV}, 40$ $\mathrm{mA}, \lambda_{\text {avg }}=1.7903 \AA$ ) on a PANalytical X'Pert PRO diffractometer equipped with a thetatheta vertical mode goniometer, incident Fe filter, an air cooled X'Celerator Real Time 
Multiple Strip (RTMS) detector, and spinner stage. The spectra were converted to $\mathrm{Cu} \mathrm{K} \alpha$ radiation for comparison to standard patterns. Powder XRD data were also measured using $\mathrm{Cu} \mathrm{K} \alpha_{1}, \mathrm{~K} \alpha_{2}$ split radiation ( $45 \mathrm{kV}, 40 \mathrm{~mA}, \lambda_{\text {avg }}=1.5418 \AA$ ) on a PANalytical X'Pert PRO diffractometer equipped with a theta-theta vertical mode goniometer, diffracted beam Ni filter, an air cooled X'Celerator RTMS detector, and spinner stage. Quantitative determinations of phase abundances were determined using Rietveld analysis on X'Pert HighScore Plus and GSAS software (reported as weight percent). The XRD samples were prepared by placing powders onto a background-less polycarbonate sample holder.

\section{Transmission Electron Microscopy}

TEM was conducted using a FEI Technai G2 F20 field emission TEM and a scanning transmission electron microscope (STEM) operating at $200 \mathrm{kV}$ (point-to-point resolution $<0.25 \mathrm{~nm}$ and a line-to-line resolution of $<0.10 \mathrm{~nm}$ ). TEM samples were prepared by placing 2-3 drops of dilute ethanol suspensions onto carbon-coated copper grids. The composition of $\mathrm{Ni}_{\mathrm{SiO}}$ structures were characterized by energy dispersive spectroscopy (EDS) line scans in STEM mode.

Size and Morphology Analysis

Particle dimensions were measured with ImageJ. In all cases, measurements and statistics were obtained for $>50-100\left[\mathrm{Ni}\left(\mathrm{N}_{2} \mathrm{H}_{4}\right)_{3}\right] \mathrm{Cl}_{2}$ complexes, silica nanocapsules, or $\mathrm{Ni}^{0}$ particles. Averages are reported \pm standard deviations.

Scanning Electron Microscopy

SEM was conducted using a FEI Quanta 250 FE-SEM (maximum resolution of $1.2 \mathrm{~nm}$ ) equipped with secondary and backscattered electron detectors and IXRF Systems 
EDS system. SEM samples were prepared by placing 2-3 drops of dilute ethanol suspensions onto glass cover slips.

\section{Optical Characterization}

\section{Fourier Transform Infrared Spectroscopy}

Vibrational infrared spectra were recorded with a Bruker IFS66 V FT-IR spectrometer (transmittance mode) equipped with a DTGS detector with 16 scans at a

resolution of $4 \mathrm{~cm}^{-1}$. The samples were prepared by dilution with $\mathrm{KBr}$ and pressed into a pellet. Background spectra were collected under identical conditions. Samples were continuously purged with dry $\mathrm{N}_{2}$ to minimize water vapor absorbance.

Ultraviolet-Visible Spectroscopy (UV/Vis)

Absorption spectra were measured with a StellarNet-Black-Comet diffuse reflectance spectrometer equipped with a 2048 pixel Charge Coupled Device (CCD) detector, slit size of $100 \mu \mathrm{m}$, and a spectral range of $280-900 \mathrm{~nm}$. Dark and light background spectra were obtained for all samples. The sample was placed at the same distance from the probe as the dark and light spectra background standards. Absorption spectra were also measured with a photodiode-array Agilent $8453 \mathrm{UV} / \mathrm{Vis}$ spectrophotometer. Solvent absorption was recorded and subtracted from all spectra. 


\section{REFERENCES}

${ }^{1}$ Balat, M. Int. J. Hydrogen Energy 2008, 33, 4013-4029.

${ }^{2}$ Marbán, G.; Valdés-Solís, T. Int. J. Hydrogen Energy 2007, 32, 1625-1637.

${ }^{3}$ U.S. Department of Energy, Energy Efficiency and Renewable Energy. http://www1.eere.energy.gov/hydrogenandfuelcells/storage/current_technology.html (accessed September 2012).

${ }^{4}$ Bogdanović, B.; Schwickardi, M. J. Alloys Compd. 1997, 253,1-9.

${ }^{5}$ Liang, G.; Huot, J.; Boily, S.; Van Neste, A.; Schulz, R. J. Alloys Compd. 1999, 292, $247-252$.

${ }^{6}$ Orimo, S.; Fujii, H. Appl. Phys. A 2001, 72, 167-186.

${ }^{7}$ Ershova, O.G.; Dobrovolsky, V.D.; Solonin, Yu.M.; Khyzhun, O. Yu..; Koval, A. Yu. J.Alloys Compd. 2008, 464, 212-218.

${ }^{8}$ Milanese, C.; Girella, A.; Bruni, G.; Berbenni, V.; Cofrancesco, P.; Marini, A.; Villa, M.; Matteazzi, P. J. Alloys and Cmpd. 2008, 465, 396-405.

${ }^{9}$ Züttel, A. Naturwissenschaften 2004, 91, 157-172.

${ }^{10}$ Leung, W.B.; March, N.H.; Motz, H. Phys. Lett. A 1976, 56, 425-426.

${ }^{11}$ Rock, P.A. Chemical Thermodynamics; MacMillan: New York, 1969; p 478.

${ }^{12}$ Zhou, L. Renewable Sustainable Energy Rev 2005, 9, 395-408.

${ }^{13}$ Beebe, B.A.; Biscoe, J.; Smith, W.R.; Wendell, C.B. J. Am. Chem. Soc. 1947, 69, 95101.

${ }^{14}$ Zhou, Y.P.; Zhou, L. Sep. Sci. Technol. 1998, 33, 1787-1801.

${ }^{15}$ Ding, F.; Yakobson, B.I. Front. Phys. 2011, 6, 142-150.

${ }^{16}$ Farha, O.K.; Eryazici, I.; Jeong, N.C.; Hauser, B.G.; Wilmer, C.E.; Sarjeant, A.A.; Snurr, R.Q.; SonBinh, N.T.; Yazaydin, O.A.; Hupp, J.T.; J. Am. Chem. Soc. 2012, 134, 15016-15021.

${ }^{17}$ Bogdanović, B.; Sandrock, G. MRS Bull. 2002, 9, 712-716. 
18 Taylor, H. Annu. Rev. Phys. Chem. 1961, 12, 127-150.

${ }^{19}$ Robell, A.J.; Ballou, E.V.; Boudart, M. J. Phys. Chem. 1964, 68, 2748-2753.

${ }^{20}$ L'Homme, G.A.; Boudart, M.; D’Or, L. Bull. Acad. Roy. Belg. Cl. Sci. 1966, 52, 12061248, 1249-1270.

${ }^{21}$ Benson, J.E.; Kohn, H.W.; Boudart, M. J. Catal. 1966, 5, 307-313.

${ }^{22}$ Nowak, E.J.; Koros, R.M. J. Catal. 1967, 7,50-56.

${ }^{23}$ Sancier, K.M.; Inami, S.H. J. Catal. 1968, 11, 135-142.

${ }^{24}$ Sinfelt, J.H.; Lucchesi, P.J. J. Am. Chem. Soc. 1963, 85, 3365-3367.

${ }^{25}$ Fujimoto, K. Catalyst Design Based on Spillover Theory. In New Aspects of Spillover Effect in Catalysis for Development of Highly Active Catalysts, Inui, T., Fujimoto, K.., Uchijima, T., Masai, M., Eds.; Studies in Surface Science and Catalysis 77; Elsevier Science: New York, 1993; Vol. 77, pp 9-16.

${ }^{26}$ Crucq, A.; Degols, L.; Lienard, G.; Frennet, A. In Studies in Surface Science and Catalysis 17; Germain, J., Pajonk, G., Teichner, S. J., Eds.; Elsevier: Amsterdam, 1983; p 137.

${ }^{27}$ Cheng, H.; Chen, L.; Cooper, A.C.; Sha, X.; Pez, G.P. Energy Environ. Sci. 2008, 1, 338-354.

${ }^{28}$ Conner, W.C.; Falconer, J.L. Chem. Rev. 1995, 95, 759-788.

${ }^{29}$ Bloch, J.; Mintz, M.H. J. Alloys Compd. 1997, 253, 529-541.

${ }^{30}$ Tan, Z.; Chun, C.; Heilweil, E.; Bendersky, L.A. Int. J. Hydrogen Energy 2011, 26, 9702-9713.

${ }^{31}$ Oguchi, H.; Tan, Z.; Heilweil, E.J.; Bendersky, L.A. Int. J. Hydrogen Energy 2010, 35,1296-1299.

${ }^{32}$ Tan, Z.; Heilweil, E.J.; Bendersky, L.A.; In-situ Kinetics Studies on Hydrogenation of Transition Metal(=Ti, Fe) Doped Mg Films. Mater. Res. Soc. Symp. Proc. 2010, 1216W04-04.

${ }^{33}$ Zaluska, L.; Zaluska, A.; Tessier, P.; Strom-Olsen, J.O.; Schulz, R.; J. Alloys Compd. 1995, 217, 295-300.

${ }^{34}$ Bobet, J.L.; Grigorovab, E.; Khrussanovab, M.; Khristovb, M.; Radevb, D.; Peshevb, 
P. J. Alloys Compd. 2002, 345, 280-285.

${ }^{35}$ Tzanétakis, P.; Hillairet, J.; Revel, G. Phys. Status Solidi B 1976, 75, 433-439.

${ }^{36}$ Zhang, J.; Fisher, T.S.; Ramachandran, P.V.; Gore, J.P.; Mudawar, I. J. Heat Transfer 2005, 127, 1391-1399.

${ }^{37}$ Bérubé, V.; Radtke, G.; Dresselhaus, M.; Chen, G. Int. J. Energy Res. 2007, 31, 637663.

${ }^{38}$ Gao, C.; Lu, Z.; Yin, Y. Langmuir 2011, 27, 12201-12208.

${ }^{39}$ Over, H.; Hertel, T.; Bludau, H. Phys. Rev. . 1993, 48, 5572-5578.

${ }^{40}$ Fan, F.; Liu, D.; Wu, Y.; Duan, S.; Xie, Z.; Jiang, Z.; Tian, Z. J. Am. Chem. Soc. 2008, 130, 6949-6951.

${ }^{41}$ Xia, Y.; Yang, P.; Sun, Y.; Wu, Y.; Mayers, B.; Gates, B.; Yin, Y.; Kim, F.; Yan, H. Adv. Mater. 2003, 15, 353-389.

${ }^{42}$ Sugawara, A.; Coyle, T.; Hembree, G. G.; Scheinfein, M. R. Appl. Phys. Lett. 1997, 70, 1043-1045.

${ }^{43}$ Jorritsma, J.; Gijs, M. A. M.; Kerkhof, J. M.; Stienen, J. G. H. Nanotechnology 1996, 7, 263-265.

${ }^{44}$ Yang, C.; Sheu, H.; Chao, K. Adv. Funct. Mater. 2002, 12, 143-148.

${ }^{45}$ Yu, Y.; Chang, S.; Lee, C.; Wang, C. J. Phys. Chem. B 1997, 101, 6661-6664.

${ }^{46}$ Braun, E.; Eichen, Y.; Sivan, U.; Ben-Yoseph, G. Nature 1998, 391, 775-778.

${ }^{47}$ Jorgenson, M.R.; Bartl, M.H. J. Mater. Chem. 2011, 21, 10583-10591.

${ }^{48}$ Obare, S. O.; Jana, N. R.; Murphy, C. J. Nano Lett. 2001, 1, 601-603.

${ }^{49}$ Cao, G.; Liu, D. Adv. Colloid Interface Sci. 2008, 136, $45-64$.

${ }^{50}$ Ajayan, P.M.; Iijima, S. Nature 1993, 361, 333-334.

${ }^{51}$ Kitaura, R.; Nakanishi, R.; Saito, T.; Yoshikawa, H.; Awaga, K.; Shinohara, H. Angew. Chem. Int. Ed. 2009, 48, 8298-8302.

${ }^{52}$ Martín, J.; Maiz, J.; Sacristan, J.; Mijangos, C. Polymer 2012, 53, 1149-1166. 
${ }^{53}$ Napolsky, K.S.; Eliseev, A.A.; Knotko, A.V.; Lukahsin, A.V.; Vertegel, A.A.; Tretyakov, Y.D. Mater. Sci. Eng., C 2003, 23, 151-154.

${ }^{54}$ Crowley, T.A.; Ziegler, K.J.; Lyons, D.M.; Erts, D.; Olin, H.; Morris, M.A.; Holmes, J.D. Chem. Mater. 2003, 15, 3518-3522.

${ }^{55}$ Zhang, Z.; Dai, S.; Blom, D.A.; Shen, J. Chem. Mater. 2002, 14, 965-968.

${ }^{56}$ Huang, M.H.; Choudrey, A.; Yang, P. Chem. Commun. 2000, 1063-1064.

${ }^{57}$ Lee, K.; Lee, S.; Cheon, J. Adv. Mater. 2001, 13, 517-520.

${ }^{58}$ Han, Y.; Kim, M.; Stucky, G.D. Chem. Mater. 2000, 12, 2068-2069.

${ }^{59}$ Yang, X.; Tang, H.; Cao, K.; Song, H.; Sheng, W.; Wu, Q. J. Mater. Chem. 2011, 21, $6122-6135$.

${ }^{60}$ Woo Park, J.; Chae, E. H.; Kim, S.H.; Ho Lee, J.; Kim, J.W.; Mi Yoon, S.; Choi, J. Mater. Chem. Phys. 2006, 97, 371-378.

${ }^{61}$ Nicholls, D.; Swindells, R. J. Inorg. Nucl. Chem. 1968, 30, 2211-2217.

${ }^{62}$ Bruynooghe, S.; Bertin, F.; Chabli, A.; Gay, J.-C.; Blanchard, B.; Couchaud, M. Thin Solid Films 1998, 313-314, 722-726.

${ }^{63}$ Sacconi, L.; Sabantini, A. J. Inorg. Nuclear Chem. 1963, 25, 1389-1393.

${ }^{64}$ Nicholls, D.; Rowley, M.; Swindells, R. J. Chem. Soc. (A) 1966, 950-952.

${ }^{65}$ Cordente, N.; Respaud, M.; Senocq, F.; Casanove, M.; Amiens, C.; Chaudret, B. Nano Lett. 2001, 1, 565-568.

${ }^{66}$ Yu, K.; Kim, D.J.; Chung, H.S.; Liang, H. Mater. Lett. 2003, 57, 3992-3997.

${ }^{67}$ Ghosh, S.; Ghosh, M.; Rao, C.N.R. J. Cluster Sci. 2006, 18, 97-111.

${ }^{68} \mathrm{Ni}$, X.; Su, X.; Yang, Z.; Zheng, H. J. Cryst. Growth 2003, 252, 612-617.

${ }^{69}$ Wu, Z.; Ge, S.; Zhang, M.; Li, W.; Mu, S.; Tao, K. J. Phys. Chem. C 2007, 111, 85878593.

${ }^{70}$ Deng, J.; Li, H.; Wang, W. Catal. Today 1999, 51, 113-125.

${ }^{71}$ Lee, S.; Chen, Y. Ind. Eng. Chem. Res. 1999, 38, 2548-2556. 
${ }^{72}$ Glenn O. Mallory; Juan B. Hajdu; Juan B. Hajdu. Chapter 1: The Fundamental Aspects of Electroless Nickel Plating. In Electroless Plating: Fundamentals and Applications, American Electroplaters and Surface Finishers Society, 1990, p. 14.

${ }^{73}$ Li, H.; Li. H.; Deng, J. Mater. Lett. 2001, 50, 41-46.

${ }^{74}$ Mueller, R.; Kammler, H.K.; Wegner, K.; Pratsinis, S.E. Langmuir 2003, 19, 160-165.

${ }^{75}$ Legrand, J.; Taleb, A.; Gota, S.; Guittet, M.-J.; Petit, C. Langmuir 2002, 18, 41314137.

${ }^{76}$ Lu, K.; Zhu, X. Thin Solid Films 2009, 517, 4479-4483.

${ }^{77}$ Berger, S.V. Acta Chem. Scand. 1953, 7, 611-622.

${ }^{78}$ Bartholomew, C.H. Sintering and Redispersion of supported Metals: Perspectives from the Literature of the Past Decade. In Catalyst Deactivation 1997; Bartholomew, C.H., Fuentes, G.A., Eds.; Studies in Surface Science and Catalysis; Elsevier Science: Amsterdam, The Netherlands, 1997; Vol. 111, pp 585-592.

${ }^{79}$ Nakayama, T.; Arai, M.; Nishiyama, Y. J. Catal. 1984, 87, 108-115.

${ }^{80}$ Arai, M.; Ishikawa, T.; Nishiyama, Y. J. Phys. Chem. 1982, 86, 577-581.

${ }^{81}$ Boudjahem, A.G.; Monteverdi, S.; Mercy, M.; Bettahar, M.M. J. Catal. 2004, 221, 325-334.

${ }^{82}$ Dahlberg, K.A.; Schwank, J.W. Chem. Mater. 2012, 24, 2635-2644.

${ }^{83}$ Patil, K.C. Proc. Indian Acad. Sci. (Chem. Sci.) 1986, 96, 459-464.

${ }^{84}$ Chen, X.; Zhang, T.; Zheng, M.; Wu, Z.; Wu, W.; Li, C. J. Catal. 2004, 224, 473-478.

${ }^{85}$ Lif, J.; Skoglundh, M.; Löwendahl, L. Appl. Catal., A 2002, 228, 145-154.

${ }^{86}$ Li, H.; Xu, Y. Mater. Lett. 2001, 51, 101-107.

${ }^{87}$ Li, H.; Lin, H.; Xie, S.; Dai, W.; Qiao, M.; Lu, Y.; Li, H. Chem. Mater. 2008, 20, 3936-3943.

${ }^{88}$ Ller, R.K. Colloidal Silica-Concentrated Sols. The Chemistry of Silica: Solubility Polymerization, Colloid and Surface Properties, and Biochemistry, Wiley \& Sons: New York, 1979; p 328. 
${ }^{89}$ Minhao, Y.; Henderson, M.J.; Gibaud, A. Thin Solid Films 2009, 517, 3028-3035.

${ }^{90}$ Ller, R.K. Silica Gels and Powders. The Chemistry of Silica: Solubility Polymerization, Colloid and Surface Properties, and Biochemistry, Wiley \& Sons: New York, 1979.

${ }^{91}$ Nam, C.W.; Woo, S.I. Thin Solid Films 1994, 237, 314-319.

${ }^{92}$ Kerker, M. Analysis of Particle Size. The Scattering of Light and Other Electromagnetic Radiation; Academic Press: New York, 1969.

${ }^{93}$ Heller, W. Phys. Rev. 1945, 68, 5-10.

${ }^{94}$ Hu, Y.; Zhang, Q.; Goebl, J.; Zhang, T.; Yin, Y. Phys. Chem. Chem. Phys. 2010, 12, 11836-11842.

${ }^{95}$ Gao, C.; Zhang, Q.; Lu, Z.; Yin, Y. J. Am. Chem. Soc. 2011, 133, 19706-19709.

${ }^{96}$ Lee, J.; Park, JC.; Bang, JU.; Song, H. Chem. Mater. 2008, 20, 5839-5844.

${ }^{97}$ Zhao, L.; Zhao, Y.; Han, Y. Langmuir 2010, 26, 11784-11789.

${ }^{98}$ Park, JC.; Lee, HJ.; Jung, HS.; Kim, M.; Kim, HJ.; Park, H.; Song, H. ChemCatChem 2011, 3, 755-760.

${ }^{99}$ Zhang, Q.; Zhang, T.; Ge, J.; Yin, Y. Nano Lett. 2008, 8, 2867-2871.

${ }^{100}$ Zhang, T.; Ge, J.; Hu, Y.; Zhang, Q.; Aloni, S.; Yin, Y. Angew. Chem. Int. Ed. 2008, 47, 5806-5811. 